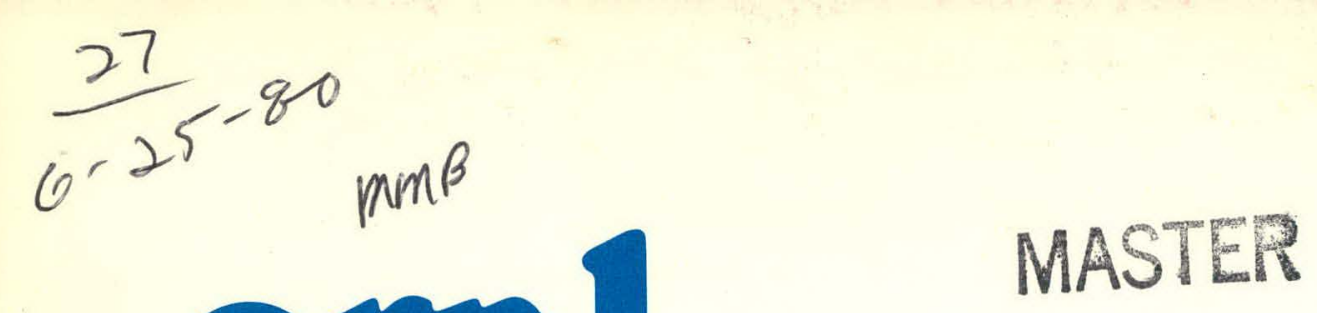

ORNL/TM-7375

\title{
Fossil Energy Program Progress Report for April 1980
}

\author{
L. E. McNeese
}

\author{
Fossil \\ Energy \\ Program
}

OPERATED BY

UNION CARBIDE CORPORATION FOR THE UNITED STATES DEPARTMENT OF ENERGY 


\section{DISCLAIMER}

This report was prepared as an account of work sponsored by an agency of the United States Government. Neither the United States Government nor any agency Thereof, nor any of their employees, makes any warranty, express or implied, or assumes any legal liability or responsibility for the accuracy, completeness, or usefulness of any information, apparatus, product, or process disclosed, or represents that its use would not infringe privately owned rights. Reference herein to any specific commercial product, process, or service by trade name, trademark, manufacturer, or otherwise does not necessarily constitute or imply its endorsement, recommendation, or favoring by the United States Government or any agency thereof. The views and opinions of authors expressed herein do not necessarily state or reflect those of the United States Government or any agency thereof. 


\section{DISCLAIMER}

Portions of this document may be illegible in electronic image products. Images are produced from the best available original document. 
Printed in the United States of America. Available from National Technical Information Service

U.S. Department of Commerce

5285 Port Royal Road, Springfield, Virginia 22161

NTIS price codes-Printed Copy: A06; Microfiche A01

This report was prepared as an account of work sponsored by an agency of the United States Government. Neither the U nited States Government nor any agency thereof, nor any of their employees, makes any warranty, express or implied, or assumes any legal liability or responsibility for the accuracy, completeness, or usefulness of any information, apparatus, product, or process disclosed, or represents that its use would not infringe privately owned rights. Reference herein to any specific commercial product, process, or service by trade name, trademark, manufacturer, or otherwise, does not necessarily constitute or imply its endorsement, recommendation, or favoring by the United States Government or any agency thereof. The views ana opinions or autnor's expressea nerein do not necessarily state or reflect those of the United States Government or any agency thereof. 
Contract No. W-7405-eng-26

FOSSIL ENERGY PROGRAM

PROGRESS REPORT FOR APRIL 1980

L. E. McNeese

Program Director

Date Published - June 1980

OAK R.IDGE NATIONAL LABORATORY

Oak .Ridge, Tennessee 37830

operated by

UNION CARBIDE CORPORATION

for the

DEPARTMENT OF ENERGY

This book was prepared as an account of work sponsored by an agency of tha United States Government.

Neither the United States Government $\mathrm{mr}$ any Reenry therent, nar eny of their amplovoos, makcs ony

warranty. express or implied, of assumes any legal liability or responsibility for the acauracy.

completeness. Or usefulness of any intormotion, apparatus, product. or process disclosed. or

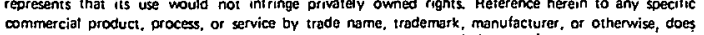

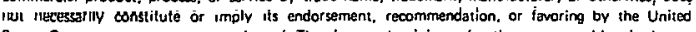

States Government ar any agency thereot. The vieus and opinions of authors expressed herein do not

necessarily state or reflect those of the United States Government or any agency thereof.

ETSTRISUTHS OF THS DOCURENT IS UALLIMITED

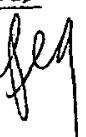




\section{THIS PAGE \\ WAS INTENTIONALLY \\ LEFT BLANK}


ABSTRACT. . . . . . . . . . . . . . . . . . . . 1

1. SUMMARY . . . . . . . . . . . . . . . . . . . . 1

2. COAL CONVERSION DEVELOPMENT . . . . . . . . . . . . . 6

2.1 Physical Properties of Coal Liquids. . . . . . . . . . 6

2.2 New Liquefaction Techniques. . . . . . . ..... 7

2.3 References................... 10

3. CHEMICAL RESEARCH AND DEVELOPMENT . . . . . . . . . . . . 12

3.1 Chemistry and Structure of Coal. . . . . . . . . . . . . 12

4. MAterials techNology. . . . . . . . . . . . . . . . 13

4.1 Pressure Vessel and Piping Materials . . . . . . . . 13

4.2 Fossil Energy Welding and Cladding Development . . . . . 14

4.3 Fireside Corrosion of AFBC Heat Exchanger Materials. . . 14

4.4 Failure Prevention and Analysis. . . . . . . . . . . . . 15

4.5 Materials Research for Liquefaction Systems. . . . . . 15

4.6 Development of Modified $9 \mathrm{Cr}-1$ Mo Structural Steel . . . 16

4.7 Ceramic Recuperators (Heat Exchangers) . . . . . . . 17

5. COMPONENT AND PROCESS EVALUATION STUDIES. . . . . . . . . . . 18

5.1 Technical Support to Large Liquefaction Projects . . . . 18

5.2 Component Test Facilities. . . . . . . . . . . 18

6. TECHNICAL SUPPORT TO MAJOR LIQUEFACTION PROJECTS. . . . . . . 19

6.1 Engineering and Design-Review. . . . . . . . . . . . . . 19

6.2 Technology Overview. . . . . . . . . . . . . . 22

6.3 Design Data Validation... . . . . . . . . . . 24

6.4 Components . . . . . . . . . . . . . . . . 28

6.5 Materials. . . . . . . . . . . . . . . 30

6.6 Environmental and Health............ . . . 36

6.7 General Technical Support. . . . . . . . . . . . 37

7. PROCESS ANALYSIS AND ENGINEERING EVALUATIONS. . . . . . . 41

7.1 Liquefaction Technology Assessment (LTAS). . . . . . . . 41

7.2 Direct Combustion. . . . . . . . . . . . . . . . 42

7.3 Advanced Power Conversion Systems. . . . . . . . . . . 42

7.4 Process Modeling . . . . . . . . . . . . . . . . . . 43

7.5 Coal Liquefaction Advanced Research Digest . . . . . 44

8. FOSSIL ENERGY ENVIRONMENTAL ANALYSIS. . . . . . . . . . . . . 45

8.1 Fossil Energy Environmental Project. . . . . . .. . . . 45

8.2 Economic Regulatory Administration Support Project . . . 46

8.3 Fossil Energy Program Support. . . . . . . . . . . 55 
$\underline{\text { Page }}$

9. COAL PREPARATION AND WASTE UTILIZATION. . . . . . . . . . 57

9.1 High-Gradient Magnetic Separation. . . . . . . . . . . 57

9.2 Open-Gradient Magnetic Separations . . . . . . . . . 58

9.3 Material Preparation . . . . . . . . . . . . . . . 65

9.4 ORNL/TVA Support Work for Magnetic Separation. . . . . 65

10. COAL PREPARATION PLANT AUTOMATION . . . . . . . . . . . . . 67

10.1 Physical Measurements . . . .. . . . . . . . . 68

10.2 Analytical Instruments. . . . . . . . . . . . . 69

10.3 Systems Application . . . . . . . . . . . . . 70

10.4 Mathematical Méthods. . . . . . . . . . . . 71

10.5 Information and Reports . . . . . . . . . . . . 71

10.6 Data Acquisition. . . . . . . . . . . . . . . 72

11. ATMOSPHERIC FLUIDIZED BED COAL COMBUSTOR FOR COGENERATION

(AFBCCC). . . . . . . . . . . . . . . . . . . . . 73

11.1 objective . . . . . . . . . . . . . . . . . 73

11.2 Status Summary. . . . . . . . . . . . . 73

12. TENNESSEE VALLEY AUTHORITY (TVA) FLUIDIZED BED COMBUS'IION

(FBC) DEMONSTRATION PLANT PROGRAM TECHNICAL SUPPORT . . . . • 74

12.1 AFBC Technology Support - Task 2. . . . . . . . . . . . 74

$12.24 \times 4$ Cold Flow Model - Task 3. . . . ... . . . . . 74

12.3 AFBC Modeling and Simulation - Task 4a. . . . . . . 75

12.4 Analytical Support and Alternative Design Concepts

Evaluation - Task 4b. . . . . . . . . . . . 76

12.5 AFBC Bench Scale Facility - Task 5. . . . . ..... 76

12.6 Assessment of the State-of-the-Art of PFBC Systems -

Task 6...................... 79

12.7 AFBC Technical Source Book and R\&D Evaluation -
Task 8....... . . . . . . . . . . . . . 79

12.8 Materials Support for TVA Pilot and Demonstration AFBC

Plant's - Task 9.................. . 80

12.9 Dynamic Modeling of the TVA Fluidized Bed Combustion

Pilot Plant - lask 10 . . . . . . . . . . . . 80

12.10 Coal Feed Tests - Task 11. . . . . . . . . . . 85

12.11 Materials Evaluation and Testing - Task $12 . . . . . .90$

12.12 Keferences for Section 12. . . . . . . . . . . 91

13. COAL COGENERATION/DISTRICT HEATING PLANT ASSESSMENT • . • . . 92

13.1 Objective . . . . . . . . . . . . . . . . . . . . , 92

13.2 Status Summary. . . . . . . . . . . . . . 92

14. PERFORMANCE ASSURANCE SYSTEM SUPPORT FOR FOSSIL ENERGY

PROJECTS. . . . . . . . . . . . . . . . . . . . . . . . 93

14.1 Objective . . . . . . . . . . . . . . . . . . 93

14.2 Status Summary. . . . . . . . . . . . . . . . . 93 
15. INTERNATIONAL ENERGY TECHNOLOGY ASSESSMENT. . . . . . . . . . . 94 15.1 . Liquefaction Technology Including Gasifier Development Status. . . . . . . . . . . . . . . . . . . . 94

15.2 Coal Liquefaction Materials . . . . . . . . . . . 95

15.3 International Survey of Atmospheric Fluidized Bed

Combustion Technology . . . . . . . . . . . . 95 


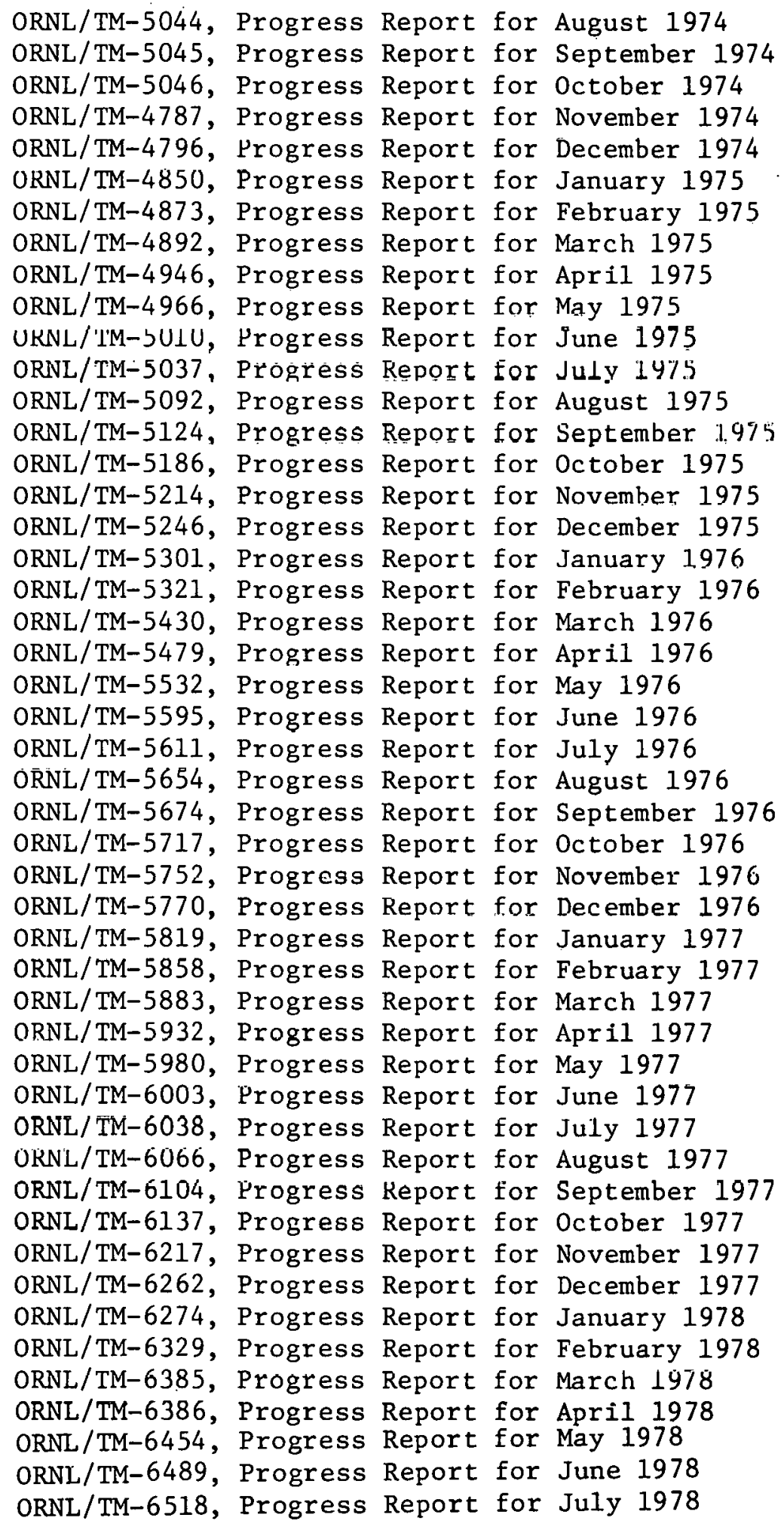


ORNL/TM-6592, Progress Report for August 1978

ORNL/TM-6630, Progress Report for September 1978

ORNL/TM-6666, Progress Report for October 1978

ORNL/TM-6682, Progress Report for November 1978

ORNL/TM-6767, Progress Report for December 1978

ORNL/TM-6815, Progress Report for January 1979

ORNL/TM-6829, Progress Report for February 1979

ORNL/TM-6886, Progress Report for March 1979

ORNL/TM-6923, Progress Report for April 1979

ORNL/TM-6928, Progress Report for May 1979

ORNL/TM-6997, Progress Report for June 1979

ORNL/TM-7031, Progress Report for July 1979

ORNL/TM-7057, Progress Report for August 1979

ORNL/TM-7095, Progress Report for September 1979

ORNL/TM-7144, Progress Report for October 1979

ORNL/TM-7171, Progress Report for November 1979

ORNL/TM-7210, Progress Report for December 1979

ORNL/TM-7251, Progress Report for January 1980

ORNL/TM-7285, Progress Report for February 19.80

ORNL/TM-7322, Progress Report for March 1980 
FOSSIL ENERGY PROGRAM REPORT FOR APRIL 1980

\begin{abstract}
This report - the sixty-ninth of a series - is a compendium of monthly progress reports for the ORNL research and development programs that are in support of the increased utilization of coal and other fossil fuel alternatives to oil and gas as sources of clean energy. The projects reported this month include those for coal conversion development, chemical research and development, materials technology, component and process evaluation studies, technical support to major liquefaction projects, process analysis and engineering evaluations, fossil energy environmental analysis, coal preparation and waste utilization, coal preparation plant automation, atmospheric fluidized bed coal combustor for cogeneration, technical support to the TVA fluidized bed combustion demonstration plant program, coal cogeneration/district heating plant assessment, performance assurance. system support, and international energy technology assessment.
\end{abstract}

\title{
1. Summary
}

L. E. McNeese

Highlights of our progress in April are as follows:

Coal conversion development - A series of pipeline viscometer differential pressure measurements are being made by varying the slurry tcmpcrature while the feed rate is held constant. During the month a run was completed on 35 wt \% Illinois No. 6 coal slurry at $0.793 \mathrm{~g} / \mathrm{s}$ feed rate and $13.9 \mathrm{MPa}(2000 \mathrm{psig})$ pressure for the temperature range of 400 to $720 \mathrm{~K}$. The estimated viscosity of the slurry at the gelation peak was $10 \mathrm{mPa} \cdot \mathrm{s}$ ( $10 \mathrm{cp}$ ) compared to $17 \mathrm{mPa} \cdot \mathrm{s}$ for earlier measurements at lower slurry rates. Additional runs at different slurry rates will be made in the future to further characterize the rheological behavior of the slurry. Previously, only $30 \%$ of phenol/coal reaction products could be examined by NMR due to limited solubility (30\%) in the preparative solvent. A technique involving silylation of $\mathrm{OH}$ groups has allowed nearly complete solubility and examination of the total reaction products by NMR is in progress. The amount of conversion during phenol/coal reactions was shown to be linearly related to the vapor density, allowing reduction in the phenol/coal ratio without reducing the amount of converted product. 
Chemical research and development - Kinetic study of the thermolysis of 1-naphthol has begun. A ${ }^{14} \mathrm{C}$-labeling study of the extent of retention of "solvent" by the SRC product in the Kerr-McGee Critical Solvent Deashing Process is in progress; complete results will be given next month.

Materials technology - The study of the effect of coal conversion environments on the hydrogen attack of pressure vessel steel was continued. A test in which several samples having different microstructures are exposed to hydrogen at $540^{\circ} \mathrm{C}$ and $13 \mathrm{MPa}$ is under way, but strain gages indicate no significant volume changes due to hydrogen attack at this point. In the task to develop weld overlay cladding techniques with type $320 \mathrm{Cb}$ stainless steel, six strip clad plates have been received from Sandvik, Inc., and are being sectioned for metallographic examination and corrosion exposure tests. The study of fireside corrosion of AFBC lieat exchanger materials continued with the major effort concentrating on the preparation of the final topical report on the $4500-h$ exposure tests in the FluiDyne AFBC. In the failure prevention and analysia task, the examination for potential cracking of four pieces of type 316 stainless steel pipe from the Wilsonville SRC Pilot Plant was continued. The investigation of materials performance in liquefaction systems continued. These studies include stress-corrosion cracking in vartous areas of liquefaction systems and the evaluation of materials for the Conoco Zinc Chloride Hydrocracking Process. In the task for development of modified $9 \mathrm{Cr}-1$ Mo steel, the fabrication of the two $14-\mathrm{Mg}$ heats procured previously into shapes for mechanical property testing continued. In the ceramic recuperator task, the post-test examination of tubes from CRAF Test 1 continued. In addition, sample materials for the second test, to begin in June, were received and bids for the coal-oil mixture for that test were received.

Component and proress evaluation gtudics - At the request of the office of Engineering Support DOE/ASFE, we are preparing rcvioions to two Field Task Proposal/Agreements (FTPAS) dealing with a dry coal feeder test facility and a slurry system test facility. A third FTPA has also been requested, covering an ash letdown and solid waste disposal test fac1l1ty.

Technical support to major liquefaction projects - Support is provided by Oak Ridge National Laboratory and Union Carbide Nuclear Division Engineering for the major liquefaction projects being managed by DOE Oak Ridge Operations - SRC I and SRC II Demonstration Plants and H-Coal Pilot Plant projects. Activitieo arc rcported nniler tweily-fuur epccific subtasks grouped into seven broad categories--engineering and design review, technology overview, design data validation, components, materials, environmental and health, and general technical support. 
A laboratory study demonstrated that losses of Kerr-McGee critical solvent resulting from chemical reaction under CSD conditions are neglible and that losses resulting from physical occlusion with the products are small. Significant progress is reported in studies of corrosion in fractionation columns of liquefaction plants. The preliminary draft environmental impact statement for the SRC I demonstration plant and the draft environmental statement for the SRC II demonstration plant, both essentially completed, will be issued early next month. The safety assessment of the $\mathrm{H}-\mathrm{Coal}$ reactor will be issued prior to initiation of coal-fed operation of the pilot plant next month.

Process analysis and engineering evaluations - Examination of the Purdue physical properties package code has been completed and a report describing results of the evaluation program, Testing and Validation of the Purdue Physical Properties Package (PPROP) Code, ORNL/TM-7374 (Draft), has been prepared. The Purdue code was designed to estimate physical properties of streams encountered in process modeling studies, with emphasis on coal conversion. Computer runs made at ORNL to test the operability and range of routines and functions used in the code showed that most performed satisfactorily; however, the ability of the code to deal with pseudo components is uncertain and incorrect results were produced when process flowsheet calculations were performed. Because of the problems and limitations uncovered, the PPROP program is judged to be unreliable for its intended purpose.

Fossil energy environmental analysis - In the Stored Solids Study, leaching measurements were initiated on samples of SRC-I solid product. In the demonstration plant EIS work, intensive efforts went into the preparation of the preliminary draft EIS for SRC-I and the Draft EIS for SRC-II. In the ERA Support Program, two new projects were begun. A study on the generic health effects of air pollution is part of the Northeast Regional Analysis. The second project is a study of the potential problems small utilities may have in implementing the Powerplant and Industrial Fuel Use Act. During the month, progress was made in developing information regarding energy projects having potential NEPA compliance requiremente. Additional copies of the Environmental Compliance Handbook were sent to DOE Headquarters and progress was made on the Industrial Hygiene/Occupational Medicine Workshop planning.

Coal preparation and waste utilization - Continuous carousel separation tests (HGMS) have been performed on two coals and the products analyzed. These separations consistently equaled or exceeded those obtained during the batch solenoid tests. The results of the extensive series of open-gradient separations yield products which closely approach those obtained with high-gradient separators. Preparation is now underway for a series of high throughput tests with the open-gradient solenoid. A series of tests is being performed by TVA at ORNL to characterize the magnetic separability of a Jackson County, Alabama, Fabius coal. 
Coal preparation plant automation - Development studies have begun on sensors to monitor slurry flow rates, slurry concentrations, particle size, level, and density. The state-of-the-art literature and field surveys were continued. On visits to five coal preparation plants, team members gained information on application of computer control, ultrasonic flow and level instrumentation, programmable logic controllers, nuclear density gages, and Gunson-Sortex ash monitors. The planning of preliminary on-site tests continued; a set of summary information was generated specifying the inputs and outputs, process variables, and potential measurement methods for several of the key processes. A review was made of development work being done in the area of on-line monitoring of coal by utilization of $x$-ray diffraction techniques. The computer data base on coal preparation and instrumentation documents was expanded with a total of 523 references to date. A survey of the literature for references to ruggedized data acquisition equipment potentially suitable for coal cleaning plant application has been initiated.

Atmospheric fluidized bed coal combustor for cogeneration (AFBCCC) The revised cost proposal for the amended subcontract received from Westinghouse was reviewed and Westinghouse was requested to consider offering some cost reduction. Agreement was reached on a lower cost figure and Westinghouse will submit the latest proposal in writing early in May.

Tennessee Valley Authority (TVA) fluidized bed combustion (FBC) demonstratjon plant program technical support - Work continued on the sulfur capture code in the modeling task. Four sulfur capture models were reviewed. These are: (1) Wen's grain model, 1 (2) Hartman and Coughlin's grain model, 2 (3) MIT's grain model, 3 and (4) MIT's pore plugging model.4 At present, a grain model code similar to those proposed by Hartman and Coughlin ${ }^{2}$ and MIT $^{3}$ has been written.

In the bench scale combustor, testing was completed on Lowellville limestone. Additional data were obtained at a superficial velocity of $1.8 \mathrm{~m} / \mathrm{sec}(6 \mathrm{ft} / \mathrm{sec})$. Because there was some concern that the rather large particle size of the Lowellville stone was the cause of poor sulfur capture, a series of tests was run with a high percentage of fines in the limestone feed. At a superficial velocity of $1.5 \mathrm{~m} / \mathrm{sec}(5 \mathrm{ft} / \mathrm{sec})$, indications are that feeding fines in the form of $6 \times 0$ mesh material does indeed improve the sulfur capture performance of the limestone.

In the Materials Support for TVA Pilot and Demonstration AFBC Plants Task, specimens from the second 1000-h Leatherhead AFBC run are ready to be examined metallographically. Samples selected from both the second 1000-h tube and the full 2000-h tube are $1-1 / 4 \mathrm{Cr}-1 / 2 \mathrm{Mo}$ and 2-1/4 Cr1 Mo steels, types 304 and 310 stainless steel, and Incoloy $800 \mathrm{H}$. Very cursory and preliminary observations indicate that the two sample sets: are very similar in corrosion response. 
Additional studies, using the dynamic model, were made of the variable bed-height mode to specifically investigate the use of superficial velocity and associated bed shrinkage as the method for exposing tubes and controlling heat transfer. The maximum rate of load change that could be handled was $2.5 \% / \mathrm{min}$, and the subsequent deactivation of heat-transferarea-times-coefficient by slumping could occur at an average rate of only $1.25 \% / \mathrm{min}$ without incurring controls instabilities.

In coal feed tests, we are now able to routinely feed coal having 8\% surface moisture with little difficulty. Using this feeding technique, we have continued to demonstrate that $8 \%$ moisture coal has a significant buildup tendency, even in the long sweep $90^{\circ}$ elbows. From visual observation of the elbows, it appears that the buildup occurs as "knobs" of coal (each about $1 \mathrm{~cm}$ high) along the outer radius walls of the elbow. The appearance and location of the "knobs" suggest that the buildup is an impaction phenomenon. Tests have now been run with three different air velocities. The results of these tests indicate the higher the air velocity, the faster the rate of buildup.

The first test run of the material evaluation muffle furnace has been completed. Following this run, a series of runs was made to characterize the relationship between initial $\mathrm{CO}_{2}$ and $\mathrm{CO}$ inputs on the output of the zirconia probe with various material in the specimen zone. Runs were made with no samples present, pre-oxidized samples, and samples with heavy bed deposits. The resulting runs indicate that these samples had only a small effect on the reproducibility of oxygen levels in the test facility.

Coal cogeneration/district heating plant assessment - The conceptual reference design work of United Engineers is now at the $95 \%$ completion stage. Extensive progress was made on the documentation.

Performance assurance system support for fossil energy projects Work is continuing on a failure modes and effects analysis of a generic coal slurry preheater. A revised report of this study is being prepared.

International energy technology assessment - ORNL is supporting the Lawrence Livermore Laboratory in making an assessment of international energy technology. A request was prepared for a research and development subcontract to provide assistance in reviewing the state-of-the-art of foreign and domestic literature and in trip reports from technical travelers who visited countries where the subject technology is under development or in use. In the area of coal liquefaction materials, an action plan was defined and information gathering was initiated. In the area of atmospheric fluidized bed combustion, the Sixth International FBC conference in Atlanta, April 9-11, provided an excellent opportunity to obtain information on foreign FBC development. 


\section{COAL CONVERSTON DEVELOPMENT}

J. R. Hightower, Jr.

Coal conversion development activities are carried out in the Chemical Technology Division. This section discusses two projects conducted for the Office of Coal Processing -- Physical Properties of Coal Liquids and New Liquefaction Techniques.

\subsection{Physical Properties of Coal Liquids}

F. Fi. Oswald, F. T.. Ynunghlnon, M. R. Gihson, L. S. Dickeisun, dnd R. L. Andrewis

The objective of this project is to measure and correlate physical properties (viscosity, density, thermal conductivity, and heat capacity) of various coal-solvent slurries and solids-free, coal-derived liquids at typical processing conditions, up to $31 \mathrm{MPa}$ (4500 psig) hydrogen pressure and $810 \mathrm{~K}\left(1000^{\circ} \mathrm{F}\right)$ in a bench-scale, continuous flow system. This system includes a slurry preheater and a hydrogenation reactor to simulate processing conditions prior to physical property measurement. Immediately after physical property measurement, the test fluids will be quenched and sampled for chemical characterization. Physical properties will ultimately be correlated with chemical characteristics of the test liquid to provide information useful to designers.

Results of pipeline viscometer differential pressure measurements on $35 \mathrm{wt} \%$ slurry from 400 to $725 \mathrm{~K}$ at a constant slurry feed rate are presented.

\subsubsection{Work accomplished}

As outlined in the last quarterly report, ${ }^{1}$ a series of runs are being made in which the slurry feed rate to the system will be held constant, and the slurry will be preheated with incremental increases in preheater discharge temperature. The heated slurry is passed directly through the pipeline viscometer located at the preheater exit. Viscometer temperature is controlled to match the preheater discharge temperature, and the viscometer differential pressure is recorded as a function of temperature from 400 to about $730 \mathrm{k}$. At each measurement temperature, the preheater is operated with constant heat flux along its length. This procedure will be repeated over the range of slurry feed rates possible with the positive displacement feed pump $(20.4-1.0 \mathrm{~g} / \mathrm{s})$. These measurements will characterize the flow behavior of slurry in the gelation region and will provide broad rheological characterization information on slurry outside of this area. 
A run was completed on $35 \mathrm{wt} \%$ slurry at $0.793 \mathrm{~g} / \mathrm{s}$ slurry feed rate and $13.9 \mathrm{MPa}(2000 \mathrm{psig})$ pressure. Results are presented in Figure 2.1--a plot of viscometer differential pressure vs slurry temperature. This curve is similar to the curve reported in the last quarterly report 1 at $0.665 \mathrm{~g} / \mathrm{s}$ slurry feed rate except for the height of the gelation peak. For the latest run, peak viscometer differential pressure was $\sim 2.48 \mathrm{kPa}\left(10\right.$ in $\mathrm{H}_{2} \mathrm{O}$ ) at $640 \mathrm{~K}$ and $0.793 \mathrm{~g} / \mathrm{s}$ slurry feed rate compared to $3.84 \mathrm{kPa}\left(15.5\right.$ in $\left.\mathrm{H}_{2} \mathrm{O}\right)$ at $650 \mathrm{~K}$ and $0.665 \mathrm{~g} / \mathrm{s}$ slurry feed rate for the earlier measurements. The estimated viscosity of the slurry at the gelation peak was $10 \mathrm{mPa} \cdot \mathrm{s}(10 \mathrm{cp})$ compared to $17 \mathrm{mPa} \cdot \mathrm{s}$ for the earlier measurements. The decrease in peak viscometer differential pressure does not seem consistent with the increase in slurry feed rate. One possible explanation is slurry age. The earlier run was made with slurry which was mildly agitated at room temperature for 5 days prior to the run. The latest measurements were made on slurry prepared 20 days prior to the run. It could be possible that the coal becomes somewhat solvated over an extended period of time, thereby reducing the magnitude of the gelation phenomenon during the preheating operation. Mechanical failures in the Coal Liquids Flow System caused the delays in using the feed slurry preparations. Typically, slurry is made up 16 hours before it is used, but because of the effort required to dry and size the coal used in the slurry, older slurry is used if a run is delayed. If it is established during future measurements that slurry age has an appreciable affect on slurry rheology, only fresh slurry will be used.

\subsubsection{Future work}

Runs similar to the one reported this month will be made at different slurry feed rates to produce a family of viscometer differential pressure vs slurry temperature curves. This information will be used to characterize the rheological behavior of slurry during the preheating process.

\subsection{New Liquefaction Techniques}

J. W. Larsen,* R. K. Hessley,* T. L. Sams, and B. R. Rodgers

The purpose of these research studies is to provide a better understanding of the chemical processes involved in the liquefaction of coal based on recent advances in knowledge of the structure of coal. The technical approach includes exploitation of the chemistry advances to develop new process concepts based on rapid conversion without the addition of external hydrogen.

*Chemistry Divisiun. 
ORNL DWG 80-725

$35 \%$ ILL. NO, 6 (-170 MESH) COAL /

WILSONVILLE RECYCLE SOLVENT

PRESSURE $=13.9 \mathrm{MPa}(2000 \mathrm{PSIG})$

SLURRY MASS RATE $=0.793 \mathrm{~g} / \mathrm{s}$

VISCOMETER DIMENSIONS =

$2.77 \mathrm{~mm}$ ID $\times 0.61 \mathrm{~m}$ LONG

TEMPERATURE ( $\left.{ }^{\circ} \mathrm{F}\right)$

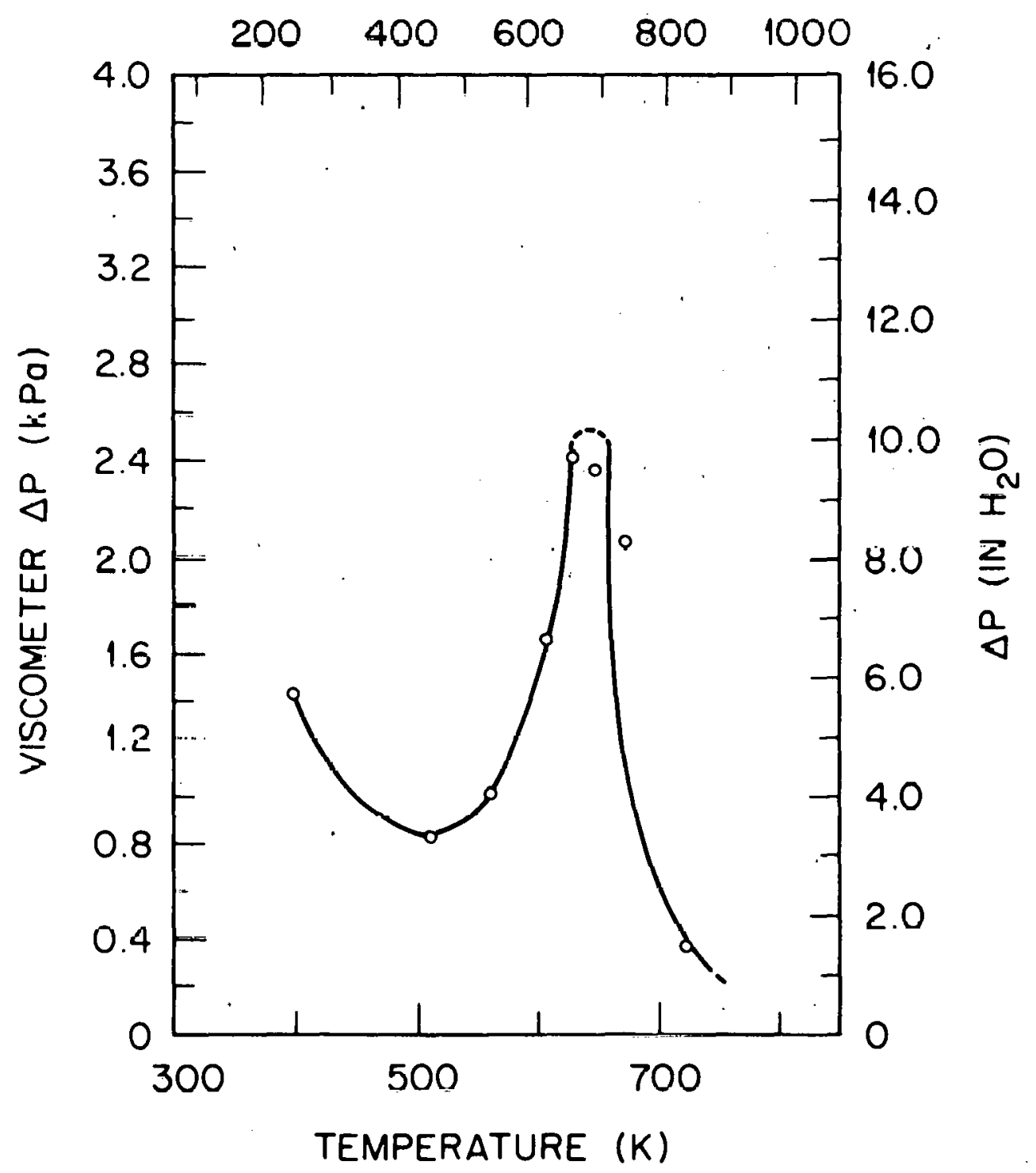

Fig. 2.1. Viscometer differential pressure vs slurry temperature. 
Present research is aimed at exploring the conversion of subbituminous and bituminous coals by the use of supercritical phenol, including the mechanisms of hydrogen transfer and structural studies of the converted products. Production of phenol from coal is also being explored at a reduced pace since this is the necessary step to utilization of the above reaction in a process scheme.

\subsubsection{Structural studies}

Wyodak coal was subjected to a liquefaction process involving phenol and heat as described in previous reports. The reacted material was fractionated into two portions on the basis of pyridine solubility. The extent of pyridine solubility defined conversion and was dependent on at least three variables: (1) phenol:coal ratio, (2) temperature, and (3) contact time. The degree of conversion was divided into three ranges for subsequent analyses. High conversion resulted in a yield of pyridine solubles $>60 \%$ of the weight of coal in the feed. Medium conversion yields wer $\bar{e}$ in a range of $30-60 \%$ pyridine soluble material, while low conversion yields contained $<30 \%$ pyridine soluble material. $1_{\mathrm{H}}$ and ${ }^{13} \mathrm{C}$ nuclear magnetic resonance (NMR) analyses on high conversion samples reported last month were encouraging in that the technique appeared to be a promising method for determining structures present in reacted coal products. However only a limited proportion of the sample was run and further studies are reported below.

To prepare the samples discussed last month for NMR analysis, the pyridine soluble portion from the phenol/coal reaction was exhaustively extracted with $\mathrm{CDCl}_{3}$. Unfortunately only $30 \%$ of the.coal-derived material was soluble and it was the results on this material that were reported. To examine all structures in the products, a method that increases the solubility in $\mathrm{CDCl}_{3}$ without interfering with the subsequent NMR analyses is necessary. This was accomplished by silylating the $\mathrm{OH}$ group of alcohols (mostly phenols) in the coal-derived products by refluxing pyridine in a mixture containing hexamethyl-di-silazane under a nitrogen atmosphere. This converts phenols to the following structure

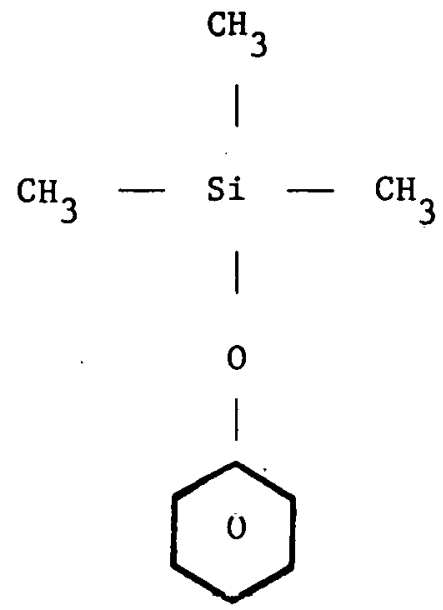


and increases the solubility of the coal-derived products in $\mathrm{CDCl}_{3}$ from $30 \%$ to nearly complete solubility for the Wyodak/phenol runs. Solubility of Bruceton/phenol reaction products are also significantly increased by this technique.

Samples utilizing the above technique are presently being analyzed by NMR and results will be presented next month.

\subsubsection{Hydrogen transfer mechanisms}

While phenol is instrumental to the conversion of coal by the process discussed previously, it is not known whether its action is due to the vapor or the liquid. During heat-up phenol is a liquid, but at reaction temperatures $\left(460^{\circ} \mathrm{C}\right)$ it is above its critical temperature $\left(421.1^{\circ} \mathrm{C}\right)$ and exists as a dense gas. If its action is through the gas phase, the density of th1s phase should effect conversion. Preliminary results were reported last month, and complete results are given in Figure 2.2. The results are quite encourag1ng because of the potential for reducing the amount of phenol required for the conversion. By changing the volume, a $2 / 1$ phenol/Wyodak run has been made where the density was held the same as for a $10 / 1$ phenol Wyodak run. The determination of conversion is currently in progress and all early indications point to a positive result.

\subsubsection{Future plans}

Structural studies will continue to emphasize NMR, if the results of current studies of silylated products are positive. Other techniques to increase solubilization in the NMR preparative solvent $\left(\mathrm{CDCl}_{3}\right)$ are in progress. One of these, $\mathrm{HNO}_{3}$ oxidation followed by acetylation will be reported next month.

The OH group was previously shown to be very instrumental in the $\mathrm{H}$-transfer mechanism. Two methods to examine exchange reactions and functionality are being studied: deuterization of the hydrogen in the $\mathrm{OH}$ group and replacing the $\mathrm{OH}$ group with an $\mathrm{SH}$ group. A mercaptobenzene/Wyodak run will be made within the coming month and progress repor Léd.

\subsection{References}

1. L. E. McNeese (ed.), Fossil Energy Program Quarterly Progress Report for the Period Ending March 31, 1980, ORNL-5658, Oak Ridge National Laboratory, Oak Ridge, Tennessee (in process). 
ORNL DWG 80-794

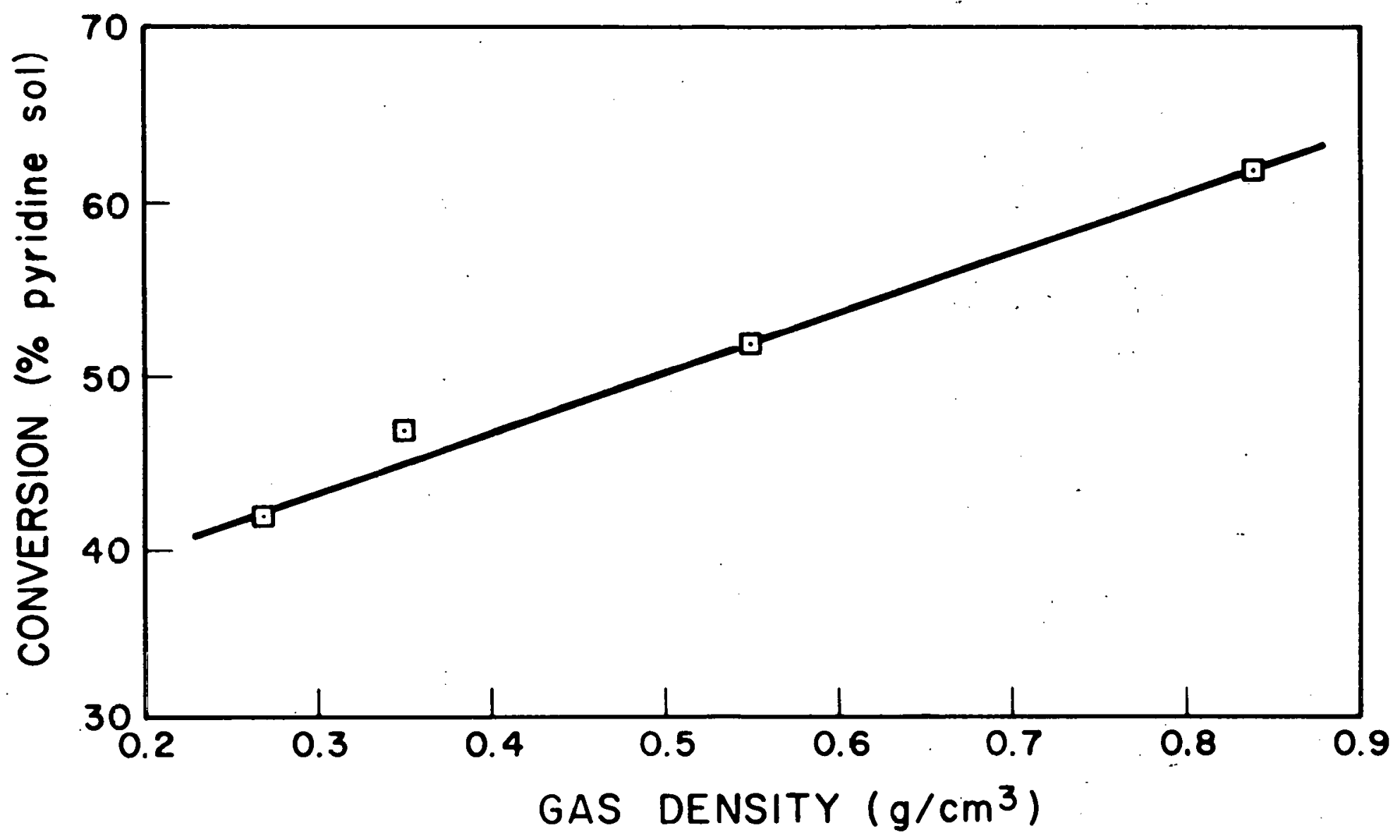

Fig. 2.2. Conversion during phenol/coal reactions depends on vapor density. 
3. CHEMICAL RESEARCH AND DEVELOPMENT

M. L. Poutsma

\subsection{Chemistry and Structure of Coal}

M. L. Poutsma and C. L. Wolf

Our deductions concerning the mechanism of thermolysis of 1naphthol have been so far derived largely from considerations of products. Further progress will require kinetic information in the liquid phase. This study will require use of a solvent so as to measure initial rates vs. concentration. 'lhe requirements for such a "solvent" are somewhat unusual, i.e., long-term stability at $400^{\circ} \mathrm{C}$ and a vapor pressure less than that of 1 -naphthol. Scouting studies suggest that m-terphenyl may qualify, and extensive purification of this material has been completed. 


\title{
4. MATERIALS TECHNOLOGY
}

\author{
R. A. Bradley
}

This section describes the research and development performed by the Metals and Ceramics Division on the Fossil Energy Materials Program supported by the Department of Energy's Office of Advanced Research and Technology. It includes tasks on pressure vessel and piping materials, welding and cladding development, corrosion of AFBC materials, failure prevention and analysis, materials research for liquefaction systems, development of modified $9 \mathrm{Cr}-1$ Mo alloy, materials for ceramic recuperators, and evaluation of foreign materials technology for coal liquefaction systems.

\subsection{Pressure Vessel and Piping Materials}

\author{
W. J. Stelzman, R. O. Williams, and D. A. Canonico
}

This task is concerned with the safety and reliability of the vessels and piping for second-generation coal conversion systems. While there are many aspects of this problem, we are currently concerned with the effects of hydrogen. At low temperatures, hydrogen contributes to the brittle fracture of steels; this effect is most prevalent when a steel is heattreated to high strength levels. At elevated temperatures and high pressures hydrogen will react with carbon in low-alloy steels to form methane bubbles at the grain boundaries and cause a general degradation of properties.

Generally such steels are not in internal equilibrium. Holding at elevated temperatures will cause the partitioning of the chromium and molybdenum to the carbide, the coarsening of the carbide particles, and in some cases the formation of new carbide phases. These processes are controlled by the diffusion of the chromium and molybdenum in the ferrite, by the degree of dispersion of the carbide phase, and perhaps by the nucleation of new phases. The partitioning of the chromium and molybdenum lead to a reduction of the carbon activity. The formation of a new carbide phase may also lead to a further reduction. The problem is complex because of the wide range of structures that are possible in steels.

The run where a number of samples having different structures are exposed to hydrogen at $540^{\circ} \mathrm{C}$ and pressures to $13 \mathrm{MPa}$ (1930 psi) was restarted but our efforts to repair the hydrogen leak were only partially successful. Consequently, the pressure is somewhat lower than earlier in the run. The signals from the strain gages that monitor the length changes have been stable in most cases. One gage shorted out and another opened up. It is apparent that most of the samples have not exhibited significant volume changes.

The draft report covering the scope of our research is being revised incorporating reviewers' comments. 


\subsection{Fossil Energy Welding and Cladding Development}

D. P. Edmonds and G. M. Goodwin

The objective of this task is to develop techniques for weld overlay cladding of components for coal conversion systems and to characterize welds of thick-section steels. Six strip-clad plates have been received from Sandvik, Inc., during this reporting period. These materials are part of the subcontract to obtain $21 / 4 \mathrm{Cr}-1$ Mo steel base metals clad with type 320 stainless steel using the submerged-arc strip-cladding process. Materials received were: 2RK65 (Sandvik heat), 2RM69 (type 310LMo stainless steel), 3RE14 (type 309 stainless steel), NiCrMo-3 (Inconel 625), Sanicro 28 (Sandvik heat), and Sanicro 41 (Sandvik heat). clads on ASTM A-387 Grade 22 steel. Base metals for each of the clads are $30 \times 60 \times 2.5 \mathrm{~cm}$ and minimum clad thickness is $4.5 \mathrm{~mm}$. Plates were preheated to $200-250^{\circ} \mathrm{C}$ before welding and interpass temperatures of $300^{\circ} \mathrm{C}$ maximum were maintained during welding. These clads, along with previous type 320 stainless steel clads made at ORNL, are being sectioned for metallographic examination and corrosion testing. Both all-clad metal and composite (base metal-clad metal) U-bend corrosion specimens will be tested in an SRC environment. Results will indicate the relative corrosion resistance in a coal conversion environment of a number of potential reaction vessel and piping cladding materials. Also, metallographic results will help to explain results found from the corrosion testing. The final type 320 stainless steel clad should be received in the next two months.

\subsection{Fireside Corrosion of AFBC Heat Exchanger Materials}

T. G. Godfrey and. J. H. DeVan

The Engineering Technology Division at ORNL is developing an AFBC to cogenerate electricity and process heat for an industrial complex in the size range 5 to $50 \mathrm{MW}(\mathrm{e})$ capacity. Further information on the Coal Combustion for Cogeneration (CCC) Program may be found in Section 11 of this report. Our support of this program involves materials compatibility tests conducted in a $0.46-$ by $0.46-\mathrm{m}$ (18- by 18-in.) AFBC at the FluiDyne Corporation of Minneapolis. This AFBC was used to conduct five sequential tests of heat exchanger materials for a total of $4500 \mathrm{~h}$. The five tests intervals were $500,1000,500,1000$, and $1500 \mathrm{~h}$, respectively. A draft of the paper "Heat Exchanger Materials for Fluidized-Bed Coal Combustors" presented at the 6 th International Conference on Fluidized Bed Combustion (Atlanta, April 9-11, 1980) is in the final stage of revision. This submission is being expanded, primarily with more detail, into the topical report on the $4500-h$ test in the FluiDyne AFBC. 


\subsection{Failure Prevention and Analysis}

R. W. Swindeman

4.4.1 Examination of pipe from Wilsonville SRC Pilot Plant - J. R. Keiser, R. W. Swindeman, V. B. Baylor, and M. D. Allen

This effort has consisted of examining four pieces of type 316 stainless steel pipe that were sent to us by operating personnel at the Wilsonville SRC Pilot Plant. The examinations were performed at their request and results have been provided to them. Preliminary results of this examination were reported in the previous monthly report.

The only uncompleted work consists of electron microprobe studies to identify the material found in cracks in the pipe connecting the preheater to the dissolver. A sample has been submitted and this work should be completed in the near future.

\subsection{Materials Research for Liquefaction Systems}

R. W. Swindeman

4.5.1 Materials to resist stress-corrosion cracking in coal 1iquefaction pilot plants - J. R. Keiser and V. B. Baylor

This work is being performed to assess the resistance of various materials to stress-corrosion cracking in coal liquefaction plants. Efforts this month were directed toward preparing the safety assessment for the laboratory autoclave facility, providing racks of U-bend specimens for the Fort Lewis SRC Pilot Plant and the H-Coal Pilot Plant at Catlettsburg, Kentucky, and examining three racks of U-bends which had been exposed in the Wilsonville fractionation column.

The U-bend specimens have been cleaned and are being weighed. After the weight and dimensions have been measured, the specimens will be carefully examined for evidence of cracks. The only specimen showing a gross change is the one made of E-Brite $26 \mathrm{Cr}-1$ Mo which had been consumed completely by corrosion. Corrosion rates and the results of examinations for cracks will be reported later.

Fifteen racks of U-bend specimens were shipped to the Catlettsburg $\mathrm{H}$-Coal Plant and five racks were sent to the Fort Lewis SRC Pilot Plant.

\subsubsection{Materials for the Zinc Chloride Hydrocracking Process - V. B. Baylor and J. R. Keiser}

The purpose of this work is to evaluate materials proposed for use in the regeneration and cundenser vessels of the zinc chloride coal liquefaction process. Corrosion coupons are being exposed in a quartz experimental loop to an environment containing $\mathrm{HCl}$, dry air, and $\mathrm{ZnCl}_{2}$ at 
temperatures ranging from 550 to $950^{\circ} \mathrm{C}$. A 500-h exposure was completed this month using $5 \% \mathrm{HCl}$ in air. Several coupons were lost from the hot leg and were identified as Incoloy MA956. Many specimens on the cold leg were appreciably attacked, making identification difficult. All specimens will be cleaned and measured, with scale and metal samples submitted for analysis.

Some problems were encountered during the run with plugging of the outlet line by condensed salts that had to be boiled or melted away. After the run, we found devitrification of the loop in one area and a change in color of the quartz from clear to blue. We speculate that the blue color of the glass and the solidified residue resulted from metallic corrosion of the high nickel and especially the cobalt-base alloys.

The loop was not reusable due to the localized attack and the failure of the joints which attach the specimen trees to the loop. Two heaters also reached the end of their operating life. Two more loops were ordered from the glass shop, along with sufficient heaters and gases to last through the end of the fiscal year.

\subsection{Development of Modified $9 \mathrm{Cr}-1$ Mo Structural Stee1 \\ V. K. Sikka}

Large heat fabrication, mechanical property characterization, weldability, and steam corrosion studies continued during the last month.

The fabrication order for the conversion of ingots from the two $14-\mathrm{Mg}$ heats was placed near the end of January and the delivery of various products is expected by June 1980. Meanwhile, we have cut two 30-cm-thick sections from the electroslag-remelted ingots of the two $14-\mathrm{Mg}$ heats. These sections have been fabricated to plate stock for preliminary testing and evaluation. The plates were fabricated by the follnwing processes to evaluate the effect of fabrication: (1) hot forging, (2) hot forging and hot rolling, (3) hot forging and cold rolling after tempering, (4) hot forging and cold rolling after softening treatment, (5) hot extrusion, (6) hot extrusion, hot forging, and cold rolling after tempering, (7) hot extrusion, hot forging, and cold rolling after softening, and (8) hnt. extrusion and hot forging. Charpy-impact testing nf the plates made by the above-mentioned processes were completed during the last month. The lowest transition temperature values were obtained for the plate made by cold rolling after a tempering treatment. Cold rolling after softening treatment produced a higher transition temperature. The highest transition temperature was obtained for plates finished either by hot forging or hot extrusion. Hot rolling after hot forging produced a lowering in transition temperature. Metallographic studies on plates made by various fabrication processes are currently in process.

Tensile tests at room temperature and $593^{\circ} \mathrm{C}$ were completed on highsilicon ingot 30394 of Heat 1 . Two tests ruptured on the low-silicon ingot of Heat 2. Three creep tests each on ingots 30182 and 30394 are currently 
in progress. One test at $649^{\circ} \mathrm{C}$ on ingot 30182 is examining the effect of an hour-long weekly cycle on the creep behavior of this alloy. This test is expected to fail during the next month.

Charpy-impact tests were completed on the high-silicon ingot 30394 of Heat 1. Data shows that for electroslag-remelted process impact properties are the same for both the low-silicon $(0.2 \%)$ and high-silicon $(0.5 \%)$ material. Similar results for the creep properties are currently being investigated.

As a part of the new strategy to obtain an earlier ASME Code case approval of modified $9 \mathrm{Cr}-1$ Mo, testing was started on the tube heats. Tubes from the heat used in making the Tennessee Valley Authority tubing were the first of these heats to be tested. Tensile tests on this heat were completed in February. Three creep tests on this heat are currently in progress. Additional tube heats from Combustion Engineering, Chattanooga, Tennessee, are expected at ORNL during the first week of May 1980.

\subsection{Ceramic Recuperators (Heat Exchangers) \\ V. J. Tennery and G. C. Wei}

In this period, we continued to characterize post-test ceramic tubes from the Ceramic Recuperator Analysis Facility (CRAF) Test 1 . The measurements of linear thermal expansion coefficients of post-test and as-received ceramic tubes were essentially completed. The thermal expansion coefficients of sintered- $\alpha$ SiC, Refel SiC, CVD SiC on SiC, Carbofrax-A, Carbofrax-M, MAS 8200, and Zirmul increased somewhat due to the high-temperature (about $1022^{\circ} \mathrm{C}$ ), long-term $(500 \mathrm{~h}$ ) exposure to residual oll combustion products. However, the thermal expansion coefficients of post-test $\mathrm{AD} 998, \mathrm{Al}_{2} \mathrm{O}_{3}, \mathrm{KT} \mathrm{SiC}$, and $\mathrm{CVD} \mathrm{SiC}$ remained the same as as-received materials. Nodules from post-test sintered- $\alpha$ and KT SiC tubes were analyzed with a DTA thermal analyzer. A glass transition behavior was observed in material from both nodules. The glass transition temperature $\left(1063^{\circ} \mathrm{C}\right)$ of nodule material from sintered $-\alpha$ $\mathrm{SiC}$ is lower than that in the $\mathrm{KT}$ nodule $\left(1088^{\circ} \mathrm{C}\right)$. This is consistent with the chemical analysis results from the nodule material showing a higher ( 300 . ppm) concentration of boron in sintered- $\alpha$ nodule material than in $\mathrm{KT}$ nodule material $(10 \mathrm{ppm})$. The DTA results also confirmed that the temperatures of the nodules were above their glass transition points during the CRAF Test 1 exposure.

In this month we received KT SiC tubes for $\overline{\mathrm{C}} \overline{\mathrm{RAF}} \overline{\mathrm{T}}$ Test 2 using coaloil mixture (COM) as a fuel. A purchase order for NC $430 \mathrm{SiC}$ tubes with proprietary butt joints was placed. Information on coal combustor and handling equipment was collected for preliminary studies on construction of a coal-fired furnace or conversion of the present oil-fired furnace to a multiple-fuel-fired (coal and oil) furnace for CRAF tests planned in FY 1982 and beyond. 


\title{
5. COMPONENT AND PROCESS EVALUATION STUDIES
}

\author{
D. M. Eissenberg
}

The objective of component and process evaluations is to ensure that coal conversion (1iquefaction, gasification, pyrolysis) processes, subsystems, and components have satisfactory functional performance, lifetime, reliability, and safety for their intended applications, and that sufficient component and subsystem performance data are available to permit process design optimizations. Activities to be carried out include performance and cost analyses; assessments of operating plants; field tests; operation of test loops; and the development of advanced processes, subsystems, and components.

Present activities are primarily those carried out as part of the technical support to large liquefaction projects. In addition, studies are being initiated aimed at the development of processes, subsystems, and components for more generic coal conversion applications.

\subsection{Technical Support to Large Liquefaction Projects}

P. K. Carlson, W. A. McAuley, L. F. Parsly, and A. N. Smith

Activities in this area are in support of the H-Coal pilot plant and SRC demonstration projects and are described in more detail in Chapter 6. Work in support of the H-Coal pilot plant (6.7.2) included calculation and analysis of temperature distributions in the reactor vessel shell during six specific time-temperature excursions. Slurry pressure letdown loop (6.4.3) construction continued. The computer design program was used to size a full size letdown system for the SRC II Demonstration Plant. Responses to the RFP for a wet grinding study (6.3.2) are due May 6. A revised work statement for SRC Components Design Review (6.4.2) was prepared for review.

\subsection{Component Test Fac111ties}

\section{M. Eissenberg}

At the request of the Office of Engineering Support DOE/ASFE, we are preparing revisions to two Field Task Proposal/Agreements (FTPAs) previously submitted, one dealing with a dry coal feeder test facility and one with a slurry system test facility. A third FTPA has also been requested, covering an ash letdown and solid waste disposal test facility. These FTPAs will be discussed at a meeting to be held in Washington next month. 


\title{
6. TECHNICAL SUPPORT TO MAJOR LIQUEFACTION PROJECTS
}

\author{
H. D. Cochran
}

Support is provided by Oak Ridge National Laboratory and Union Carbide Nuclear Division Engineering for the major 1iquefaction projects being managed by DOE Oak Ridge Operations--SRC I and SRC II Demonstration Plants and H-Coal Pilot Plant Projects. Activities under twentyfour specific subtasks are reported in seven broad categorles--engineering and design review, technology overview, design data validation, components, materials, environmental and health, and general technical support.

\subsection{Engineering and Design Review}

This section reports on three subtasks whose objectives are focused on review of engineering and design of the SRC I and SRC II demonstration plants and the H-Coal pilot plant: engineering design review, SRC/H-Coal process and design review, and solid-liquid separations design review.

\subsubsection{Engineering design review - J. J. Kurtz and T. W. Picke1}

Objective - This activity consists of providing technical assistance to the DOE-ORO SRC Projects Office on the SRC I and SRC II projects. The SRC-I project involves the design, construction, and operation of a coal liquefaction plant for the production of a clean solid boiler fuel. The SRC-II project is for the production of a clean liquid boiler fuel. The government-funded preliminary design of the SRC I project is contracted with the Southern Company Services (SCS), Inc., and the SRC II project contract is with the Pittsburg \& Midway ( $\mathrm{P} \& \mathrm{M}$ ) Coal Mining Company.

The principal purposes of the SRC projects review and evaluation activities are to provide objective assessments of the contractors' technical progress, identification of potential problems, and critiques of project deliverables.

Status summary - The SRC I project technical status review meeting was monitored in the International Coal Refining Company's office (formerly the Joint Venture Group).

Project document reviews for SRC I included comment reviews of the design basis memorandum (DBM) for the gas systems section and the process design criteria for the 6000 TPSD demonstration plant. ORNL staff personnel assisted UCC-ND Engineering in these reviews. A screened list of comments pertinent to the present stage of process design definition was transmitted to the DOE-ORO SRC Projects Office. 
A geotechnical study report of the SRC I site by ATEC Associates was reviewed in conjunction with a review of extensive soll investigation work proposed by ATEC Associates, Rust, and ICRC. A preliminary comment report was transmitted to the DOE-ORO SRC Projects Office. A more detailed assessment of soil liquefaction risks attending a seismic event at the site was requested by DOE-ORO and is underway.

The SRC II project technical status review meeting was monitored in the P\&M Denver office.

The SRC II draft statement of work, dated April 17, was reviewed and unsolicited comments were provided informally to the DOE-ORO SRC Projects Offlce.

\subsubsection{SRC/H-Coal process and design review - A. R. Irvine, J. F. Fisher, W. R. Gambill, H. F. Soard}

Objective - The objective of this activity is to provide review and analysis of key process areas of the SRC demonstration plants and those aspects of the $\mathrm{H}-\mathrm{Coal}$ pilot plant that will provide information useful in the design and evaluation of the SRC I and SRC II demonstration plants.

Status summary - Fired preheater design and performance is a matter of serious concern in any direct liquefaction plant. The information pertaining to preheater performance at $\mathrm{Ft}$. Lewis that was presented by K. Parimi of Gulf at a Denver meeting is being transmitted to Oak Ridge for our review. Attempts are being made to have SRC I preheater designers visit here for an update on their design effort. The rather minimal amount of data pertaining to preheater tests that is provided in the monthly reports is being reviewed. In a related effort, most of the issues of the International Journal of Multiphase Flow have been reviewed. Also, a paper has been found which reports shear-enhanced thermal conductivity of a slurry. The enhancement of thermal conductivity increases as the particle diameter increases. For a preheater with 6 to 8 in. NPS tubes, the minimum particle size which has a significant effect on the effective thermal conductivity is 50 to $100 \mu \mathrm{m}$.

The problem of selection of feed coals for the SRC I and SRC II demonstration plants is being studied. We believe that the primary consideration is that the coals used as demonstration plant feed materials should maximize the amount of useful information obtained. The literature has been searched to determine the magnitude, location, and sulfur content of bituminous coal beds in the eastern and central states. The problems of determining and maintaining constancy of feed coal reactivity have been identified as potential major considerations in both demonstration and commercial scale plant design and operation. 
6.1.3 Solid liquid separations design review - B. R. Rodgers, B. M. Benjamin, * and T. L. Samis

Objective - The objective of this project is to provide technical support to DOE-ORO in the area of solids/liquid separations. The first request was to determine to the extent possible in the laboratory, the fate of the Kerr-McGee solvent lost in their deashing process, or at least if it was chemically reacted. The time frame was to be two months.

Status summary - Kerr-McGee (K-M) solvent tagged with carbon-14 was chemically synthesized by the Chemistry Division. This material was contacted with Kerr-McGee process feed supplied by the Wilsonville SRC Pilot Plant operators at typical operating conditions supplied by Air Products and Chemicals, Inc. The products were separated by first venting the gases, then washing the bomb with methylene chloride $\left(\mathrm{CH}_{2} \mathrm{Cl}_{2}\right)$, filtering, and Soxhlet extracting the solids with $\mathrm{CH}_{2} \mathrm{Cl}_{2}$. The liquids were separated by vacuum distillation into $\mathrm{CH}_{2} \mathrm{Cl}_{2}$, KerrMcGee solvent and $\mathrm{CH}_{2} \mathrm{Cl}_{2}$ soluble SRC. Radiotracer assays were then performed on all materials by combustion with oxygen and analysis using a Cory Model $401 \mathrm{M}$ vibrating reed electrometer. To determine whether the $\mathrm{C}^{14}$ tagged solvent was adsorbed or chemically bound, large excesses of unlabeled solvent were equilibrated with the products, a process that would desorb any unreacted solvent by equilibrium exchange. The results are given in Table 6.1 .

Table.6.1 Results of radiotracer analyses of Kerr-McGee process simulated products

\begin{tabular}{lcc}
\hline Product & $\begin{array}{c}\text { Percent of } \mathrm{K}-\mathrm{M} \text { solvent } \\
\text { lost to product } \\
\text { before equilibration }\end{array}$ & $\begin{array}{c}\text { Percent of K-M Solvent } \\
\text { lost to product } \\
\text { after equilibration }\end{array}$ \\
\hline Gases & negligible & \\
$\mathrm{CH}_{2} \mathrm{Cl}_{2}$ & negligible & 0.04 \\
$\mathrm{SRC}\left(\mathrm{CH}_{2} \mathrm{Cl}_{2}\right.$ & 0.42 & \\
soluble portion) & & \\
$\mathrm{SRC}\left(\mathrm{CH}_{2} \mathrm{Cl}{ }_{2}\right.$ & less than 0.001 & \\
insoluble portion)
\end{tabular}

*Chemistry Division. 
The conclusion is clear: essentially none of the $K-M$ solvent is chemically reacted and less than a half percent is adsorbed. The reportedly high solvent loss at Wilsonville $(1.7 \%)$ must be due to some other reason such as fugitive losses or poor separation techniques.

An updated work plan for this effort is in preparation and should be formulated by the next reporting period. The next logical step in the present assignment is to examine the $\mathrm{K}-\mathrm{M}$ Pilot Plant at Wilsonville. Recent discussions between the Chemical Technology and Chemistry Divisions suggest that isotope dilution techniques may be suitable for examining the losses in products from this unit. This has not been discussed with DOE/ORO and thus it is not known at present whether they desire to continue this effort.

A final report on the current assignment, due June 7, will be transmitted by May 9 .

\subsection{Technology Overview}

This section reports on five subtasks whose objectives are to provide a broad overview of direct liquefaction technology--Direct Liquefaction Technology Overview and four technical field representation tasks,

6.2.1 Direct 1iquefaction technology overview - R. W. Glass, K. H. Lin,

A. R. Irvine, J. P. Belk, J. R. Horton, J. K. Huffstetler,

B. Nelman, W. R. Reed, and B. T. Thompson

Objectives - The objectives of this task are:

1. To keep abreast of significant developments in coal conversion $R \& D$ activities, and of progress in coal liquefaction facilities to derive and document technical data of importance to design and operation of pilot, demonstration, and commercial plants.

2. To evaluate documents submitted to DOE by contractors, and to provide any other technical assistance in response to requests from DOEORO.

3. To conduct short- to intermediate-term studies on subjects which could have major impact on coal liquefaction technology and economics.

4. To develop and to make available in one package an independent source of technical information and data base as an aid to DOE program management and other participants in the DOE program to design, construct, and operate demonstration and commercial plants.

Scope - The task effort will be directed toward the following areas of activities and types of technical information: 
1. R $₫ D$ activities relevant to (a) modification and improvement of key unit processes and associated equipment, (b) physical and chemical properties of major process streams and products, and (c) processes for upgrading of liquefaction products.

2. Plant experience data from pilot plants and PDUs that are crucial to the design and operations, including (a) significant operation and maintenance experiences, and (b) technical problems encountered due to deficiency in the design or to abnormal process conditions, and specific solutions to the problems.

Status summary - Major activities in different areas that have been carried out under this task are outlined below:

1. Planning - The work statement for the task has been revised to indicate more specific definitions of activities in various areas under the task including: (a) review of progress in coal liquefaction technology, (b) direct liquefaction data source books, (c) direct liquefaction technical file, (d) ad hoc technical studies, and (e) technical assistance to DOE-ORO. Top priority will be given to item (e), and studies of other items [(a) through (d)] will be interrupted as required to. accomplish specific studies requested by DOE-ORO. Because of the manpower limitation at present (most of the participants in the task are on a part-time basis), the tentative priority among items (a) through (d) will be assigned in that order.

2. Review of technical literature pertaining to SRC, H-Coal and EDS projects is in progress for the purpose of maintaining awareness of any important developments in coal liquefaction technology. The technical literature includes published papers and topical reports, as well as informal documents, such as progress reports, demonstration plant design documents, etc. Through this activity, technical data of importance to design, construction, and operation of coal liquefaction plants will be derived and documented.

3. Liquefaction technology f1le - Suggested plans for a technical reference file of all pertinent data relating to major liquefaction projects were submitted for review and approval. An informal file of meeting and progress reports, etc., has been established pending approval and funding of this activity.

4. Ad hoc technical studies - The draft final report by Econergy, Inc. to be available shortly, w111 be studied and used as a reference to determine tentative plans regarding the direction and scope of our own study on upgrading of coal liquid products. The draft report presents the results of their coal liquids upgrading study which was completed recently. 
5. Technical assistance to DOE-ORO - The following documents were reviewed: (a) H-Coal Pilot Plant preoperations safety review questions and ASFI answers, and (b) SRC I Demonstration Plant process design criteria and design basis memorandum.

6. Data source books - In continuing the work on the SRC source book for FY 1980, an attempt is being made to match the schedules and availability of the personnel to various sections in the source book, taking into consideration their priorities in other projects. Much source book material to be included in this year's work will come from other SRCrelated programs in support of major liquefaction projects. Relative priorities in preparation of the source book material have been identified based both on consideration of critical needs in DOE programs and on the availability of background material. Other activity for this month included procurement of additional resources for the SRC collection of technical information at Building 1000 .

\subsubsection{Technical representation at field sites - R. W. Glass}

Objective - The objective is to place a UCCND technical representative at each of the major development sites - H-Coal, Exxon Coal Liquefaction Plant, Harmarville, Ft. Lewis, and Wilsonville. The purpose is to facilitate the flow of information between the above-mentioned sites, DOE and ORNL.

Status summary - We are continuing to make a strong attempt to identify a person to be the technical representative at the H-Coal pilot plant. Plans for the technical representative at $\bar{F} t$. Lewis are progressing in second priority. A position charter for the H-Coal pilot plant site representative has been transmitted to DOE-ORO for initiation of discussion with ASFI. A candidate site representative for the Ft. Lewis location has been identified but the position charter has not been defined.

\subsection{Tesien Data Validation}

This section reports on three subtasks whose objectives are aimed at providing experimental measurements to answer questions which have arisen in designing the SRC demonstration plants. These subtasks are: Coal Slurry Mixing Tests, Wet Grinding for SRC Processes, and Vacuum Bottoms Viscosity Measurement.

6.3.1 Coal slurry mixing tests - J. R. Hightower, Jr., E. L. Youngblood, and L. S. Dickerson

Objective - The objective of this project is to study the changes that occur in physical properties (particularly viscosity) in coal slurries during mixing at temperatures up to $533 \mathrm{~K}\left(500^{\circ} \mathrm{F}\right)$. The system includes a small scale mix tank with an agitator and slurry circulation system of the type used for feed makeup in the SRC processes. Continuous 
ORNL DWG 80-531R

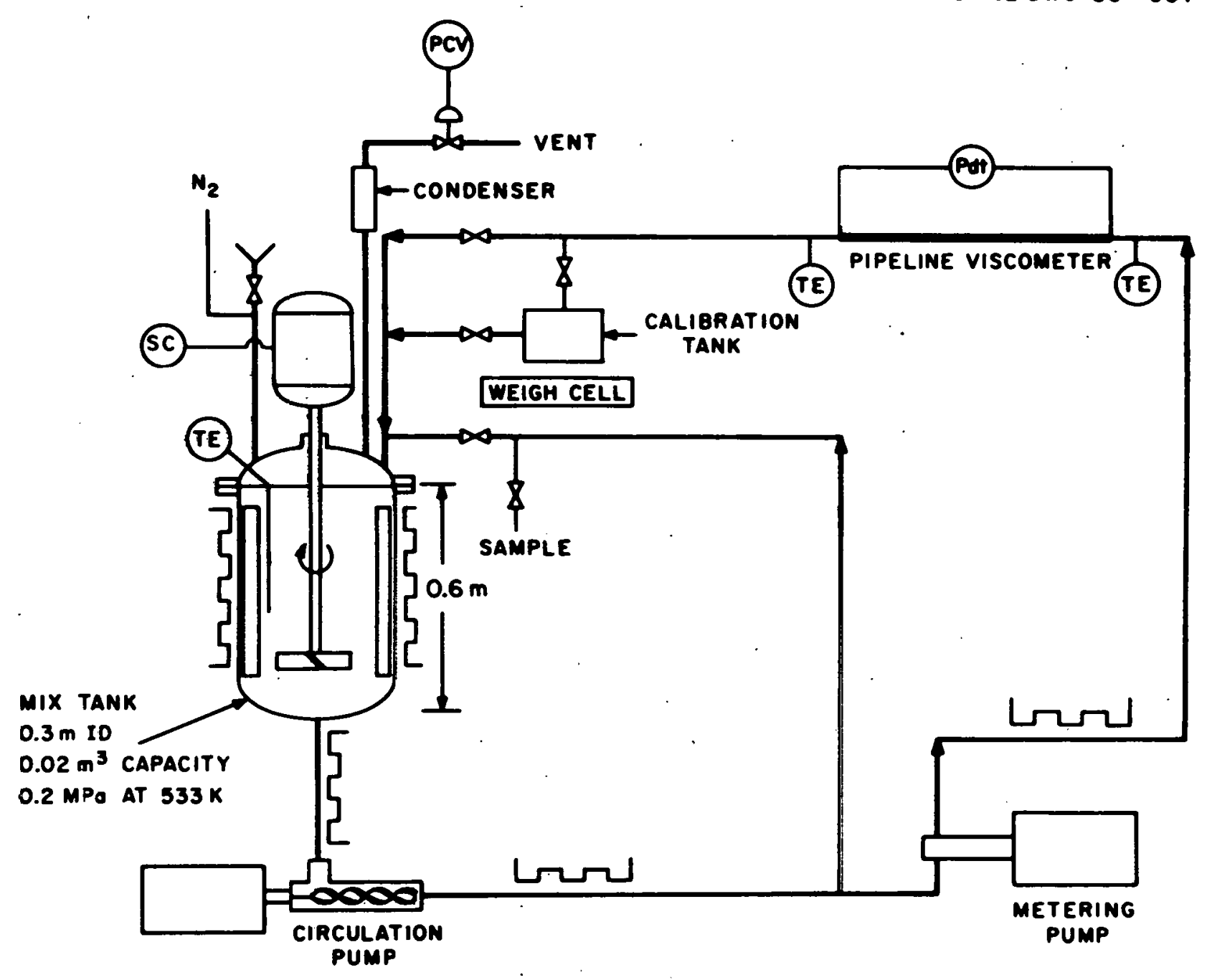

Fig. 6.1. Schematic of slurry mixing system. 
viscosity measurements will be made with an on-line pipeline viscometer. The ultimate objective of the study is to establish conditions that will permit the slurry preparation system in the SRC demonstration plants to be operated at increased temperature thereby improving the overall process thermal efficiency and cost.

Status summary - During April the design and procurement of equipment was continued. A trip was made to the Ft. Lewis pilot plant and to Denver to obtain information regarding slurry mixing and to determine test conditions of interest to the SRC II design group. The SRC I design group was also contacted to determine test conditions of interest to them. A simplified schematic of the slurry mixing system that is being designed is shown in Fig. 6.1. Purchase orders have been placed for the circulation pump, weigh cell, and electrical heaters. A 0.02 $\mathrm{m}^{3} / \mathrm{h}$ capacity metering pump and much of the instrumentation needed for the system is already avallable. Equipment specifications have been obtained from two manufacturers for agitators and reactor vessels that may'be suitable for the mixing system. However, delivery times on some of the equipment are 12 to 15 weeks.

Tentative test conditions of most interest to the SRC II Demonstration Plant design group are: temperatures in the range of 422 to $477 \mathrm{~K}$ (higher if possible), viscosity at shear rates of 50 to $2000 \mathrm{~s}^{-1}$, residence times up to 60 minutes, and Powhatan No. 6 coal ( $80 \%-200$ mesh). Testing of a second type of coal (Powhatan No. 5 or Ireland) is of more interest than tests with a different particle size. Addition of coal at different times to give different residence times is also of interest. Tentative test conditions of interest to the SRC I design group are: temperatures up to $505 \mathrm{~K}$ (higher if possible), viscosity at shear rates of 50 to $1000 \mathrm{~s}^{-1}$, Kentucky No. $9 \mathrm{coal}(70 \%-200$ mesh), and tests at two agitator speeds to determine if this is an important variable. The slurry mixing system is being designed for operation at these conditions. Additional input from the design groups will be obtained as the program progresses.

During the next month design and procurement of the equipment will continue. A limited amount of construction and installation of equipment will be started. Preparation of a safety summary and quality assurance assessment for the facility will be started.

\subsubsection{Wet Grinding for the SRC II Process - W. A. McAuley}

Objective - The study will investigate the feasibility of incorporating a wet grinding process into the SRC II Demonstration Plant. The presently proposed dry grinding/mixing system has encountered problems such as coal swelling and gel formation.

Status summary - Inquiries concerning the Request for Proposal (RFP M-1032) have been received from Battelle Columbus Laboratories and Econergy Associates; both companies are quite interested in doing the feasibility study. The closing date for recelpt of proposals is May 5, 1980. 
Proposals will be evaluated on the basis of the following criteria in descending order of importance:

1. Previous experience in grinding technology.

2. Demonstrated expertise in detailed planning of development and testing programs.

3. Availability of physical and software resources.

4. Experience and educational qualifications of the project staff.

\subsubsection{Vacuum bottoms viscosity measurement - J. R. Hightower, Jr. B. R. Rodgers and J. H. Wilson}

Objective - The objective of this project is to provide a tested and calibrated instrument for installation at the Ft. Lewis SRC pilot plant or other suitable site which is capable of providing on-line viscosity measurement of residuals obtained from the vacuum still of the SRC II process. This type instrument is necessary to provide indication of the onset of irreversible polymerization or coking problems which would interfere with controlled feeding of vacuum still bottoms to a gasifier.

Status summary - Detailed technical discussions were held with SRC II Pilot Plant personnel concerning the vacuum still operations. Much useful information was obtained on suitable valves, pumps, etc. that, according to their extensive experience, might be suitable for this erosive and corrosive application. Marpak and WKM ball valves with graphoil packing are currently being investigated for use on our system. Ft. Lewis vacuum still bottoms (VSB) are dumped directly on a metal belt for solidification and consequently they have limited experience pumping this material. They suggested that gear pumps would probably work best but a high level of wear would have to be acceptable.

Ft. Lewis currently measures the VSB viscosity by remelting the solidified (and oxidized) material in either a Haake or Brookfield viscometer located in their plant laboratory. The Haake has been in "operation" since July of 1979 but has been very unreliable. The current problem is serious baseline drifts of $200-300 \%$ during a run. The Brookfield that they use at present has a limitation on shear rate and viscosity of about $186 \mathrm{~s}^{-1}$ and $500 \mathrm{cP}$, respectively. They are negotiating with Brookfield to supply an apparatus capable of $372 \mathrm{~s}^{-1}$ and $5000 \mathrm{cP}$. We are also trying to purchase one of these devices according to the specification which they provided the manufacturer.

Discussions were also held with the SRC II design team in Denver: Gulf Mineral Resources Co. and Badger Energy, Inc. They gave us the current thinking on the Demonstration Plant design ranges for the VSB and with the help of the Ft. Lewis information we have selected the following as the initial ranges for design of our viscometer. 


Temperature
Solids Content
Viscosity
Density
Fusion Point
Pressure

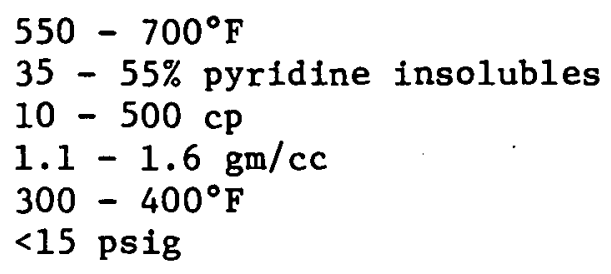

GMRC is assigning to Badger the responsibility for designing a pumparound loop to be installed on the Ft. Lewis vacuum tower. The primary purpose is to test pumps, valves and other components. They agreed to provide for inclusion of our VSB viscometer in this loop. We promised to provide a self-sufficient package only requiring specified tap sizes and room requirements for their design. 'Ihis should help the efficient integration of the viscometer into the Ft. Lewis operation; however, it does require extending our original schedule. The plans for the loop design call for completion of preliminary design around October, 1980, detailed design around February, 1981, and completion of construction around August, 1981. The original commitment on the viscometer development (April, 1981) was already tight and should be extended to coincide with the loop design.

Plans are being made to visit the SRC I design team in the near future. Initial procurement items to be ordered next month are: BranLube Positive Displacement Pump, WKM and Marpak valves, Brookfield viscometer and melting point apparatus.

\subsection{Components}

Activities in this area include review and evaluation of component problems encountered in operating coal liquefaction pilot plants and PDU's, assessment of the adequacy of critical components selected for use in SRC I' and II Demonstration Plants, and the development and testing of improved components for use in the Demonstration Plants.

Three elements are currently authorized:

- Component and Technology Workshop

- Component Design Review

- Packed Bed Pressure Letdown System Study

6.4.1 Workshop on equipment for coal liquefaction facilities - M. Siman-Tov, W. R. Williams, J. R. Horton

Objective - The objective of this project is to organize and conduct a workshop on critical equipment for coal liquefaction facilities which will provide a forum for information dissemination and discussion on equipment availability, reliability, and operating experience affecting the performance and reliability of these facilities. 
Status summary - During April, tentative decisions on the scope, location, and agenda for the workshop were made, and a work statement was prepared for DOE-ORO. The equipment areas to be discussed include pumps, valves, heaters and heat exchangers, and materials handling and slurry mixing. Attendance at the meetings shall be by invitation. A list of potential participants has been prepared. The workshop is being scheduled for June 16-18, 1980, in Oak Ridge, Tennessee. Pumps will be discussed on the first day and a half, valves on the second day, and the remaining two topic areas on the third day in concurrent sessions. There will be no formal proceedings for the workshop, but a summary of it will be prepared and distributed as required. These tentative decisions are to be discussed with DOE-ORO SRC Projects Office personnel on May 1.

\subsubsection{Component design review - D. M. Elssenberg}

Objective - The objective of the component design review is to identify critical components in the SRC I and SRC II Demonstration Plants and to provide assessments as to their expected performance based on Phase I design specifications and analysis of similar components utilized in pilot plants or other comparable service. Where appropriate, recommendations will be proposed for alternate specifications, alternate component selection or development and testing programs which would lead to improved components.

Status summary - A revised work statement for subtask 7 was prepared for review by DOE/ORO and ORNL program management.

\subsubsection{Packed bed pressure letdown study - D. M. Eissenberg}

Objective - The objective of this study is to develop an improved slurry pressure letdown system for possible application to the SRC I and II Demonstration Plants. The improved system utilizes a packed bed for pressure drop, with flow control provided by addition of clean liquid which volatilizes at the temperature/pressure conditions within the packed bed.

Status summary - Significant progress toward completion of the test loop was made during April including the following:

1. Receipt of slurry and gas flow meters. These are currently awaiting calibration at $\mathrm{Y}-12$ shops.

2. Receipt of gas bottle rack and manifold. The manifold is currently being certified for operation at $\mathrm{Y}-12$ Mechanical Inspection Department.

3. Initiation of procedures to acquire engineering drawing and pressure reviews by the Engineering Division as required by safety and QA guidelines.

4. Receipt of an instrument application drawing from I\&C Division. This division is handling procurement and design of the instrumentation. 
Computer studies continued during April. Calculations done up to this point have been primarily aimed at determining the shape and approximate dimensions of a packed column sized to handle half the flow of an SRC II demonstration sized plant. When the size and shape of the column are thus fixed, calculations are to be done to find out which combinations of high-pressure (HP) separator effluent.flow and HP vapor condensate will give the same overall bed $\Delta \mathrm{P}$. These calculations will give an indication as to what turndown ratio is possible with the system and what the size of the control system should be.

Two runs (inlet temperatures $427^{\circ}, 454^{\circ} \mathrm{C}$ ) have been made so far. These runs show a required bed length of approximately $5.4 \mathrm{~m}$ using $38 \mathrm{~mm}$-diam. packing (spheres) and an I.D. ranging from $0.2 \mathrm{~m}$ inlet to $0.4 \mathrm{~m}$ outlet. The code is capable of varying the diameter of the column to give a bed constructed of constant $I$. $U$. sections in $50 \mathrm{~mm}$ increments joined by conical reducers. The shape thus limits $\Delta \mathrm{P}$ per unit length to a preset maximum. Setting this maximum at $3.4 \mathrm{MPa} / \mathrm{m}(150 \mathrm{psi} / \mathrm{ft})$ gave the above results.

\subsection{Materials}

This section reports on five subtasks whose objectives are focused on the materials of construction for coal liquefaction plants - the H-Coal Materials and Technology Task Force, Materials Design Review and Coordination of Materials R\&D for SRC Projects, Quality Assurance Support for H-Coal Pilot Plant Welding, H-Coal Materials Testing and Failure Analysis, and Investigation of Corrosion in Fractionation Areas of Liquefaction Plants.

6.5.1 H-Coal materials and technology task force - R. A. Bradley, K. H. Lin, P. K. Carlson, V. Cuthrie, J. R. Horton, H. A. Mitchell, B. Niemann, L.Parsly, W. R. Reed, and R. W. Swindeman

Objective - The objective of this task is to evaluate the materials of construction and the coal 1iquefaction technologies planned for use in the H-Coal Pilot Plant. The evaluation attempts to ensure the maximum utilization of the existing information and experience from other liquefaction pilot plants and process demonstration units (PDUs) and to provide the bases for efficient and reliable operation of the H-Coal Plant. The scope of the evaluation includes the following five subjects pertaining to the H-Coal Pilot Plant:

1. materials of construction and potential materials-related problems in the Plant,

2. reliability of critical components in the Pilot Plant design,

3. potential problems associated with the Plant equipment and accessories due to deficiencies in the engineering design, 
4. significant operating and maintenance experiences from other liquefaction pilot plants which will be useful to the H-Coal Pilot Plant; and

5. an incident report system to distribute information on technical problems.

Status summary - The final Task Force report, entitled Report of the H-Coal Materials and Technology Task Force (ORNL/CF-80/59), will be issued soon. The report incorporates comments from DOE-ORO. With issuance of this report, the activities of the Task Force were concluded.

6.5.2 Materials design review and coordination of materials R\&D for SRC projects - R. R. Judkins, R. A. Bradley, and A. R. O1sen

Objective - The objectives of this task are to assist in the review of contractor documents for materials selection, to review and provide input to materials testing and failure analysis plans, and to coordinate materials research and development for SRC projects.

Status summary - Agenda for meetings with SRC contractors to initiate materials design reviews for the SRC demonstration plants were submitted to DOE. Reviews of SRC I design documentation - Design Basis Memorandum for Areas 15, 16, 17, and 18 and Process Design Criteria (Rev. 1) - were completed. Material recommendations for Areas 11, 12, and 34 of the SRC-II plant were obtained and reviews of this material were initiated.

\subsubsection{Quality assurance support for $\mathrm{H}$-Coal pilot plant welding - K. K. Klind $t$}

Objective - The objective of this activity is to provide technical support to DOE-ORO in the resolution of weld quality problems in the piping system at the $\mathrm{H}$-Coal pilot plant. 1980 .

Status summary - No support was needed during the month of April

6.5.4 $\frac{\text { H-Coal materials testing and fallure analysis }}{\text { V. B. Baylor, J. R. Keiser, and R. W. Swindeman }}$

Objective - The objective of this task is to provide assistance to the Ashland Synthetic Fuels, Inc. (ASFI) in developing and implementing a materials testing, surveillance, and failure analysis plan for the H-Coal Pilot Plant at Catlettsburg, Kentucky. The scope of work involves the review of the materials of construction, participation in the materials testing effort, and the preparation of a fallure analysis plan acceptable to the participants of the H-Coal Project. 
Status summary - A revised materials testing and failure analysis plan was received from ASFI through DOE-ORO. This plan was reviewed in detail, and comments were submitted to DOE-ORO for subsequent transmittal to ASFI.

Preparations are being made to investigate the general corrosion and U-bend samples that were installed in the H-Coal Plant for exposure in the oil-operational mode in March and April. The samples will be removed in May and replaced by new racks of test samples.

\subsubsection{Investigation of corroston in fractionation areas of liquefaction}

plants - R. A. Bradley, J. R. Keiser, V. B. Baylor, M. Howell, and $R$. W. Swindeman

Object1ve - Because of the severe corrosion observed in the fractionation area of SRC pilot plants, a multidisciplinary study is under way at ORNL to determine the mechanism and a means to control this corrosinn.

Status summary - During this month, analysis of liquids have been performed, laboratory tests have been conducted, and racks of coupons have been cleaned and weighed. In addition, test coupons from Wilsonville have been shipped to Fort Lewis for exposure in the wash solvent column.

Liquids analyzed have been supplied by both the Fort Lewis and Wilsonville SRC Pilot Plants. The Wilsonville sample was collected in mid-January when no sodium carbonate was being added to the feed coal. As a result, the corrosion rate measured by probes in the fractionation column showed a significant increase over that measured when carbonate is being used. Results are shown in Table 6.2. The most significant information contained in these results is the distribution of watersoluble and water-insoluble chlorine-bearing compounds. Clearly, the water-soluble chlorides segregate at the top of the column while the insoluble chlorides segregate at the lower portions of the column (where corrosion is the greatest).

Analysis has also been completed on a sample collected at Wilsonville in mid-February when sodium carbonate additions were at the maximum and corrosion rates were low. The results, shown in Table 6.3 , indicate the chlorine content is significantly different between the "corrosive" and "noncorrosive" feeds.

Resill ta of the analyses of samples cullectcd at Fore Lewis on February 6 were given in the March report. Measurements of the watersoluble chloride content are as follows:

\begin{tabular}{lccc}
\hline Chloride $(\mu \mathrm{g} / \mathrm{ml})$ & Overhead & Feed & Bottoms \\
\hline Total & 139 & 117 & 241 \\
Water-soluble & - & 97 & 41 \\
\hline
\end{tabular}


Table 6.2 Analysis of Wilsonville fractionation column liquids collected on January 15, 1980

(no $\mathrm{Na}_{2} \mathrm{CO}_{3}$ added for about six days ${ }^{a}$ )

\begin{tabular}{|c|c|c|c|c|}
\hline Liquid & Feed & Tray $1^{b}$ & Tray $9^{c}$ & Tray $15^{d}$ \\
\hline Neutralization number $\left(\mathrm{mg}_{\mathrm{g}} / \mathrm{g}\right)$ & 0.68 & 0.29 & 0.29 & 0.41 \\
\hline $\mathrm{Cl}(\mu \mathrm{g} / \mathrm{ml})$ & 348 & 211 & 315 & 376 \\
\hline Water-soluble $C 1(\mu \mathrm{g} / \mathrm{m} 1)$ & 281 & 234 & 87 & 25 \\
\hline S (wt \%) & 0.169 & 0.271 & 0.174 & 0.225 \\
\hline$N(w t \%)$ & 0.88 & 0.23 & 0.43 & 0.26 \\
\hline$C(w t \%)$ & 86.58 & 82.06 & 85.48 & 85.46 \\
\hline H (wt \%) & 8.58 & 9.05 & 9.54 & 9.09 \\
\hline $\mathrm{H}_{2} \mathrm{O}$ (wt \%) & $<0.03$ & $<0.03$ & $<0.03$ & $<0.03$ \\
\hline $\mathrm{Na}(\mu \mathrm{g} / \mathrm{ml})$ & 1.0 & 1.0 & 1.0 & 1.0 \\
\hline $\mathrm{Cr}(\mu \mathrm{g} / \mathrm{ml})$ & $\therefore \quad 1.0$ & 0.7 & 1.5 & 2.0 \\
\hline $\mathrm{Fe}(\mu \mathrm{g} / \mathrm{ml})$ & 1.5 & 1.2 & 1.6 & 1.8 \\
\hline $\mathrm{N} 1(\mu \mathrm{g} / \mathrm{ml})$ & $<0.5$ & $<0.5$ & 0.1 & 0.15 \\
\hline
\end{tabular}

${ }^{a}$ Corrosion rates measured at time of sampling.

$b_{\text {Tray } 1 \text { - carbon steel probe, } 3.4 \mathrm{~m} 11 / \text { year. }}$

$c_{\text {Tray }} 9$ - type 316 stainless steel probe, 176 mil/year.

$d_{\text {Tray } 15}$ - type $304 \mathrm{~L}$ stainless steel probe, $232 \mathrm{mil} /$ year.

Table 6.3 Analysis of fractionation column feed

Feed produced from Kentucky 9 coal

Liquid

W1 thout $\mathrm{Na}_{2} \mathrm{CO}_{3}$,

With $\mathrm{Na}_{2} \mathrm{CO}_{3}$

"corrosive"

"noncorrosive"

Neutralization number (mg/g)

0.68

0.37

Total C1 $(\mu \mathrm{g} / \mathrm{g})$

348

85

$\mathrm{S}($ wt \%)
$\mathrm{N}($ wt \%)
$\mathrm{H}_{2} \mathrm{O}$ (wt \%)

0.169

0.45

0.88

0.59

$<0.03$

$<0.1$ 
These measurements indicate that the chlorides moving to the bottom of the tower are predominately of the water-insoluble type. Although there was not enough sample available to measure the water-soluble chloride content of the overhead fraction, from the content of the column feed it would appear that the overhead fraction would contain predominately water-soluble chlorides. This would give the same distribution of chlorides as is observed at Wilsonville. However, the operating conditions at Fort Lewis on February 6 were such that the maximum corrosion was occurring in the overhead line and not in the column. Hence, the common feature which relates the areas of maximum corrosion at Fort Lewis and Wilsonville is the temperature, not chlorine content (i.e., the maximum corrosion is observed at 450 to $500^{\circ} \mathrm{F}$ regardless of the distribution of water-soluble and -insoluble chlorides.

Laboratory tests have been conducted to measure the effect of a number of compounds on the corrosion of steel in phenol. We have also attempted. to identify a mixture of aromatic compounds which would have the corrosive characterization of the fractionation column feed.

At temperatures below $200^{\circ} \mathrm{C}$, we have not found mono-, di-, or trichlorophenol to increase the corrosion rate of steel in phenol. When naphthol was used as the solvent and the exposure temperatures were $230^{\circ} \mathrm{C}$ or higher, corrosion rates of $2.5 \mathrm{~mm} /$ year (100 mil/year) or higher were observed for carbon steel. Studies with these compounds are continuing.

Six racks of samples were removed from the Wilsonville fractionation column in March and sent to ORNL for examination. Initial results show that, as expected, the greatest weight losses occurred on samples from the middle manway. 'lihe weight losses for the middle manway corrosion coupons are given in Table 6.4. Corrosion rates tor all samples will be calculated and reported later.

Racks of corrosion coupons and U-bend specimens were shipped to Fort Lewis for installation during their May shutdown. 
Table 6.4 Weight loss of corrosion coupons at the middle manway

\begin{tabular}{lc}
\hline \multicolumn{1}{c}{ Alloy } & Weight 1 loss $\left(\mathrm{g} / \mathrm{m}^{2}\right)$ \\
\hline Hastelloy C-276 & 0.25 \\
Inconel 625 & 11.1 \\
Hastelloy G-3 & 12.0 \\
Hastelloy G & 13.7 \\
Incoloy 825 & 51.4 \\
Carpenter 20Cb3 & 71.1 \\
Haynes 20 Mod & 73.0 \\
Alloy 904L & 107 \\
Monel 400 & 116 \\
Type 321 stainless steel & 277 \\
Type 317 stainless steel & 450 \\
Type $317 \mathrm{LM}$ stainless steel & 486 \\
2RE69 & 522 \\
Type 304 stainless steel & 553 \\
Type 310 stainless steel & 744 \\
\hline
\end{tabular}




\subsection{Environmental and Health}

The objectives of this task are: (1) to assist DOE in the preparation of the NEPA-required Environmental Impact Statements for the SRC-I and SRC-II demonstration plants; (2) to provide environmental technical assistance to DOE in support of these projects; (3) to assist DOE in the review of plans for landfilling of solid wastes from H-Coal operations; (4) to provide support to DOE in the accumulation, synthesis, and interpretation of environmental and health data related to direct coal 1iquefaction technologies, especially.SRC and H-Coal processes.

\subsubsection{SRC I and SRC II environmental impact statements - C. R. Boston and S. G. DeCicco}

SRC I demonotration project - $\Lambda$ n intonoivo offort wont into tho preparation of the preliminary draft Environmental Impact Statement (PDES) throughout April as the May 1 delivery date approached. Nuthors, editors, reviewers, and DOE worked closely to assemble the comprehensive document.

Major issues which have surfaced Include the following: occupational and public health effects from producing and transporting SRC, with emphasis on the presence of carcinogenic substances; major traffic congestion along Route 60 during the peak construction effort, especially in the direction of Henderson, Kentucky; the proposed site is located on a floodplain and more than $60 \%$ of the site would be inundated by a 100year or 500-year flood of either the Green River or the Ohio River (Executive Orders 11988 and 11990 require DOE to prove that there is no practicable alternative to siting the plant on the floodplain); the loss of prime agricultural land (over $90 \%$ of the site has been designated as "prime" farmland by the U.S.D.A. - Soll Conservation Service and federal actions are discouraged from removing such land from active or potential use). The PDES will assess these and other adverse and beneficial effects as well as potential for reducing adverse impacts through the use of alternative sites and/or alternative plant designs.

SRC II demonstration project - While effort on the SRC I PDES was peaking, an intensive effort also went into preparing the SRC II Draft Environmental Impact statement (DES). Whereas the PDES is an internal DOE document, the DES is the first document issued to the public for review and comment. The SRC 11 DES will be the first environmental statement to be issued by the Department of Energy on a syncher1c fuel demonstration project and is expected to receive a great deal of attention by industry, government agencies, conservation and environmental groups, neighbors at the proposed site, and the public at large. On May 5, ORNL is to deliver a draft of the document for DOE approval. Comments and revisions as a result of this review are expected. 
The May progress report will summarize the findings presented in the DES, which is expected to go to the EPA on May 23. It is expected that EPA will publish the Notice of Availability in the Federal Register on May 30 inftiating the 45-day public comment period. A public hearing will be scheduled by DOE near the close of the comment period.

\subsubsection{Environmental review for $\mathrm{H}$-Coal landfill - T. H. Row}

The initial review of landfill plans for the H-Coal project was completed in July 1979. No further activity is expected on this task until the summer of 1980 .

\subsubsection{Environmental and health status of SRC and $\mathrm{H}-\mathrm{Coal}$ processes - R. F. Kimball, N. B. Munro, C. J. Oen, and L. W. Rickert}

The initial organizing phase of the critical review on mutagenesis in relation to SRC and $\mathrm{H}-\mathrm{Coal}$ processes has been largely completed during this month. Conferences between R. F. Kimball and N. B. Munro, the primary staff for this review, and members of the Information Division have resulted in decisions on strategies for searching computerized files for pertinent documents. Initial searches of both the Environmental Data Base and Environmental. Mutagen Information files have provided a series of initial documents that are being used to establish the detailed procedures for the project. Conferences with personnel of the Comparative Mutagenesis Program and the Analytical Chemistry Program have provided information and documents on the existing research in the field. An initial outline for a computerized file of pertinent documents has been developed and a hard copy file of these documents has been started.

\subsection{General Technical Support}

General technical support is provided for the SRC I and SRC II projects and for the H-Coal project on an as requested basis.

\subsubsection{SRC I and SRC II general technical assistance - H. D. Cochran}

There is no current activity in this area.

\subsubsection{H-Coal pilot plant general technical assistance - H. D. Cochran}

The following activity on $\mathrm{H}-\mathrm{Coal}$ reactor safety assessment (headed by $\mathrm{H}$. A. Mitchell) is in progress in this area. 
6.7.3 H-Coal reactor safety assessment - H. A. Mitchell, B. L. Booker, R. C. Gwaltney, R. A. Just, L. F. Parsly, A. N. Smith,

R. W. Swindeman

Objectives - The purpose of the reactor safety assessment is to determine the adequacy of the vessel and to identify any significant failures which would affect the reactor operation and to determine the adequacy of systems to limit or control those effects. The safety assessment encompasses the major reactor components and subsystems, the instrumentation directly associated with the reactor and normal, upset, and emergency procedures. A brief description of the tasks performed to satisfy the objectives of the safety assessment are presented below.

A major task of the assessment will be to determine whether a catastrophic failure could occur during start-up or operation of the reactor. Consideration will be given to the ability, to control the reactor under normal and upset conditions. In addition, those events which require emergency actions will be addressed. The results of this task will be presented in an interim report.

Materials data will be gathered on the alloys used to fabricate the H-Coal reactor. Creep, fatigue, and creep-failure interaction data will be assembled, and curves will be developed for comparison with the design data in Section VIII, Division 1 and Division 2 of the ASME Boiler and Pressure Vessel Code for service in the temperature range of 400 to $900^{\circ} \mathrm{F}$.

A thermal dynamic analysis of the process conditions should be performed for certain upset and emergency conditions. This analysis should provide information relating the time response of systems important for safety, operator actions taken during upset or emergencies, and the process conditions inside the vessel.

A comparison will be made of the transients that the reactor is expected to experience and the transient design conditions specified in the User's Design Specification in order to confirm the histogram of pressures and temperatures for the vessel. This comparison should establish a set of umbrella events which can conservatively represent the operation of the vessel.

A thermal model should be developed to relate the process, grid support ring, and vessel wall temperatures during normal, upset, and emergency conditions. This model should be verified during break-in operation on oil by thermocouple data taken from the vessel.

An inelastic (elastic-plastic-creep) analysis of selected regions of the vessel will be made to assess accumulation of creep-failure damage. This analysis will be based on the temperature-pressure history for the proof-test, refractory drying cycles, and operational and emergency conditions specified in the reactor vessel design specification. The analyses to be performed are a series of simplified one-dimensional analyses. The results of these analyses will indicate whether there is a need for more detailed analysis. 
Status summary - Efforts during April have been concentrated on making calculations of the temperature distribution in the vessel shell, particularly during transients associated with normal operation, upsets, and emergencies, and on developing a set of umbrella events which would encompass the various process and utility failures which potentially could occur during the plant lifetime. We succeeded in reducing the number of scenarios to be considered in the stress histogram to six: refractory drying cycle; preliminary testing; normal start-up, operation, and shutdown; cool down to hot standby and restart; emergency event with controlled cooldown and crash cooldown. The last of these is so severe that were it ever to happen, a reappraisal of the condition of the vessel should be made before continuing operation.

The temperature distribution calculations indicate that the information available to the operators is adequate to permit them to control the rates of heating and cooling to maintain any desired temperature differences. It will be necessary, in particular, to cool rather slowly during shutdowns to maintain the $100^{\circ} \mathrm{F}$ temperature difference criterion specified in the operating procedures.

Materials data were collected that would aid in the creep-fatigue analysis of the $\mathrm{H}-\mathrm{Coal}$ reactor vessel (K201). Of interest were physical properties (thermal conductivity, thermal expansion coefficient, and heat capacity), elastic properties (Young's modulus, Poisson's ratio), plastic flow behavior (yield strength, plastic modulus, cyclic hardening behavior), creep behavior (creep law and cyclic creep hardening behavior), and failure criteria (stress-rupture, fatigue, and creep-fatigue damage interaction). Alloys of interest were $21 / 4 \mathrm{Cr}-1$ Mo steel (F22 - Class 2) and type 347 stainless steel overlay cladding. When no data could be found, we recommended a substitute data correlation, developed for a similar alloy and available in either the ASME Boiler and Pressure Vesse 1 Code Case N-47 or the Nuclear Systems Materials Handbook. Table 6. summarizes our recommendations. 
Table 6.5 Recommendations for Materials Data to be Used in the Creep-Fatigue Analysis

\begin{tabular}{|c|c|c|}
\hline \multirow[b]{2}{*}{ Property } & \multicolumn{2}{|c|}{ Material } \\
\hline & $\begin{array}{c}21 / 4 \text { Cr-1 Mo Base Metal and } \\
\text { held Metal }\end{array}$ & $\begin{array}{l}347 \text { Jtainless Steel and } 309 \\
\text { Stainless Steel Cladding }\end{array}$ \\
\hline Young's Modulus & ASME Code cr NSMH Data & ASME Cole for Base Metal \\
\hline Poisson's Ratio & ASME Code er NSMH Data & ASME Cole for Base Metal \\
\hline Thermal Expansion & ASME Code $\mathrm{cr}$ NSMH Data & ASME Cole for Base Metal \\
\hline Heat Capacity & ASME Code CI NSMH Data & ASME Cole for Base Metal \\
\hline Thermal Conductivity & ASME Code cr NSMH Data & ASME Cote for Base Metal \\
\hline Plastic Flow & New correlation* & New correlation* \\
\hline Creep Flow & Hew correlation & 316 Stainless Steel Base for NSMH \\
\hline Stress-Rupture & ASME Code CI NSMH for Class 1 & $\begin{array}{l}\text { ASME Cole for } 304 \text { Stainless Steel } \\
\text { Base }\end{array}$ \\
\hline Fatigue & New correlation* & ASME Cole (Code Case N-47) \\
\hline Damage Interaction & & ASME Code iCode Case $N-47$ ) \\
\hline
\end{tabular}

* Based on modification of NSMH correlation. 


\title{
7. PROCESS ANALYSIS AND ENGINEERING EVALUATIONS
}

\author{
R. W. Glass
}

Process analysis and engineering evaluations studies are being conducted for DOE/FE to provide on a consistent basis, technical and economic assessments and evaluations of processes and systems for coal conversion and utilization.

\subsection{Liquefaction Technology Assessment (LTAS)}

R. C. Forrester III, R. Salmon, S. P. N. Singh, J. F. Fisher, R. M. Wham, and W. C. Ulrich

\section{1 .1 Objective}

The objective of the Liquefaction Technology Assessment is to provide technical information, cost information, and economic evaluations needed by the Department of Energy (DOE) to compare, on a consistent basis, coal liquefaction processes. The assessment will be carried out in several phases, starting with processes employing available technology and progressing to those which are in earlier stages of development. Technical and cost information will be provided by Fluor Engineers and Constructors through a contractual agreement with the Oak Ridge National Laboratory (ORNL). ORNL will provide the process design bases, conceptual design philosophy guidance, and economic evaluations based on the cost information provided by Fluor.

\subsubsection{Status Summary}

Revision of the Phase 0 draft report is nearly complete and the manuscript is being prepared for final editing. Publication is expected during this quarter.

Phase I continued to proceed with delivery in April by Fluor Engineers and Constructors, Houston Division, of the final report for this part of the project. The final report describes the completed conceptual designs for indirect liquefaction processes of interest and was delivered to ORNL for internal distribution and distribution to DOE.

During this month, ORNL technical staff completed examination of process economics for the four processes for "base case" financial assumptions and for numerous sensitivity cases of interest. (Details of this work were described in the January report of this series.) Study results have been summarized in a draft final report

Liquefaction Technology Assessment. Vol. I: Indirect Liquefaction of Coal to Methanol and Gasoline Using Available Technology, ORNL-5564/V1 (Draft). 
Following a brief internal review, the report will be transmitted to DOE for approval prior to limited release for external review.

Issuance of the Phase I draft final report, expected now in late May, was delayed due to a request from DOE to prepare preliminary cost estimates for a facility producing 13,000 BPSD (nominal) of methanol for gasoline blending. One of the Phase I conceptual designs prepared by Fluor was used as the basis for the scaledown facility. Results of this work will be included as an Appendix to the draft final report for Phase I.

\section{2 Direct Combustion}

E. C. Fox and T. D. Anderson

\subsubsection{Objective}

The purpose of this study program is to assist DOE/FE in their effort to develop a national strategy to increase the near-term use of coal through direct combustion; the applications of interest in this study are the small-to-moderate industrial user and the large residential/commercial user. The following objectives will be accomplished.

1. Identify and quantify the important factors restricting the use of coal in the sectors of interest.

2. Evaluate potential technological and institutional solutions to the problems identified in (1) above.

3. Make recommendations to DOE/FE relative to the most promising approdches to increasing the near"term use of coal.

\subsubsection{Status Summary}

The main report, "Conversion to Direct Coal Combustion in the Industrial and Commercial/Residential Sectors - A Study of the Barriers to Implementation in the Near Term," ORNL/TM-6139, is being prepared for final publication.

\section{3 Advanced P̈ower Conversion Systems}

$$
\text { J. E. Jones Jr. and A. P. Fraas } a
$$

\subsubsection{Objective}

The objectives of this project are to review selected major advanced power conversion systems and to assess these systems with respect to their basic R\&D status.

\footnotetext{
$a_{\text {Consultant }}$
} 


\subsubsection{Status summary}

A total of eleven systems or components of systems were evaluated. Draft reports covering all of these topics, an overall summary report, and an executive summary report have been completed and are undergoing final review. The reports entitled "Summary of the Research and Development Effort on Open-Cycle Coal-Fired Gas Turbines," and "Summary of Research and Development Effort on Air and Water Cooling of Gas Turbine Blades," ORNL/TM6254 have now been published.

\subsection{Process Modeling}

R. Salmon, D. M. Lister, P. J. Johnson, and W. C. Ulrich

\subsubsection{Objective}

The objective is to assist DOE/FE in its plan for computer analysis and computer support of coal conversion studies. Past work included assistance to Purdue and Lehigh Universities in the development of computer programs for this plan. Physical property data were collected and computerized primarily by Purdue and will be used in support of future process modeling efforts. Purdue's general design program was aimed at material and energy balances, equipment sizing and costing, plant capacity, and general economics. Lehigh's dynamic simulation programs addressed plant design primarily from the standpoint of process performance during transient operations, but can also be used for steady-state conditions. Current work includes process modeling and systems engineering support to Morgantown Energy Technology Center (METC). This comprises implementation of codes delivered by Purdue and Lehigh Universities onto the computer system at METC and development, testing, implementation and use of new process models.

\subsubsection{Status Summary}

Work continued on process modeling support for METC. We essentially completed our validation studies on the Purdue physical properties package (PPROP) code. A draft report describing results of the testing and validation program was also completed. The task of incorporating a solids handling capability into PPROP is proceeding and some preliminary coding was done for this. Among the types of solids to be included are coal, char, ash, dolomite, and limestone.

The Rajan-Wen FBC model was installed on the ORNL computer system and was executed successfully using the example problem data supplied with the code. Additional example problems were run as a first step towards understanding the problem of combining and simplifying the elutriation/attrition and combustion sections of the code. 
In accordance with recent discussions with METC, the first task on the Rajan-Wen model will be a critical evaluation to determine whether the program is sufficiently reliable and accurate to serve as a basis for the METC studies. A number of discrepancies in the model have been uncovered and transmitted to METC. Additional printout statements have been added to the program so that it will display a complete material balance for each size fraction. Analysis of these material balances and comparison with authoritative texts such as Kunii and Levenspiel will determine whether the program is giving good results. Work on this task is continuing.

7.5 Coal Liquefaction Advanced Research Digest

F. M. O'Hara, Jr., and R. W. Glace

\section{5 .1 objective}

The objective is to provide continuing technical assistance to DOE/FE-DFFP by preparing digest reviews of current or potential subjects relating to coal conversion technology.

\section{5 .2 Status Summary}

Writing was begun on the article "Free Radical Chemistry of Coal Liquefaction." Writing continues on the article "Chemical Characterization of Coal-Derived Liquids." Updating and rewriting to incorporate reviewers' comments are being done on "Coal Depolymerization" and "Chemical Reaction Kinetics of Coal Liquefaction." An extract of "Coal Depolymerization" was prepared and published in the Fossil Energy Program Quarterly Report for the Period Ending March 31, 1980. 


\section{FOSSIL ENERGY ENVIRONMENTAL ANALYSIS \\ C. R. Boston, T. H. Row}

Environmental support is provided to DOE/Fossil Energy and DOE/ Economic Regulatory Administration. The effort includes: (1) preparation of NEPA-required assessments and statements related to synfuels demonstration programs and fuel conversion implementation; (2) programmatic environmental studies that are critical to the early realization of advanced fossil technologies and minimization of the use of petroleum and natural gas; and (3) general environmental technical assistance.

\subsection{Fossil Energy Environmental Project}

C. R. Boston

The Fossil Energy Environmental Project provides DOE with program assistance in the performance of environmental assessment functions related to the expansion of fossil energy conversion technologies, performs assigned technical assistance tasks, and conducts programmatic environmental investigations that are critical to the early realization of advanced fossil energy technologies.

\subsubsection{Stored solids study - W. J. Boegly, Jr., F. S. Brinkley,} E. C. Davis, C. W. Francis, and H. W. Wilson, Jr.

An additional shipment of SRC-I material was received during April consisting of four, 20-gallon containers of dried MAR from the Kerr-McGee critical solvent deashing (CSD) process. The purpose of drying the MAR was apparently to remove ali solvent from the residue. To date, no experimental work has been initiated on this waste.

Leaching has been initiated on the SRC-I product. The ASTM-type A and the EPA-EP have been performed, and leachate samples sent to Analytical Chemistry. The ASTM-type A leaching method utilizes distilled water and no $\mathrm{pH}$ control, and of all the batch leaching tests proposed, this extraction is probably closest to representing what will happen during rainfall on SRC-I storage piles. We are also using the EPA-EP on the MAR samples on hand in case some of these materlals are landfilled instead of being gasified.

The recent shipment of SRC-II gasifier ash consists of the fine fraction of the waste. Testing has been delayed until we can obtain samples of the coarse material from this gasifier run. 


\subsubsection{Coal conversion demonstration projects}

Liquefaction projects - S. G. DeCicco

This activity is reported in Chapter 6.

Gasification projects - A. J. Witten

MLGW - The monthly meeting was held on April 24 in Chicago; T. H. Row attended. All revisions to the PDES are complete and an advanced review DES will be ready in mid-May.

Grace - The project is still on hold.

IGGG - A meeting was held with DOE and ICGG at ORNL on Aprid 15 to discuss comments on the PDES. It was agreed that only alternative sites in Illinois would be considered in the DES.

CONOCO - A meeting was held with DOE and CONOCO at ORNL on April 8 to discuss construction and operational monitoring. All PDES comments have been received and work will begin shortly on revisions.

\subsubsection{Communications}

a. Boston and Martin attended a meeting in Denver on April 9 to discuss the Project Environmental Plan for the SRC-II project.

b. Boston and Row atcended a meering in D.C. on Apr11 14 to discuss EIS schedules for the SRC projects.

\subsection{Economic Regulatory Administration Support Project}

R. M. Rush

The purpose of this project is to provide technical assistance to the Economic Regulatory Administration (ERA) of the Department of Energy in its implementation of the Powerplant and Industrial Fuel Use Act of 1978 (FUA). This act has as a general purpose the minimization of the use of petroleum and natural gas as a primary energy source in a manner consistent with applicable environmental requirements. The scope of FUA includes both new and existing electric powerplants and new and existing major fuel burning installations. Within ERA the Office of Fuels Conversion (OFC) is responsible for implementing FUA and meeting the requirements of the National Environmental Policy Act. The Fuels Conversion Analysis Division supplies the technical support for OFC. 
The initial assignment for this project relates to the conversion of two existing powerplants in the New York City area (Arthur Kill and Ravenswood) from oil as the primary fuel to coal or other alternate fue.1.

A revised draft of the Project Management Plan was received from Radian Corporation and is being reviewed by project personnel. Development of this plan has been time consuming and difficult due to changes in the Task Order from ERA and subsequent interpretation of it.

\subsubsection{Environmental analysis section - N. E. Hinkle}

Ambient noise level reports for the Ravenswood and Arthur Kill surroundings have been received from Con Ed. A report examining the noise levels of several types of coal unloading facilities has also been provided by Con Ed. These reports have been circulated to the EIS noise analysts for review. UE\&C analysts are expected to use these reports to provide estimates (or calculations) of incremental noise levels in the communities adjacent to the plants. UE\&C is also to advise if mitigating measures are required to satisfy regulatory requirements, suggest reasonable methods, and provide costs. Radian analysts will provide an impact assessment of the incremental noise level in the adjacent communities if they are determined to be significant.

A solid waste disposal feasibility study for the coal-fired Albany powerplant was received from the New York State Department of Public Service (DPS) and was circulated to the EIS team and other sectlons of the project. This report appears to provide a sound basis for a general assessment of solid waste disposal at generic types of sites when specific disposal sites have not been identified. A similar report prepared for the Con Ed facilities will also be prepared by the DPS and could be effectively used by the EIS team if available in time, and if specific sites are not identified for use by Con Ed.

Discussions are still on-going with UE\&C to determine the scope and methodology of providing on-site incremental occupational hazard information and assessment. A preliminary draft occupational hazards (excluding noise) report for Arthur Kill was prepared by UE\&C which appears to provide a reasonable generic treatment of the issues. However, providing quantification, particularly as it could be related to the Arthur Kill site, may not be possible. Since Con Ed refused access to its occupational health and safety records for Arthur Kill and Ravenswood, an alternative "model-type" approach is being developed using Tennessee Valley Authority data for its coal-fired plants. However, no similar data base has yet been identified for the baseline oil-fired case. 
A separate evaluation of occupational noise impacts is being prepared. Con Ed has not provided on-site noise levels at employee workplaces in its noise studies. However, UE\&C will make its data base available to identify on a generic basis the critical work areas and noise information. The TVA data base will also be used for typical employee noise exposures at coal fired plants.

Evaluation of literature concerning public health effects of exposure to criteria pollutants has continued. Special attention is directed at assessing reliability of various population dose conversion factors. This effort is directly related to the Generic Health Impact Study.

The ERA Office of Fuels Conversion has provided ORNL with additional suggested revisions for the EIS Implementation Plan for Arthur Kill. These revisions are being examined and will be incorporated to the extent possible. ERA/OFC has also provided a more definitive list of fue1 scenarios to be incorporated into the environmental analysis. When certain questions involving this list has been settled, the fuel scenarios will also be incorporated into the Implementation Plan.

\subsubsection{Air quality analysis section - F. C. Kornegay}

Ambient air quality data are presently being analyzed. Dispersion modeling will. commence upon the receipt of emissions information from the Engineering Analysis Section. Additional information concerning the fuel types to be considered will be required.

\subsubsection{Engineering analysis section - W. L. Greenstreet}

During April, progress was made on both engineering analysis and environmental support activities. A meeting was held with United Engineers and Constructors (UE\&C) personne1 on April 3 to discuss acoustic assessment activities to be carried out. Noise level information is to be obtained for locations both within and outside the plants. Data on noise levels outside the plants are to be given only for specified sites. ORNL and Radian will identify community locations of interest and will instruct UEE $\dot{C}$ accordingly.

In making the acoustic assessments, the primary objective is to determine noise level increments associated with plant modifications. It is expected that the bulk of the baseline data needed, including information on effects of coal handling equipment, will be supplied by Con Ed. The remainder of the baseline data plus information concerning impacts of modification is to be obtained by UE\&C.

The UE\&C work is to be held in abeyance until information requested from Con $\mathrm{Ed}$ is available. A work statement on acoustic assessment was submitted by UE\&C on April 10. 
On April 10 ORNL and UE\&C personnel met to discuss environmental support studies in general and to review and discuss a UE\&C preliminary report, "Occupational Hazards for Arthur Kill Power Plant," April, 1980. At this meeting, ORNL needs in the areas of air quality, wastes (wastewater streams and solid wastes), and occupational hazards were described and discussed in detail. Concerning hazards, it was observed that analyses of site specific hazards are difficult, but first priority should be given to being as specific as possible. This applies to determination of impacts of gaseous, liquid, and solid effluents as well as of noise on health and safety. Construction hazards are not to be considered in detail. However, safety and health hazards, which are unique in regular operation using coal, are to be addressed in detail.

A draft. of the hazards report, which takes into account the comments from the meeting, will be issued. This is one of three separate reports that will be issued on engineering support work for environmental studies; the three reports will cover emissions, occupational hazards, and acoustic assessments. The latter will contain information germane to the engineering analysis work as well.

UE\&C prepared in-house derived cost estimates on Arthur Kill modifications and equipment layout drawings for modifications proposed. Design and cost information on wet flue gas desulfurization (FGD) systems were solicited from industrial suppliers, and an equipment status check list, which resulted from the March 13 visit to Ravenswood, was transmitted to ORNL. These cost estimates will be incorporated into the revised engineering analysis report.

Comments were received from ERA on the two UE\&C reports, "Draft Alternative Fuels Evaluation for Arthur Kill and Ravenswood Power Plants" and "Draft Engineering Analysis for Arthur Kill Power Plant." In addition, information was received from ERA on fuels scenarios to be addressed in place of those given in the November 1979 task order and on the specific outline to be followed in preparing each Engineering Analysis Technical Report.

Write-ups on flue gas desulfurization systems and on operating and maintenance costs at Arthur Kill and Ravenswood were prepared by ORNL. These write-ups are intended for general information and for use by UE\&C in preparing Engineering Analysis Technical Reports.

A package of material germane to the Arthur Kill and Ravenswood studies was assembled and sent to UE\&C. Included in the package were comments by ORNL and ERA on the report, "Draft Engineering Analysis for Arthur Kill Power Plant," copies of the two ORNL write-ups mentioned above, a specific outline (developed taking into account ERA comments) to be followed in modifying the report and in preparing the Ravenswood power plant report, and the new list of fuels to be considered for both Arthur Kill and Ravenswood. 
The following additional subcontractor reports were reviewed during this period:
a. "Environmental Regulations Technical Report" by Radian,
b. "Port Reading Rail to Barge Coal Terminal" by TERA, and
c. "Implementation of the Fuel Use Act at Two Con Ed Power Plants - Project Management Plan" by Radian.

The latter was expected to represent the last version prior to issuance of the final report; a number of suggestions for revisions and changes were made concerning the englneering portion. The two EPRI documents, "Lime FGD Eystems Data Book" and "FCD Sludge Diopooal Manual", aloo werc given detailed revièws during this perlod.

Stack performance is important to power plant operation and can become more crucial when power plants are converted from oil or gas to coal. Therefore, operation of the Ravenswood unit 30 stack when various fuels are used is being examined to determine suitability for service when FGD systems are employed.

\subsubsection{Fuel supply and waste disposal analysis section - A. S. Loebl}

During April it was decided that ORNL (TERA/Versar) will be responsible for identifying the sources, amounts, and characteristics of coal to be utilized. Work on coal transportation rates and potential problems (subtasks 9 and 10) is now underway. The trainload rate for coal to Travis, N.Y., has been cancelled, consequently, an updated version of the rate can only be an indicator of a new rate which must be negutiated.

A draft report "Port Reading Rail to Barge Coal Terminal New York Harbor" (subtask 8) was transmitted to ERA on April 22. The report will be revised, as necessary, when comments are received from ERA.

A large volume of material on commercial applications of fly ash, bottom ash, and boiler slag has been collected and report writing (subtask 7) has begun.

Preliminary waste disposal sites have been identified by ERA. Further information on these sites has been obtained from the appropriate USGS maps. Development of rail rates and problems assoclated w1 th waste transportation (subtask 6 ) is in progress. One major problem related to this subtask is the location of sufficiently reliable information on the transportation of FGD sludge. This sludge presents a greater handiing problem than ash. Completion of this subtask is dependent on the ava11ability of ash and sludge volume estimates (subtask 5). These estimates will be completed following the selection of coal sources. 
A map of waste disposal sites and an improved graphic representation of the coal seam data were transmitted to ERA.

\subsubsection{Northeast regional analysis}

Air quality - F. C. Kornegay

Air quality modelling analyses are in progress at ORNL and ANL. Following some difficulties, all plants were located, emission rates were determined, and receptors located. Analysis of measured levels of the pollutants of interest is underway. The SIP scenarios for both oil and coal regulations were completed. Areas of significant overlap will be identified during the PSD scenario runs and discussions with ERA will be initiated regarding the alternatives to be considered.

Health effects of air pollution - T. H. Row and P. J. Walsh

The objective of this study is to provide a compilation and summary of the state of understanding of the health effects attributable to air pollution.

The National Ambient Air Quality Standards (NAAQS) identify six criteria pollutants: (1) sulfur oxides, (2) nitrogen oxides, (3) particulages, (4) carbon monoxide, (5) hydrocarbons, and (6) photochemical oxidants. A significant amount of experimental work has been completed that serves as the basis for the standards developed under NAAQS. This body of scientific information has received extensive reviews in the recent past (1978-1979) by prestigious organizations and the published reviews are generally unanimous in their support of current criteria pollutant standards. This study will review and synthesize the numerous publications mentioned above and present the concensus they provide for criteria pollutants. A graphical continuum will be developed from the literature to give a reasonable perspective on the standard level as compared to conventional concentrations of the pollutant.

There is no intent to develop an independent review of the scientific data behind the criteria pollutant standards. However, where the existing reviews define areas of concern, such as sulfates, we will take appropriate notice in the document. The non-criteria pollutants present a different situation. There are numerous research efforts underway, designed to provide pieces of the final picture that will be used by EPA in promulgating standards. The pollutants will be grouped into two categories initially. The first group contains sulfates, nitrates, respirable particulates, and trace elements which are of ten associated with particulates. Typical trace elements are: $\mathrm{Ca}, \mathrm{Se}, \mathrm{Hg}, \mathrm{V}, \mathrm{Cr}, \mathrm{Be}, \mathrm{As}, \mathrm{Ti}$, and $\mathrm{Ni}$. The second grouping involves polycyclic organic matter and possibly other organics. 
This project will provide a first order review of the completed and ongoing research on these pollutants. In addition, recognized experts in this field of research will be assembed for short one- to two-day working meetings to help develop an evaluation for each pollutant that puts in perspective where we are in our understanding of the nature and severity of the human health effects. Many of the same areas of research examined in the criteria pollutant reviews, epidemiology, animal toxicity, cellular and subcellular studies, will be reviewed here.

As nearly as possible, the resulting document will put a perspective on the non-criteria pollutants that will be of real value to decisionmakers, the general public and the scientific community.

Work in all aspects of the project was initiated in late April.

\subsubsection{Electric utility dispatch analysis - C. R. Hudson}

Additional data from the Northeast Power Coordinating Council was obtained and incorporated into the REUOM input data for New York Power Pool. A base case simulation of NYPP using unit specific data provided by ERA was performed and the results were given to ERA on Apr11 30 . Due to small forced outage rates being input, some units, particularly coal-fired units, ran with capacity factors of greater than 90 percent. ERA is to review the results of the base case simulation.

Based on a new NPCC report, modeling of the New England Power Pool began in April. Because of a need to obtain system rellability data, the PRODCOS' simulation code will be used for NEPOOL as well as for PJM and NYPOOL.

\subsubsection{Annual reports preparation - T. H. Row}

'l'he purpose of this work is to provide research and writing services for the preparation of the 1979 Powerplant and Industrial Fuel Use Act (FUA) Annual Report. Additionally, an annual report will be prepared describing FUA implementation activities by Federal facilities. Source material provided by ERA will be thoroughly reviewed and written text prepared. The text will summarize significant FUA implementation activities in 1979 including accomplishments, legislat1on, regulations, leadership and organization, program and schedule, funds, costs, and major problems. Visual aids including photographs and graphs may be prepared to highlight and suminarize informacton.

The 1979 FUA Annual Report is required under Section 806 of the Powerplant and Industrial Fuel Use Act of 1978, P.L. 95-620. Within DOE, its preparation is the responsibility of the Fuels Conversion Uttice, ERA. The $19 \% 9$ Keport was due to Congress on March 1, 1980, the statutory deadline specified in the legislation. The Annual Report on FUA Implementation by Federal Facilities is required under Section 403 of FUA. The Report must cover a one-year period starting 
May 8, 1979, and be ready for submission to the Congress in May 1980. This work is being performed under a subcontract with Evaluation Research Corporation.

Draft and final versions of the FUA Annual Report were published on January 28 and February 29, respectively. The draft Federal Facilities Annual Report was published on March 15. The final report is scheduled to be published in mid-May.

\subsubsection{Small utilities study - T. H. Row}

The goal of the study is to examine the special problems confronted by small utilities in FUA compliance, and, where possible, to identify technical, regulatory, or legislative remedies. The effort involves active participation of concerned regulatory and industry groups. The work consists of seven separate tasks:

Task 1 - Characterization of Small Utilities

Task 2 - Data Acquisition and Documentation

Task 3 - Public Meetings

Task 4 - Case Studies

Task 5 - Survey of Technology

Task 6 - Joint Ownership Feasibility

Task 7 - Preparation of Draft/Final Report

The intent of the study is to provide a comprehensive examination of small (less than 2000 MW total capacity) utilities which will lead to an understanding of the technologies that might be used successfully and the spectrum of legal and institutional constraints that would serve to block implementation of them. The study will include a general review of this sector of utilities, as well as specific case studies, and public meetings.

The work is being completed under subcontract and a July completion is anticipated. 


\subsubsection{Milestones}

The following dates have been established for delivery of the first draft of the indicated reports to ERA. Unless otherwise noted, work on these reports is on schedule.

Arthur Kill Powerplant

Fuel Scenario Evaluation

Environmental Regulations Technica1 Report

Fuel and Waste Technical Report

Engineering Analysis Terhniral Repnrt.

Acoustical Assessment

Environmental Impact Report

Ravenswood Powerplant

Fuel Scenario Evaluation

Environmental Regulations Technical Report

Fuel and Waste Technical Report

Engineering Analysis Technical Report

Acoustical Assessment

Environmental Impact Report

Northeast Regional Study

Air Quality Technical Report

Transportation Technical

Report

Health Effects Report

Electric Utility Dispatch Study

New York Power Pool

New England Power Pool

PA-MD-NJ Interconnection

Alinal Repurts Preparation

Draft FUA Annual Report

Final FUA Annual Report

Draft Federal Facilities Annual Report

F1nal Federal Facilities Annual Report

Small Utilities Study

Draft Report
March 20, 1980

March 25, 1980

May 31,1980

March 28. 1980

May 9,1980

October 1, 1980

March 20, 1980

delivered

March 25, 1980

delivered

May 31, 1980

May 16,1980

June 6,1980

October 1, 1980

September 15, 1980

September 1, 1980

September 1, 1980

Apr11 14, 1980

delivered

June 1, 1980

June 1, 1980

January 28, 1980 delivered

February 29, 1980 delivered

March 15, 1980

delivered

May 15,1980

July 31, 1980 


\subsection{Fossil Energy Program Support}

T. H. Row

This program was initiated with a series of visits to the Energy Technology Centers (ETC) and various Operations Offices to discuss the environmental requirements and projects of Fossil Energy Programs. These discussions resulted in a consistent set of suggested activities designed to provide the environmental effort necessary to assure commercialization of the major coal conversion programs. The ideas generated from these contacts coupled with the defined responsibilities of the Environmental Activities Branch resulted in five specific work areas:

Research planning - Provides for ongoing review of projects coupled with close project interaction to provide the insight needed to assure that all necessary environmental work is initiated.

Critical issues - Provides a detailed critical review of identified environmental problem areas with documentation of findings.

NEPA coordination - Provides assistance in scheduling required NEPA activities in support of major programs or projects.

Regulatory and legislative reviews - Provides a continuing review of all regulatory and legislative items, present and planned, and their effects on fossil energy programs.

Consultation assistance - Provides for identification of a team of experts in the environmental field available to respond rapidly to requests for assistance from the Environmental Activities Branch.

During the month, progress was made in developing information regarding energy projects having potential NEPA Compliance requirements. Additional copies of the Environmental Compliance Handbooks were sent to Headquarters and progress was made on the Industrial Hygiene/Occupational Medicine Workshop planning.

\subsubsection{NEPA compliance coordination - W. W. Goolsby}

During this report period considerable progress has been made in developing, compiling, and verifying pertinent project data related to energy projects funded in part or whole by DOE with potential NEPA requirements. The technologies involved include geothermal, solar, biomass, wind, conservation, low-head hydroelectric, ocean, resource applications, etc. Development and verification of project data is continuing by personal contact, phone conversation, and visits to DOE Headquarters, DOE Energy Technology Centers, and other involved agencies and personnel in the various technologies. 
Data sheets are being developed on each project in these technologies to provide basic information such as project title, project location, estimated project cost, technology involved, and names and location of responsible project personnel. The schedules will define project milestones with respect to conceptual design, detailed design, procurement, and construction. The environmental schedule will depict NEPA activities past, present and future. The information will provide an inventory and data base of energy research and development projects in operation or proposed. The inventory includes projects large enough for process development, pilot, demonstration, or commercial application which require(d) environmental assessments (EA) and/or environmental impact statements (EIS).

It is anticipated that this task will require more t1me and effort than required on the two Fossil Energy documents. Long range plans include development of computerized updating and reporting for all NEPA projects.

\subsubsection{Regulatory and legislative review - J. K. Huffstetler and C. J. Oen}

Work continued on the Environmental Compliance Program Handbook, and on the data file. The state of Illinois received authorization to issue.PSD permits in early April, necessitating the changing of a considerable amount of material in the Illinois "Air Quality" section. Most of the data input for Tennessee has been completed. The Tennessee General Assembly passed new legislation which will affect the section on water quality and we are waiting for copies of the new laws. Five additional copies of the Handbook on Kentucky and five copies of the Handbook on IIlinois were transmitted to DOE Headquarters at their request. This is in addition to the three copies of each previously subinitled.

\subsubsection{Industria1 Hygiene/Occupational Medicine Workshop - T. H. Row and R. A. Church}

A trip was made to Germanlown to coordlnate deca1ls of the workshop with Headquarters personnel. Several suggestions made are being incorporated in the program planning. The draft program plan was also discussed with K. Cowser (Manager, Life Sciences Synthetic Fuels Program) who provided valuable suggestions and material of use in finalizing the program plan. Potential speakers are being contacted at this time and it is hoped that all topics and speakers will firmed up by the end of May.

\subsubsection{Milestones}

Trips were made to Germantown by T. H. Row and R. A. Church for coordination on various task terms including the IH/OM Workshop and the Environmental Compliance Program Handbook. 


\section{COAL PREPARATION AND WASTE UTILIZATION}

E. C. Hise

The objectives of this program are: to develop, demonstrate, and bring to commercial viability, processes and equipment for the removal of pyrite and ash-forming minerals from dry crushed coal by either or both processes of high-gradient magnetic separation (HGMS) and opengradient magnetic separation (OGMS); to integrate the magnetic process into the coal preparation system to achieve the most effective and economic preparation of the raw coal; and to develop processes to minimize the refuse disposal by efficiently utilizing the heating value and concentrated mineral resources in that refuse.

\subsection{High-Gradient Magnetic Separation \\ E. C. Hise, M. T. McFee, D. L. Mailen}

The continuous carousel separation program at Sala Magnetics, Inc., is near completion. Both a Kentucky seam $\$ 9$ coal and Lower Kittaning coal were used to test the separation of the $-650+150 \mu \mathrm{m}$ size fraction. Results from this test series indicate that the continuous carousel separator performance equals or exceeds the performance obtained with the batch solenoid. This test series has also demonstrated that it is possible to select the operating conditions for the continuous carousel separator based on the parameters used in the separation tests with the small batch laboratory solenoid.

Continuous separation tests are now being performed with the -150 $+50 \mu \mathrm{m}$ size fraction of the Lower Kittaning coal. Preliminary results indicate a lower ash and sulfur content with a higher heating value recovery which corresponds to predictions. The remaining tests and analyses to be performed by Sala Magnetics, Inc., should be completed in early May.

A demonstration of the continuous carousel separation process was conducted on April 24, 1980, in Cambridge, Massachusetts, along with presentations by the participants in this contract. The following utilities, industries, and universities were represented: Allegheny Power Service Company; Central Illinois Light Company: Central Electricity Generating Board (Great Britain); New England Electric Company; Pennsylvania Power and Light: Allis-Chalmers Corporation; Babcock and Wilcox; Combustion Engineering, Inc.; MIT-Francis Bitter National Magnet Laboratory; Sala Magnetics, Inc.; Texas Industries, Inc.; Pennsylvania State University; and Purdue University. Representatives from ORNL and AllisChalmers/Sala Magnetics, Inc., described the current state of the contract and solicited suggestions for the future direction of the program. The concensus was that a pilot size project should be the next step for the program. A likely project would be to replace or augment the fine coal circuit at an existing preparation plant. Some form of consortium of coal operators, utilities, manufactures and government would be a desirable source of funding for this type of project. 


\subsection{Open-Gradient Magnetic Separations}

A. S. Holman, M. T. McFee, D. L. Mailen

Chemical analyses have been obtained from the open-gradient test series using our superconducting magnet in the CUSP mode. The results of these analyses indicate that the superconducting magnet is capable of producing separations equal to those obtained with the Frantz Isodynamic Magnetic Separator and the high-gradient magnetic separators. The feed coal used for these tests was a Kentucky No. $930 \times 100$ mesh size fraction with a feed ash of $12.19 \%$ and the total sulfur of $4.17 \%$.

The intent of thic teet eeries was to learn the relative importance of the following parameters:

1. the effect of the current,

2. the effect of the initial starting position of the feed stream in the radial direction, referred to as the setting (the distance from the magnet windings), and

3. the effect of the throughput (controlled by orifice size).

The sulfur and ash remaining in the product coal as a function of current are shown in Fig. 9.1. Figure 9.2 shows the same sulfur and ash data plotted against heating value recovery. These curves exhibit a strong tendency towards improved quality and increased heating value recovery as the current is increased, as do curves produced from data of separations produced by OGMS in the Frantz and HGMS systems. These graphs clearly show that the magnetizing current is, of course, an important parameter.

The sulfur and ash remaining in the product coal as a function of radial position of the feed stream origin is shown in Fig. 9.3. The splitter is located $20 \mathrm{~mm}$ from the magnet windings which is the same radial position as the orifice (the origin of the feed stream) when set at $20 \mathrm{~mm}$. Therefore, when the orifice setting is less than $20 \mathrm{~mm}$, a diamagnetic separation is performed; and when the setting is greater than $20 \mathrm{~mm}$, a paramagnetic separation is performed. Figure 9.4 shows the sulfur and ash data of Fig. 9.3 plotted against heating value recovery. Based on this graph, it would appear that the best overall results occurred during a paramagnetic separation. However, lower sulfur and ash analysis were obtained when a diamagnet separation was performed with a lower heating value recovery. Additional tests will be performed to more accurately determine the best mode of operation.

The final parameter explored was that of throughput. This was accomplished by varying the orifice diameter from $2.3 \mathrm{~mm}$ to $6.1 \mathrm{~mm}$. Figure 9.5 gives the sulfur and ash analysis as a function of orifice size, and Figure 9.6 shows the sulfur and ash analysis plotted against heating value recovery. These results are not completely understood at 


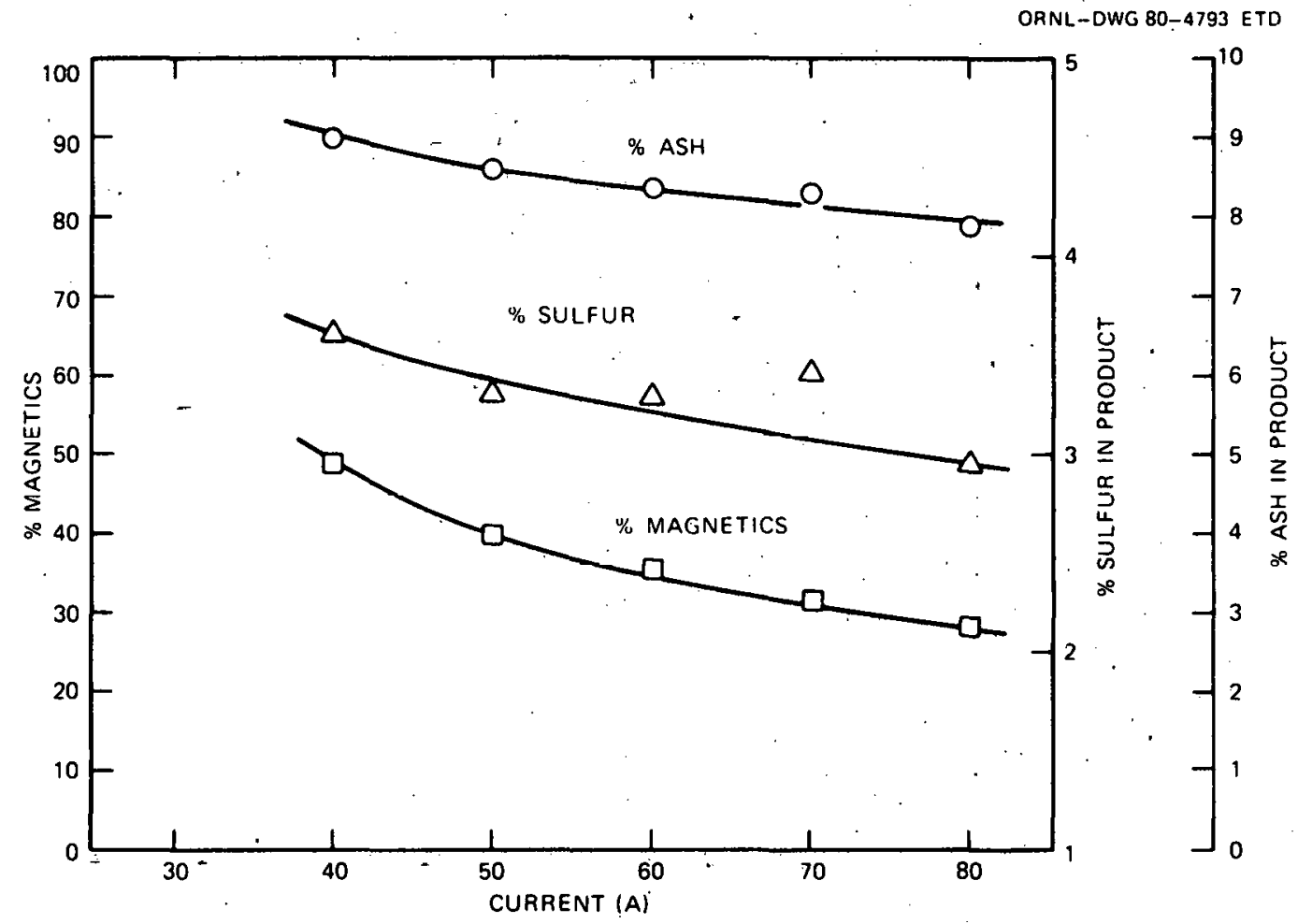

Fig. 9.1. Sulfur and ash in product coal as a function of current. 


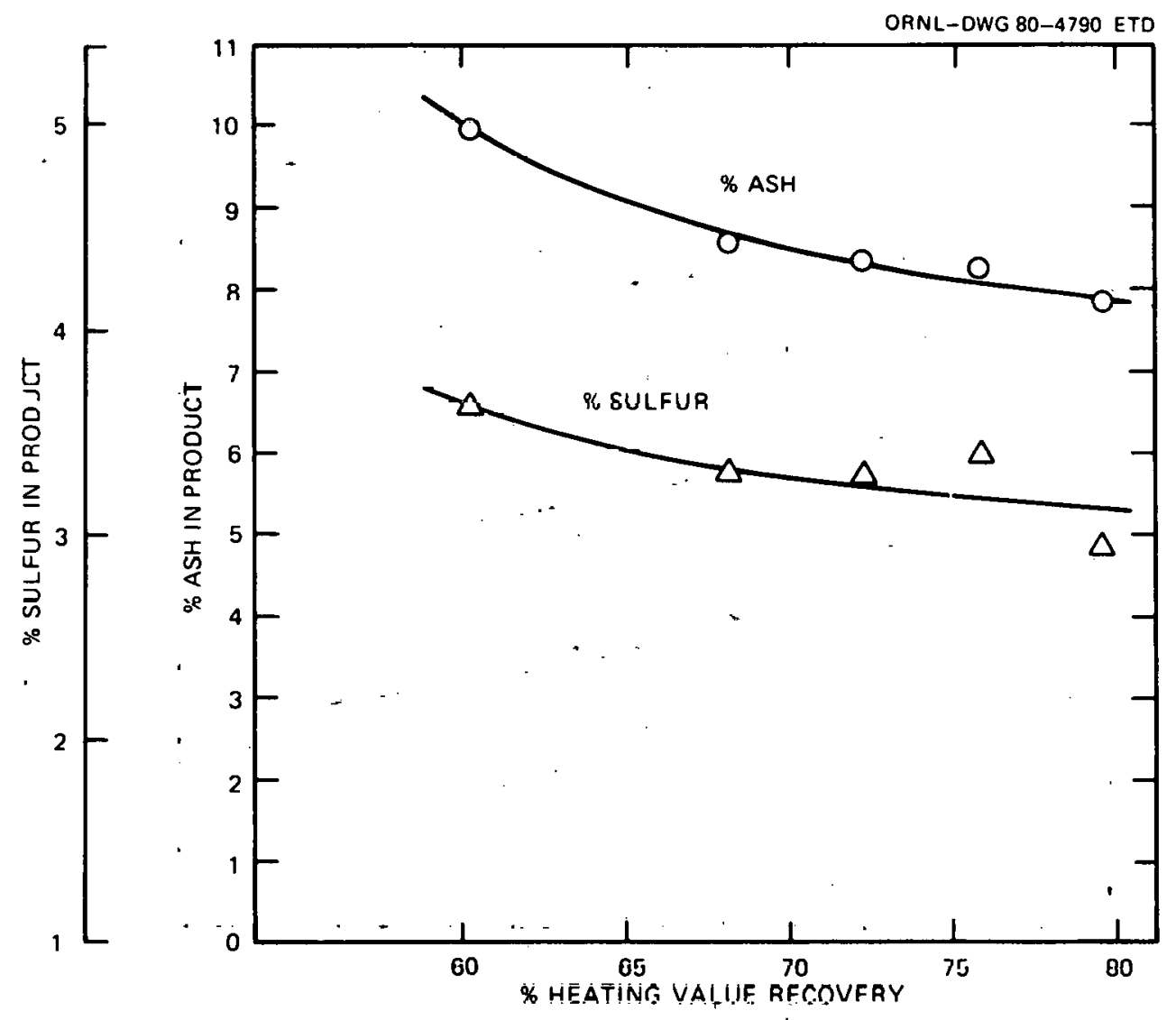

Fig. 9.2. Sulfur and ash in product coal plotted agalnst heating value recovery. 


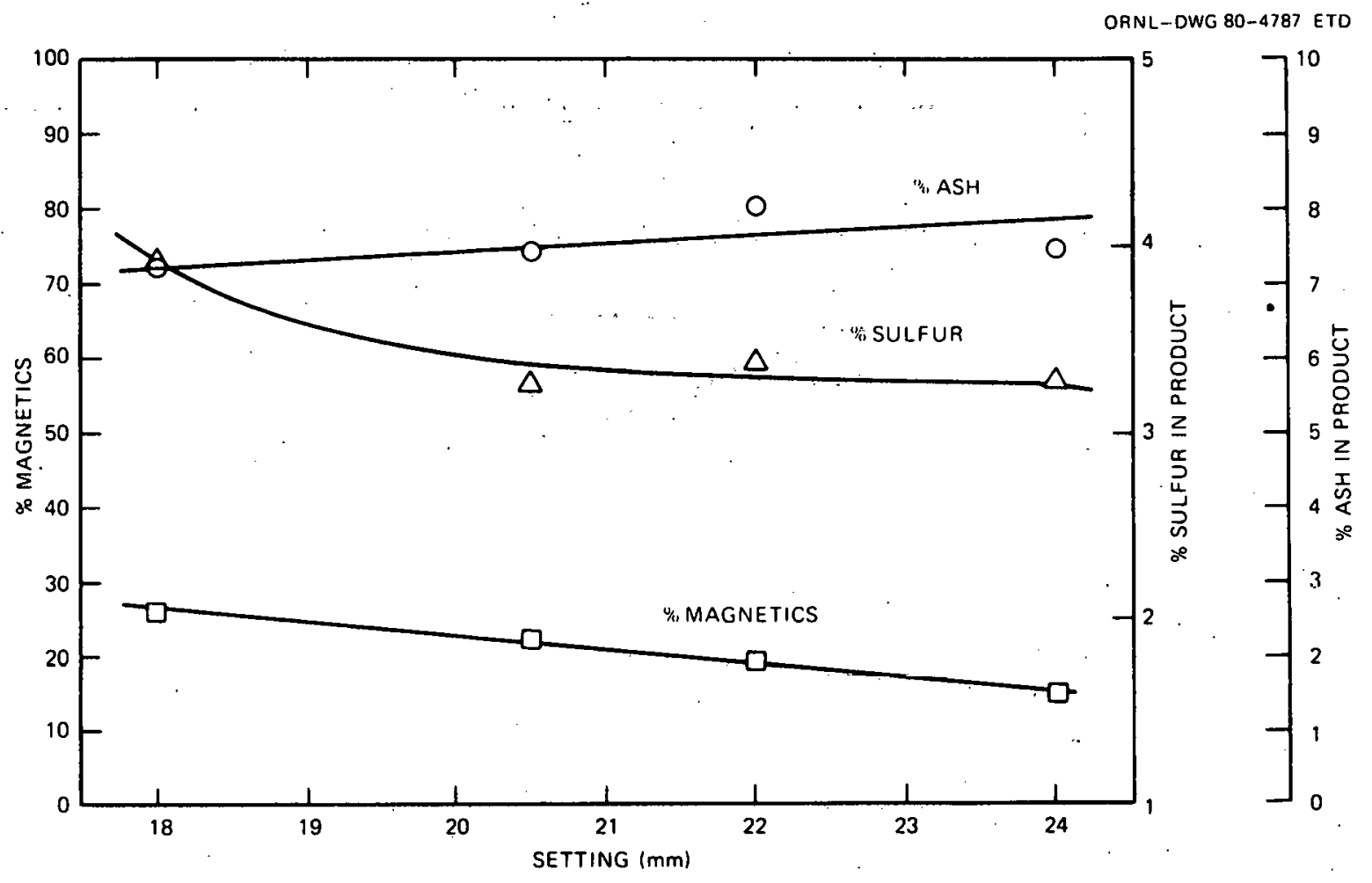

Fig. 9.3. Sulfur and ash in product coal as a function of radial position of the feed stream. 


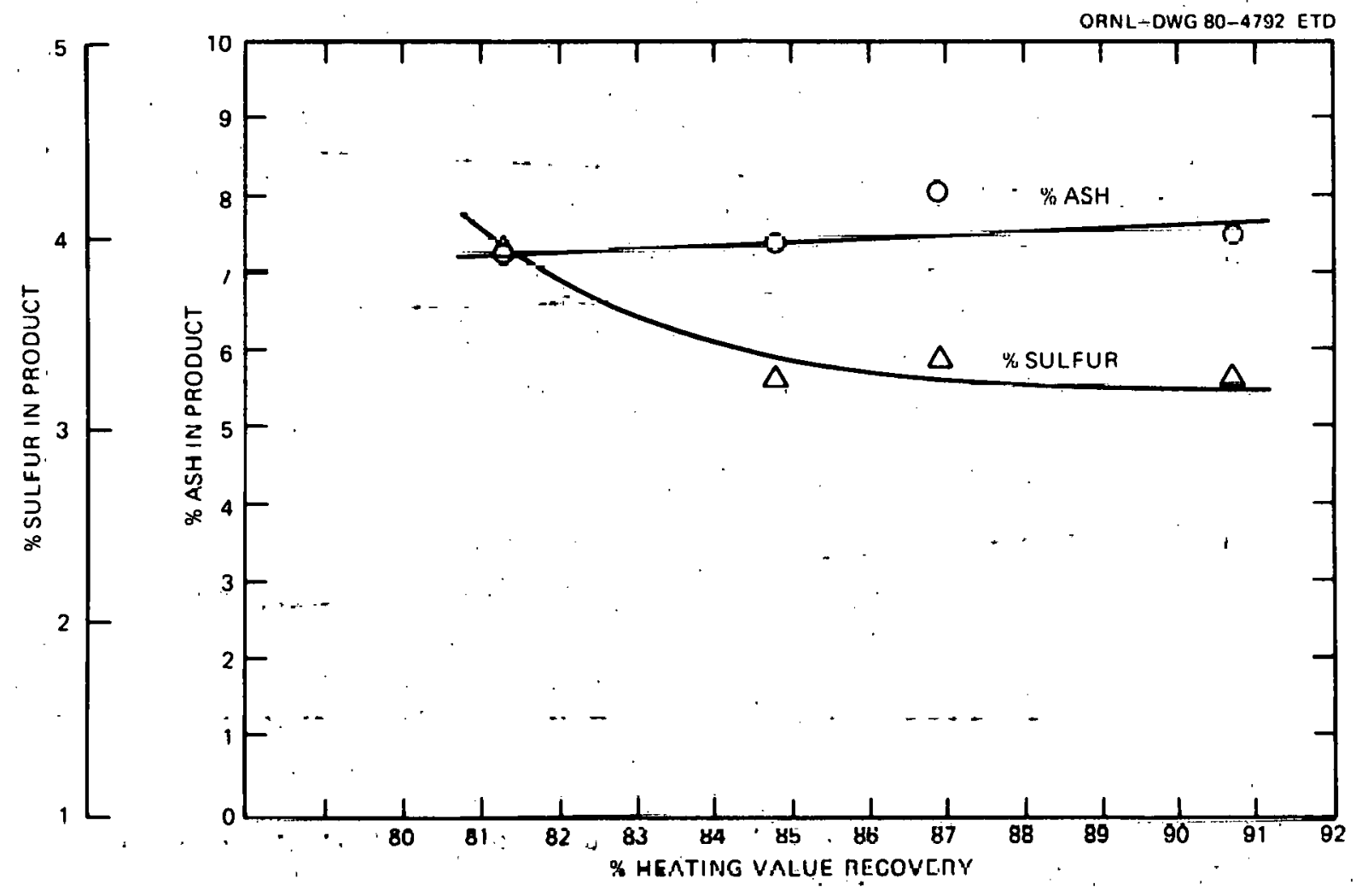

Fig. 9.4. Sulfur and ash in product coal plotted against heating value recovery. 


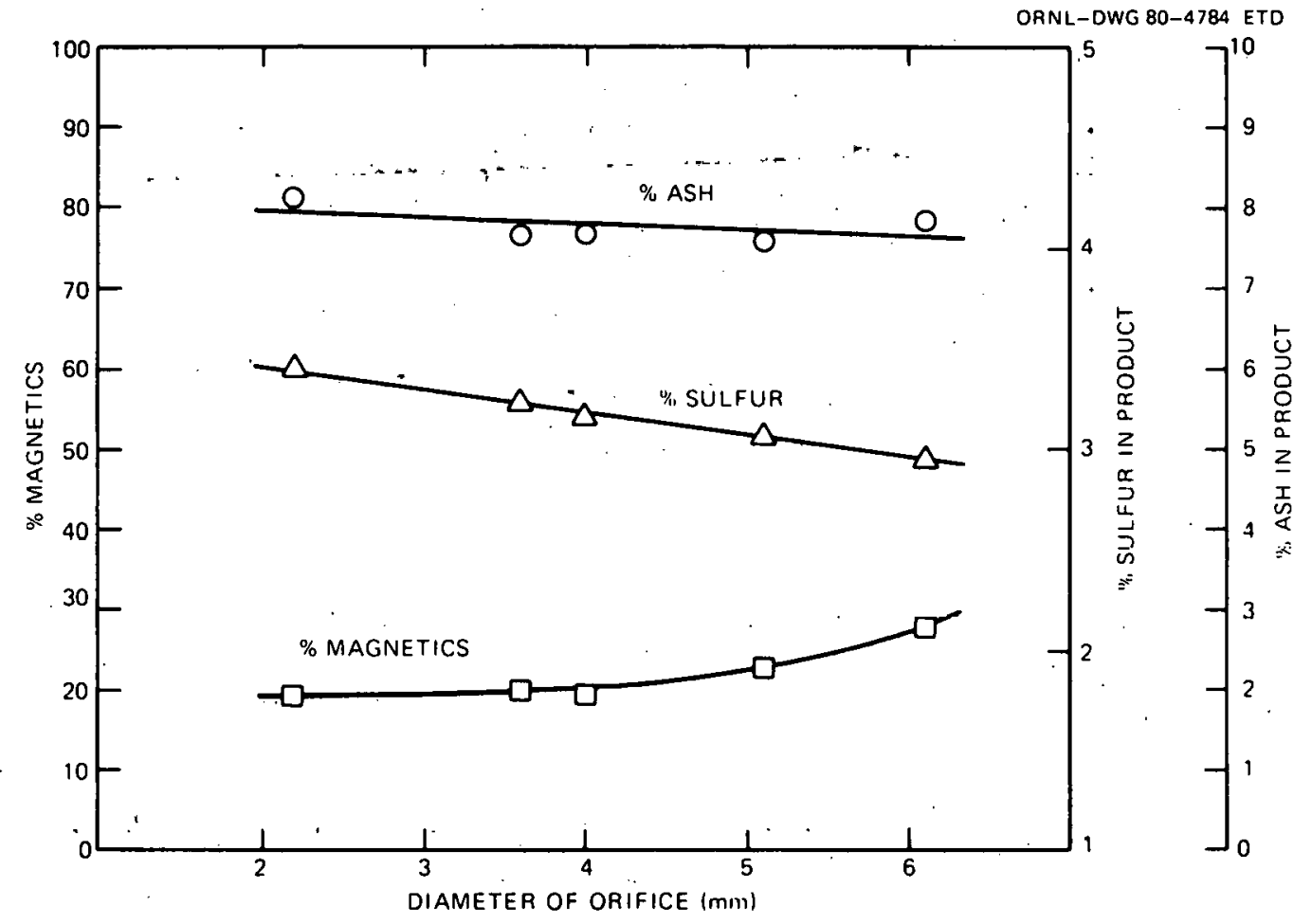

Fig. 9.5. Sulfur and ash in product coal as a function of orifice size. 


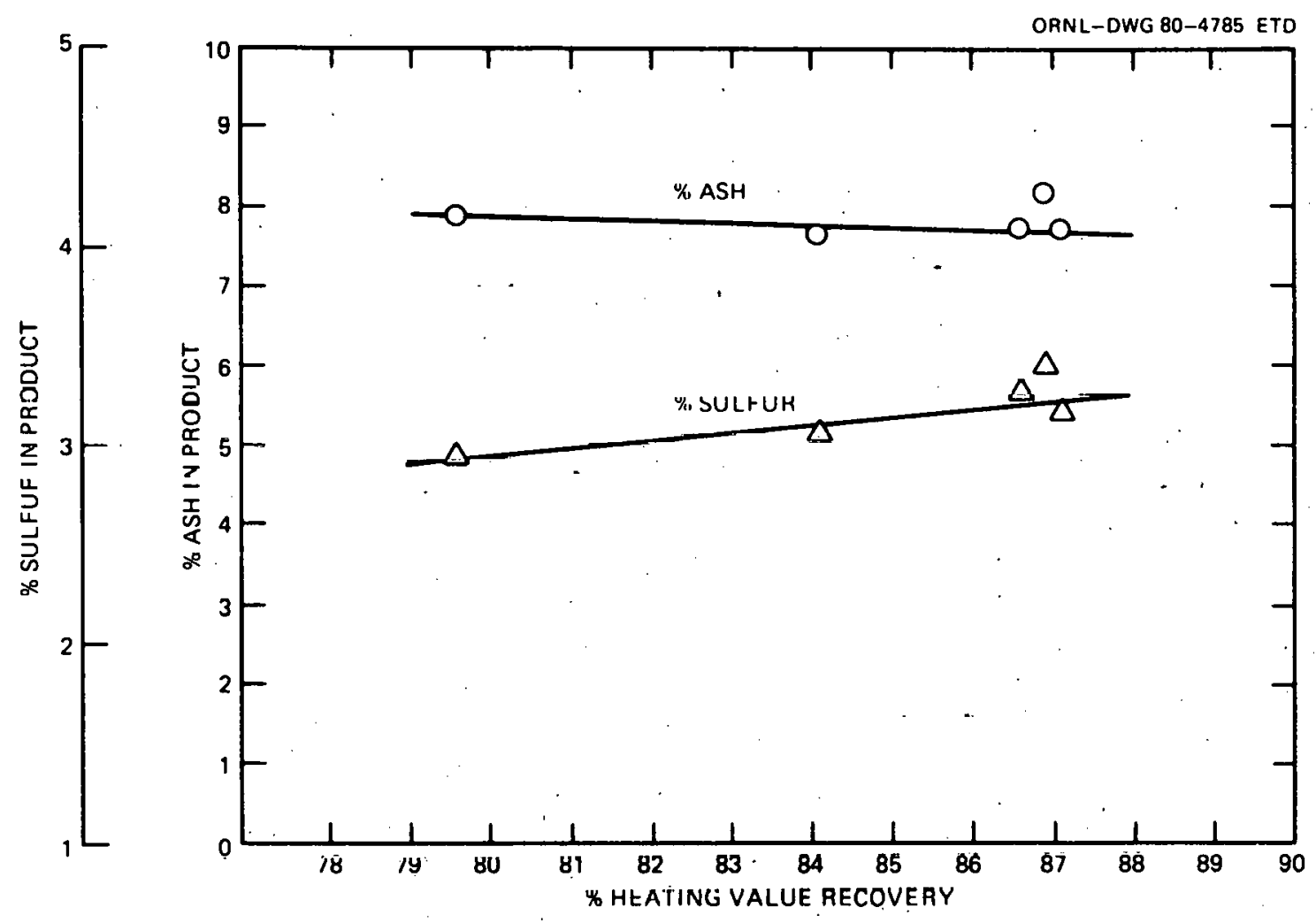

F1g. 9.6. Sulfur and ash in product coal plotted againet heating value recovery. 
this time. Both the quality of the clean coal and the heating value recovery improved up to the $5 \mathrm{~mm}$ orifice and then began to fali of $\mathrm{f}$. Additional tests need to be performed in order to understand this phenomenon.

While it is true that these initial results only approach the results obained from the Frantz and HGMS separators, we are encouraged about the possibility for this process. This was the initial test series with this process while conditions for the other processes are well established.

Fabrication is now underway on the "Wa11-Pour." This device will allow us to pour a continuous ring of coal, as opposed to the single orifice, at various flow rates. With the "Wall-Pour" we will be able to learn the true throughput of the magnet and explore the effects on quality of throughput. Fabrication should be complete by late May.

\subsection{Material Preparation \\ M. T. McFee, D. L. Mailen}

One hundred eighty kilograms of Kentucky seam \# 9 coal is currently being prepared for the superconducting magnet. Preparation of this coal should be completed by late May.

\subsection{ORNL/TVA Support Work for Magnetic Separation}

S. R. Smith ${ }^{\alpha}$

A series of tests is being performed at ORNL to characterize the magnetic separability of a sample of coal obtained from the feed belt to TVA's $500 \mathrm{t} / \mathrm{h}$ coal washing facility at Fabius, Alabama. In these tests, the $-550+150 \mu \mathrm{m}$ size fraction of the run-of-mine coal is being characterized by float-sink gravimetric testing, OGMS and HGMS. The following is a short summary of preliminary results obtained to date.

Using the bench scale Frantz Isodynamic Magnetic Separtor in the "free-fall" open-gradient mode, two $50 \mathrm{~g}$ samples of a $-550+150 \mu \mathrm{m}$ coal, from Jackson County, Alabama, were separated using the multi-splitter. These samples were then analyzed at ORNL for ash and sulfur. Results show that the feed coal, $26 \%$ ash and $0.58 \%$ sulfur, was magnetically processed to give an improved product with $16 \%$ ash and $0.8 \%$ sulfur with an acceptable heating value recovery of $84 \%$. These results will be verified by multiple runs using a single edge splitter. Float-sink testing at $1.3,1.4,1.5,1.6$, and 1.7 specific gravity $\mathrm{ZnCl}_{2}$ solutions have been completed, and samples have been submitted to Analytical Chemistry at ORNL for ash and sulfur analysis.

\footnotetext{
$a_{\text {TVA, Chemical Engineer }}$
} 
Upon completion of this series of tests, a detailed report will be submitted characterizing the magnetic separability of Jackson County, Alabama, Fabius coal. 


\title{
10. COAL PREPARATION PLANT AUTOMATION
}

\author{
N. C. Bradley and K. R. Carr
}

The Coal Preparation Plant Automation Program is being conducted at Oak Ridge National Laboratory for the DOE Pittsburgh Mining Technology Center. The objectives of this program are to develop instrumentation for the automatic control of coal preparation processes and to demonstrate overall plant automation in a typical coal cleaning plant.

During this report period, the literature and field surveys were continued. Five coal preparation plants with particular features of interest were visited. The operators and locations of the plants visited are:

1. South East Coal Co., at Irvine, Kentucky,

2. Marrowbone Development Co., at Kermit, West Virginia,

3. Armco Steel Corp., at Prenter, West Virginia, and

4. Pittston Coal Co., at Lebanon, Virginia. (Two Pittston Coal Co: plants were visited - Moss No. 3 and McClure River.)

Much useful information was obtained on these visits.

Work on the plan for preliminary on-site tests continued. A set of summary information was generated relating to the instrumentation and control of several key coal preparation processes: the static thickener, heavy media washer, jig, concentrating (Deister) table, and froth flotation cells. The set of information contains for each of these processes a block diagram showing inputs and outputs, a list of variables affecting the performance of the process, and a list of potential measurement methods corresponding to each variable. The identification and selection of commercially available instrumentation and control devices for use in the preliminary on-site testing was continued.

Training topics covered during the weekly project meetings during April were froth flotation, jigs, static thickeners, centrifugal dryers, and conveyors.

A review was made at the Ames Laboratory, Iowa State University, of development work in the area of on-line monitoring of the mineral content of coal by utilization of x-ray diffraction techniques. A summary of our review is being prepared and will be forwarded to the Pittsburgh Mining Technology Center. We also discussed other coal-related work in progress at Ames Laboratory and toured their experimental coal preparation facility.

Development and evaluation are progressing on sensors for the needed measurements of some physical paramelers. 


\subsection{Physical Measurements}

R. L. Anderson, W. H. Andrews, and M. J. Roberts

\section{1 .1 Objectives}

The objectives of this work area are to define deficiencies of existing on-line and laboratory instrumentation for physical measurements and to develop instruments needed to accomplish the physical measurements required for automation of coal preparation plants. Physical measurements include all measurements in the plant except those in the analytical instruments category described below. Examples of plant physical measurements are particle size, mass flow, viscosity, and density,

\section{1 .2 Status summary}

Work is proceeding in the development of sensors for the measurement of physical parameters in plant unit operations:

1. A microprocessor-based signal cross-correlator is being fabricated. This instrument has potential uses for on-line measurement of flow rates of slurries and possible particle size determination.

2. An ultrasonic particle size and slurry concentration sensor which uoco acouatic lenses to focus the ultrasunic beall is being urdered for test and evaluation.

3. An ultrasonic level and density probe is being developed for another program at ORNL and the progress is being monitored to ascertain the possible application of this device in coal preparation plants.

4. As part of another ORNL program, a commercial small-angle laser light-scattering suspended particle monitor has been installed in a small flow loop in the laboratory and is being evaluated. This work is being monitored for possible benefit to the coal preparation plant automation effort. 


\subsection{Analytical Instruments}

L. H. Thacker, L. N. Klatt, D. D. McCue, and D. S. Walia

\section{2 .1 objectives}

The objectives of this work area are to define deficiencies of existing on-line and laboratory analytical instrumentation and to develop instruments needed to accomplish the analytical measurements required for automation of coal preparation plants. Analytical instruments are defined as those instruments that provide information on the chemical constituents of the coal or have a principle of operation based on nuclear methods; examples of analytical instruments are ash monitors, sulfur monitors, and nuclear density gages.

\section{2 .2 Status summary}

The major activities this month involved a continuation of the state-of-the-art literature survey, a field trip, and a training seminar on the froth flotation unit operation. The visit to the coal preparation plants of South East Coal Co., Irvine, Ky., and Armco Steel Corporation, Prenter, W. Va., revealed that sophisticated digital electronic instrumentation can be utilized in a coal preparation plant; use of electronic packages of this type in analytical instruments will not present any serious problems. The Pittston Coal Co., Lebanon, VA, is operating a Gunson-Sortex ash monitor as an on-line monitor during rail car loading operations and they have obtained excellent results. South East Coal Co. plans to install a similar unit as soon as a license for the radioactive source is obtained.

A Oak Ridge Associated Universities 


\subsection{Systems Application}

R. L. Moore, L. E. Ottinger, and G. R. Wetherington, Jr.

\subsubsection{Objectives}

The objectives of this work area are to acquire and maintain an indepth knowledge of the features of the coal preparation plant environment and overall operation which affect the selection and application of instrumentation and controls, to evaluate the suitability of commercial and developmental devices for installation in coal preparation plants, and to provide the coordination to ensure compatibility and proper interfacing of the various systems and devices to be installed for demonstration in operating coal preparation plants.

\subsubsection{Status summary}

The major activities this month were:

1. continuation of the literature survey,

2. participation in training activities including the presentation of three talks on unit operations topics at weekly project meetings,

3. plant vișits, and

4. inititation of an effort to gather information on commercially available instruments having potential application in on-site tests.

During this reporting period the main phase of the state-of-the-art literature survey was completed and unit process topics covering conveyor technology, centrifugal dewatering, and jigs were researched and presented to the project team.

L. E. Ottingcr participated in the ficld ourvey of five ooal proparation plants. Information was obtained from plant personnel who have experience with applications of computer control, ultrasonic flow and level instrumentation, programmable logic controllers, nuclear density gauges, and Gunson-Sortex ash monitors. This information will be helpful in evaluation of commercial and developmental devices for installation in coal préparation plant environments. Also, L. E. Otcinger and G. R. Wetherington, Jr., attended the 6 th Annual Advanced Control Conference at Purdue University. This year's conference concerned man-machine interfaces for industrial control. Information obtained at this conference will be useful in designing operator control consoles for instrument systems the project team develops. 


\subsection{Mathematical Methods}

W. R. Hamel, G. O. Allgood, and C. H. Brown

\subsubsection{Objectives}

The objectives of this work area are to utilize mathematical analysis as a tool to study processes, develop control models, and evaluate the technical and economic merit of existing and potential instrumentation devices and systems in the coal preparation plant application. This work area includes the evaluation of existing computer models of coal preparation plants, modification of existing computer programs as required for use, and development of programs and techniques needed to support the coal preparation plant automation effort.

\subsubsection{Status Summary}

The literature review to collect information for the compilation of a state-of-the-art assessment is approximately fifty percent complete and will be finished next month.

Five coal preparation plants featuring a variety of unit operations and control techniques were visited during this reporting period to gain additional insights into the state-of-the-art of instrumentation application at coal cleaning facilities.

Preliminary work to define our approach in modeling the coal preparation unit processes continued. The principal activity was the modeling of a coarse coal circuit utilizing heavy media washers as the central unit operation.

\subsection{Information and Reports}

G. M. Caton and E. R. Rohrer

\subsubsection{Objectives}

The objectives of this work area are to compile information related to coal preparation plant design and operation, to develop a system for making information readily available to members of the project team, and to assist in the preparation of reports describing work in progress, technical developments, and milestone achievements.

\subsubsection{Status summary}

Work was continued on building the computer data base on coal preparation and instrumentation documents. At present, the data base is in three separate parts: (1) with 205 pertinent references from a retrospective DOE Remote Console (DOE/RECON) System search, (2) with 50 references from 
SDI tapes, and (3) with 168 bibliographic descriptions of acquired documents. After the formats of all three data bases are converted into a common format, they will be merged into a single data base. Listings were generated of instrumentation documents arranged by reference number and category. Two hundred and six requests for documents, information, and computer searches were processed. Ten current contents routings and eight selective routings of the coal preparation search, journal table of contents, and sections of reports were disseminated to team members.

\subsection{Data Acquisition}

J. M. Jansen and J. T. Hutton

\section{1n, 6,1 Objertives}

The objectives of this work area are to determine, select, and apply the appropriate data acquisition and processing equipment consistent with the needs for automation and compatible with the physical environment of coal preparation plants. Support activities leading to the implementation of the full-scale demonstration of an automated plant will include assistance in the selection of data acquisition equipment and techniques for use at coal plants and ORNL in the study of processes, the evaluation of installed instruments, and the development of control methods.

\subsubsection{Status summary}

The literature survey was continued. Also, a survey focusing on ruggedized equipment potentially suitable for coal preparation plants has been initiated. The equipment will primarily be computational units, acquisition devices, data loggers, terminals and printers, and enclosures. Particular attention will be directed toward specifications on vibration, temperature, thermal shock, dust, and ruggedization features.

Familiarization with process systems and potential control systems has been gained through the weekly seminars. 


\title{
11. ATMOSPHERIC FLUIDIZED BED COAL COMBUSTOR FOR COGENERATION (AFBCCC)
}

\author{
R. S. Holcomb
}

\subsection{Ob jective}

The Coal Combustor for Cogeneration (CCC) Program is directed at. the development of a fluidized-bed coal combustion system heating air inside tubes to provide high temperature clean air to drive a gas turbine to generate electricity. The heat in the air leaving the turbine exhaust would be recovered to supply industrial process heat. The gas turbine is very well suited for cogeneration since the ratio of thermal to electrical energy is about 3 to 1 for the gas turbine cycle as compared to a ratio of 5 to 1 for a back-pressure steam turbine, and the exhaust heat. from the gas turbine is available at a higher temperature. The scope of the program includes the study of industrial cogeneration plants in the size range from 5 to $50 \mathrm{MW}(\mathrm{e})$ and the construction and testing of a $0.3 \mathrm{MW}(\mathrm{e})$ technology test unit.

\subsection{Status Summary}

R. S. Holcomb, R. H. Guymon, N. W. Durfee, and W. A. Hartman

The cost proposal for the amended subcontract was reviewed. When the cost audit reports are received, the subcontract will be signed by UCC-ND and sent to Westinghouse for their signature.

Updated outline drawings of Building 9401-1 were completed. A sketch of a preliminary equipment layout for the TTU system was prepared and reviewed by the project team. It was revised and an improved layout was agreed upon. A preliminary layout drawing based on this arrangement will be initiated. 


\title{
12. TENNESSEE VALLEY AUTHORITY (TVA) FLUIDIZED BED COMBUSTION (FBC) DEMONSTRATION PLANT PROGRAM TECHNICAL SUPPORT
}

E. C. Fox

Tennessee Valley Authority has assumed a lead role in the demonstration of FBC technology for application in large utility boilers. ORNL will provide technical support and services to TVA in FBC systems. This work is to support TVA's objective to develop FBC systems for utility electric power generation which will burn high-sulfur coal and meet environmental emission standards.

TVA will be the lead agency in this work and will reimburse DOE for the work to be performed by ORNL. This work is to be conducted hy ORNL. under the terms and conditions of the Interagency Agreement between TVA, DOE, and ORNL regarding support for FBC research (reference: Agreement TV-48296A, Subagreemenl j).

\subsection{AFBC Technology Support - Task 2 \\ M. Siman-Tov and E. C. Fox}

\section{1 .1 Objective}

The objective of this program is to provide technical support of a general nature in FBC systems and respond to specific requests from TVA personnel. Such requests may include reviews, assessments, participation in TVA tasks, and similar activities.

\subsubsection{Status summary}

There was no activity under this task during this month.

\author{
12.24 44 Culd Fluw Mudel - Tásk 3 \\ M. E. Lackey and R. S. Holcomb
}

\section{2 .1 objective}

The objective of this task is to experimentally investigate slumping of a portion of a fluidized bed using a sub-scale cold flow model. The scope of work includes design and minor modification of the $4 \times 4$ cold flow model for slumping and refluidization tests and conducting bed slumping tests. 


\subsubsection{Status summary}

The $1 / 4$ scale test report by M. E. Lackey entitled "Cold Slumping Characteristics of a Fluidized Bed," has been approved for publication by TVA.

\subsection{AFBC Modeling and Simulation - Task 4a}

J. W. Wells, R. P. Krishnan, and M. Siman-Tov

\subsubsection{Objective}

The objectives of this program are to develop a simple steady-state model for conceptual design of the main cell and carbon burnup cell and to incorporate in this model the ability to predict trends in bed performance under various feed and operating parameters.

\subsubsection{Status summary}

During this month, work continued on the sulfur capture code. Four sulfur capture models were reviewed. These are:

1. Wen's grain mode 1,1

2. Hartman and Coughiin's grain mode 1,2

3. MIT's grain model, 3 and

4. MIT's pore plugging model. 4

Many previous investigators ${ }^{1-3}$ have found that the grain model was useful in analyzing the capture of sulfur dioxide $\left(\mathrm{SO}_{2}\right)$ by calcium oxide $(\mathrm{CaO})$. The model considers:

$$
\mathrm{CaO}+\mathrm{SO}_{2}+1 / 2 \mathrm{O}_{2}+\mathrm{CaSO}_{4}
$$

Each calcium oxide ( $\mathrm{CaO}$ ) particle consists of small spheres (grains) of CaO crystal. Petrographic examination of calcined limestones shows a structure similar to that proposed in the grain model. Specifically, the calcined particle shows a spongy structure composed of small but highly dense grains of $\mathrm{CaO} .5$ At present, a grain model code similar to those proposed by Hartman and Coughlin ${ }^{2}$ and $M^{2} T^{3}$ has been written. The code is being debugged. Details of this code will be given next month.

Also during this month, work began on verification and simplications of the freeboard subcode. In addition, a paper on the current ORNL/TVA $A F B C$ modeling effort was given at the Sixth International Conference on Fluidized Bed Combustion. The paper was well received. 
12.4 Analytical Support and Alternative Design Concepts Evaluation - Task 4b

E. C. Fox, C. S. Daw, and R. P. Krishnan

\section{4 .1 Objective}

The objectives of this task are to assist TVA in determining the design parameters which are critical to an effective AFBC system from the standpoints of efficiency and cost and to provide direction as to bette $r$ design options.

\section{4 .2 Status summary}

The draft report detailing the trade-offs in design parameters and evaluating the economics of various design options is being prepared.

\subsection{AFBC Bench Scale Facility - Task 5}

G. P. Zimmerman, R. H. Guymon, and R. S. Holcomb

\section{5 .1 Objective}

The objective of this task is to experimentally investigate heat transfer, sulfur capture, carbon loss, and combustion of recycle carbon using the ORNL AFBC bench scale combustor.

\section{5 .2 Status summary}

Testing was completed during the month on Lowellville limestone. Additional data were obtained at a superficial velocity of $1.8 \mathrm{~m} / \mathrm{sec}(6 \mathrm{ft} /$ sec) as shown in Table 12.1. These data are comparable with results from previous testing.

Because there was some concern that the rather large particle size of the Lowellville stone was the cause of poor sulfur capture, a series of tests was run with a high percentage of $f$ ines in the limestone feed. At a superficial velocity of $1.5 \mathrm{~m} / \mathrm{sec}$ ( $5 \mathrm{ft} / \mathrm{sec}$ ), indications are that feeding fines in the form of $6 \times 0$ mesh material does indeed improve the sulfur capture performance of the limestone. The results of this test series appear in Table 12.2 .

Two additional limestones were received from TVA early in the month. One stone was from the lower ledge of the Reed quarry in Gilbertsville, Kentucky. The other stone was from the lower white ledge of the Fredonia quarry in Fredonia, Kentucky. Both stones have been dried and sized to $6 \times 100$ mesh and are ready for testing. 
Table 12.1 AFBC sulfur capture results for Lowellville limestone

\begin{tabular}{|c|c|c|c|}
\hline $\begin{array}{l}\text { Date } \\
\text { Time }\end{array}$ & $\begin{array}{l}4-2-80 \\
10: 44\end{array}$ & $\begin{array}{l}4-2-80 \\
11: 48\end{array}$ & $\begin{array}{l}4-2-80 \\
13: 00\end{array}$ \\
\hline Bed temperature, ${ }^{\circ} \mathrm{C}\left({ }^{\circ} \mathrm{F}\right)$ & $851(1564)$ & $846(1554)$ & $844(1552)$ \\
\hline Superficial velocity, $\mathrm{m} / \mathrm{sec}(\mathrm{ft} / \mathrm{sec})$ & $1.8(5.9)$ & $1.8(5.9)$ & $1.8(5.8)$ \\
\hline Static bed depth, meters (inches) & $0.77(30.5)$ & $0.80(31.5)$ & $0.97(38.0)$ \\
\hline Gas residence time $\left(H / V_{0}\right)$, sec & 0.43 & 0.44 & 0.55 \\
\hline Coal feed rate, $\mathrm{kg} / \mathrm{hr}(1 \mathrm{~b} / \mathrm{hr})$ & $10.9(24.1)$ & $10.9(24.1)$ & $10.9(24.1)$ \\
\hline Limestone feed rate, $\mathrm{kg} / \mathrm{hr}(1 \mathrm{~b} / \mathrm{hr})$ & $5.9(13.0)$ & $6.7(14.8)$ & $8.3(18.4)$ \\
\hline Calcium to sulfur mole ratio & 4.0 & 4.5 & 5.6 \\
\hline Combustion air flow, $\mathrm{kg} / \mathrm{hr}(1 \mathrm{~b} / \mathrm{hr})$ & $102(224)$ & $102 \cdot(226)$ & $100(221)$ \\
\hline$\cdot$ & & & \\
\hline Flue Gas Components & r & & \\
\hline axygen, percent & 3.8 & 3.6 & 4.0 \\
\hline Sulfur dioxide: ppm & 1080 & 700 & 255 \\
\hline axides of nitrogen $\left(\mathrm{NO}_{\mathrm{x}}\right), \mathrm{ppm}$ & 830 & 865 & 900 \\
\hline Carbon monoxide, ppm & 335 & 280 & 305 \\
\hline Sulfur in coal, wt. percent & 4.04 & 4.04 & 4.04 \\
\hline Sulfur capture, percent & 67.4 & 79.1 & 92.2 \\
\hline
\end{tabular}


Table 12.2 AFBC Sulfur capture results ficr Lowel-ville limestone with fines

\begin{tabular}{|c|c|c|c|c|}
\hline $\begin{array}{l}\text { Date } \\
\text { Time }\end{array}$ & $\begin{array}{l}4-9-80 \\
=2: 20\end{array}$ & $\begin{array}{l}4-9-80 \\
13: 25\end{array}$ & $\begin{array}{l}4-9-80 \\
14: 26\end{array}$ & $\begin{array}{l}4-15-80 \\
13: 25\end{array}$ \\
\hline Bed temperature; ${ }^{\circ} \mathrm{C}\left({ }^{\circ} \mathrm{E}\right)$ & $846(1554)$ & $848(1559)$ & $341(1546)$ & $843(1550)$ \\
\hline Superficial relocity, $\mathrm{n} / \mathrm{sec}$ (Et/sec) & $1.5(5.0)$ & $1.5(5.0)$ & $1.5(5.0)$ & $1.5(5.0)$ \\
\hline Static bed depth, meters (inches) & $0.75(29.5)$ & $0.81(32.0)$ & $0.94(37.0)$. & $0.81(32.0)$ \\
\hline Gas residence time $\left(H / \vec{r}_{0}\right)$, se $=$ & 0.49 & 0.54 & 0.63 & 0.53 \\
\hline Coal feed rate; $\mathrm{kg} / \mathrm{hr}(\mathrm{Ib} / \mathrm{hr})$ & $9 . i(20.1)$ & $9.1(20.1)$ & 9.: $(20.1)$ & $9.3(20.6)$ \\
\hline Limestone feed rate, k.s/ar $(1 j / h r)$ & $5 .-(11.2)$ & $6.1(13.5)$ & $5.9(15.2)$ & $6.1(13.5)$ \\
\hline Calcium to sulfur mole ratio & 4.1 & 5.0 & 5.6 & $4.8^{a}$ \\
\hline Combustion air flow, $k \mathrm{~g} / \mathrm{hr}(1 \mathrm{j} / \mathrm{hr})$ & $85.7(189)$ & $85 \cdot 3 \cdot(188)$ & $85.7(189)$ & $85.7(189)$ \\
\hline \multicolumn{5}{|l|}{ Flue Gas Comzonents: } \\
\hline Oxygen, percent & 3.6 & 4.0 & 3.8 & 3.6 \\
\hline Sulfur dioxide, ppm & 650 & 470 & 280 & 550 \\
\hline Oxides of nitrogen $\left.(\mathrm{N})_{\mathbf{x}}\right)$, ppm & 830 & 860 & 940 & - \\
\hline Carbon moroxide, ppra & 365 & 325 & $30 ?$ & - \\
\hline Sulfur in co $\equiv 1$, wt. percent & 4.04 & 4.04 & 4.04 & (b) \\
\hline Sulfur capture, percent & 80.6 & 85.6 & 91.5 & $84^{a}$ \\
\hline
\end{tabular}

$a_{\text {These }}$ results ar $\equiv$ based on a typica- $4 \%$ sulfur coal.

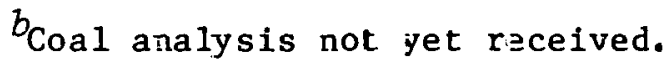


The Reed limestone was added to the combustor and fluidized at 1.5 $\mathrm{m} / \mathrm{sec}(5 \mathrm{ft} / \mathrm{sec}$ ) for two hours. After elutriation of fines, the minimum fluidization velocity was $0.66 \mathrm{~m} / \mathrm{sec}(2.15 \mathrm{ft} / \mathrm{sec})$. Fifteen and one half hours of coal combustion were required to bring the Reed limestone to a well-sulfated equilibrium. Sulfur capture testing with this material will begin next month.

\subsection{Assessment of the State-of-the-Art of PFBC Systems - Task 6 \\ R. L. Graves, M. F. Lackey, and A. P. Fraas}

\subsubsection{Objective}

The purpose of this program is to provide TVA with an assessment and overview of the state-of-the-art for PFBC systems and their associated components.

\subsubsection{Status summary}

The final report on the state-of-the-art of pressurized fluidized bed combustion systems has been approved by TVA. The required internal approvals and signatures are being obtained and publication is expected to proceed without any significant delay.

\subsection{AFBC Technical Source Book and R\&D Evaluation - Task 8 \\ M. Siman-Tov and A. A. Kahn}

\subsubsection{Objective}

The objectives of this program are: 1) to develop a single comprehensive source book of technical data for design procedures and evaluation of AFBC facilities and programs, 2) to review and evaluate existing and proposed AFBC facilities to perform research and development for TVA, and 3 ) to interpret and translate results of test studies performed for TVA and further the knowledge in AFBC research and development activities.

\subsubsection{Status Summary}

We are still awaiting comments and approval of the draft interim report from TVA before any major headway can be made. Meanwhile, the effort is limited to keeping up to date with the state-of-the-art.

\section{$a_{\text {Consultant }}$}




\title{
12.8 Materials Support for TVA Pilot and Demonstration AFBC Plants - Task 9
}

R. H. Cooper, Jr., T. G. Godfrey, M. D. Allen, J. H. DeVan, and R. A. Bradley

\subsubsection{Objective}

The objective of this task is to provide TVA technical assistance in the materials area on an as-needed basis. The principal focus of the work is the area of in-bed heat exchanger tubes and hangers, air distributors, side walls, coal feed liner nozzles, spent bed removal hardware, and cyclones for separating elutriated materials. With regard to this task, two areas have been and/or continue to be active. The first is the review of rccommcndationc for the materials of construction fọr the pilnt and demonstration plants as made to TVA in proposals, contracts, and vendor designs. The second area involves the metallographic analysis of an array of alloys exposed in an AFBC locaced in Leatherhead, England, and is pait: of a joint TVA/EPRI materials program.

\subsubsection{Status summary}

Because no request for reviews of materials of construction have been received formally by TVA, there is no activity to report in this area. Specimens from the second $1000-h$ Leatherhead AFBC run are ready to be examined metallographically. Samples selected from both the second 1000-h tube and the full 2000-h tube by $W$. D. Goins of TVA are $1-1 / 4 \mathrm{Cr}=1 / 2 \mathrm{Mo}$ and 2-1/4 Cr-1 Mo steels, types 304 and 310 srainless steel, and Inculuy $800 \mathrm{H}$. It was felt that these alloys were of primary interest to the TVA program. Very cursory and preliminary observations indicate that the two sample sets are very similar in corrosion response. Detalled examinations will begin in May.

\subsection{Dynamic Modeling of the TVA Fluidized Bed}

Cumbustion Pilot Plant - Task 10

\author{
0. L. Simith
}

\subsubsection{Object1ve}

The objective of this task is to provide dynamic modeling and transient systems analysis directly applicable to the TVA pilot plant. As an important benefit, the information obtainable from a dynamic model would help in the specification of such features as function, range, and type of instrumentation required to provide the desired plant operating characteristics. 


\subsubsection{Status summary}

Previous analyses (ORNL/TM-7251, pp. 71-82) compared the rates of automatic load following that appeared achievable. with various modes of bed operation. Sequential procedures in which a $25 \%$ change in load and coal feed was followed by a $25 \%$ change in active heat transfer surface, as by slumping one part of an unpartitioned bed, may seriously disturb the heat source/sink distribution throughout the bed and limit load following ability to rates less than about $1 \% / \mathrm{min}$. Operational modes that more nearly maintained heat source/sink distribution in the bed, as when the bed height was lowered to expose $25 \%$ of tube surface simultaneously with a $25 \%$ change in load, resulted in load following capabilities five times faster.

At TVA's request, additional studies were made of the variable bedheight mode to specifically investigate the use of superficial velocity and associated bed shrinkage as the method for exposing tubes. The useful range of bed height variation in this case may be more limited than when bed mass also is allowed to change. The tops of tubes in the present study were stipulated to be flush with the surface of the bed at full power so that any reduction of velocity and bed height begins to uncover tubes. Uncovered tubes pass into the crown zone, and existing information indicates that the heat transfer coefficient in the crown may be approximately half that of the bed. Subsequent shutdown of the bed section by stopping air flow then totally exposes the affected tubes and further reduces heat transfer to a small value.

On the basis of available information, it appears that variation of superficial velocity (above the minimum fluidizing velocity) may be used to lower bed height $\sim 9-12$ inches in a nominal 4-ft bed. During the course of a $25 \%$ reduction in load, all tubes in the manipulated quarter of the bed "moved" into the crown zone and heat transfer was cut in half. (In practice, probably less than the full height of the tube bank can be exposed by varying superficial velocity alone, so this represents an upper limit of what might be expected.) Following the $25 \%$ reduction in load, the bed section was shut down, removing tubes from crown and further reducing heat transfer. Overall, the transfer area (actually the product of area times coefficient) was reduced $12.5 \%$ during the load decrease and another $12.5 \%$ afterward. This case is intermediate between the earlier one in which change of coal feed and heat transfer area occurred sequentially and the one in which the two changed simultaneously by the same percentage.

Results of this simulation are shown in Figs. 12.1 through 12.11. The maximum rate of load change that could be handled was $2.5 \% / \mathrm{min}$, and the subsequent deactivation of heat-transfer-area-times-coefficient by slumping could occur at an average rate of only $1.25 \% / \mathrm{min}$ without incurring controls instabilities. Actual slumping may affect heat transfer more rapidly. The objective of this and the previous studies was to examine the relative load following capabilities of the various operational modes, and this case falls between the earlier ones - 2.5 times faster than the sequential case but only half as fast as the simultaneous case. 


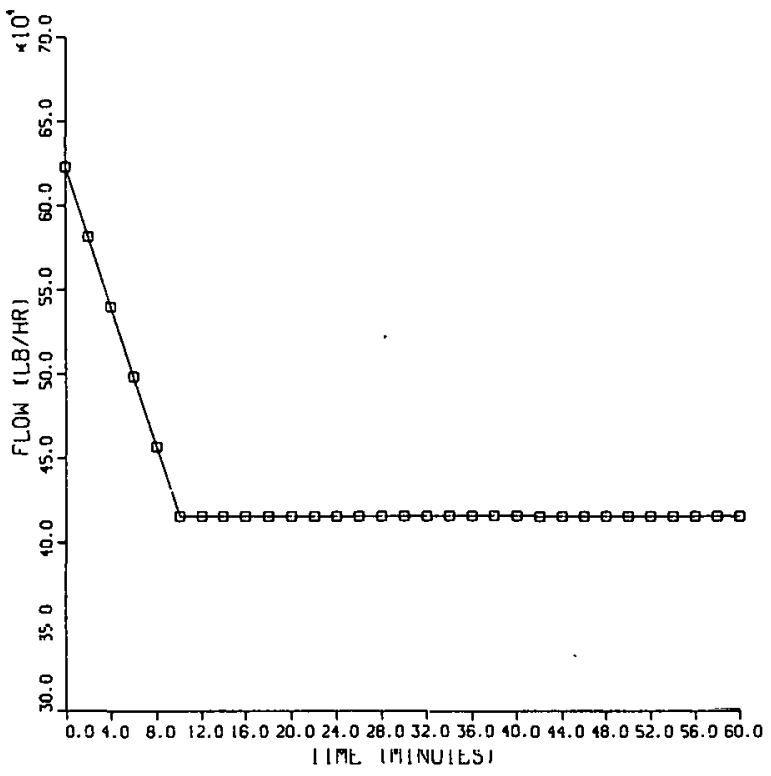

Fig. 12.1. Condenser cooling air (load).

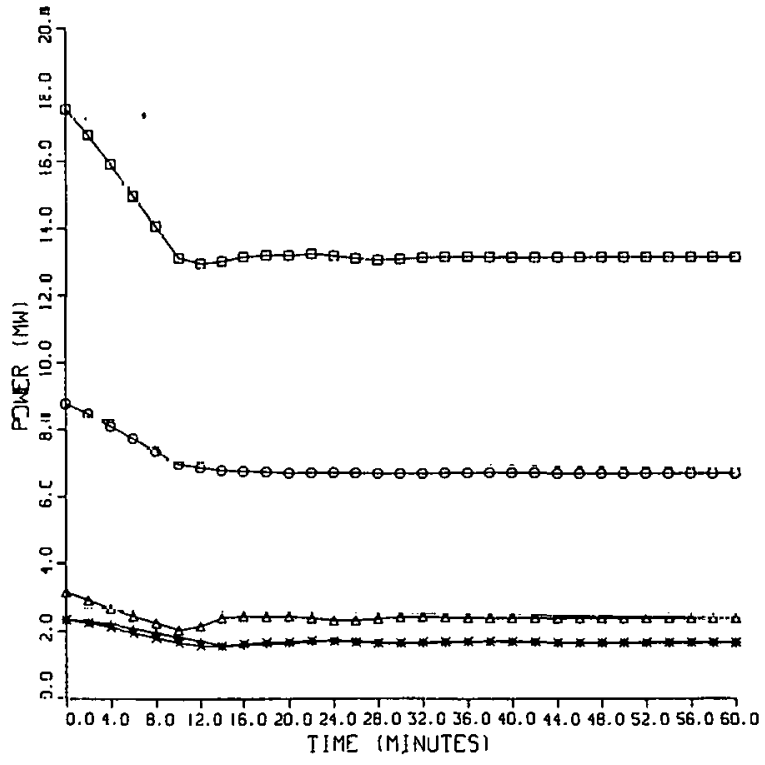

Fig. 12.3. Power generationsquares, total power; hexagons, evaporator; crosses, bed secondary and tertiary superheaters; triangles, primary superheater.
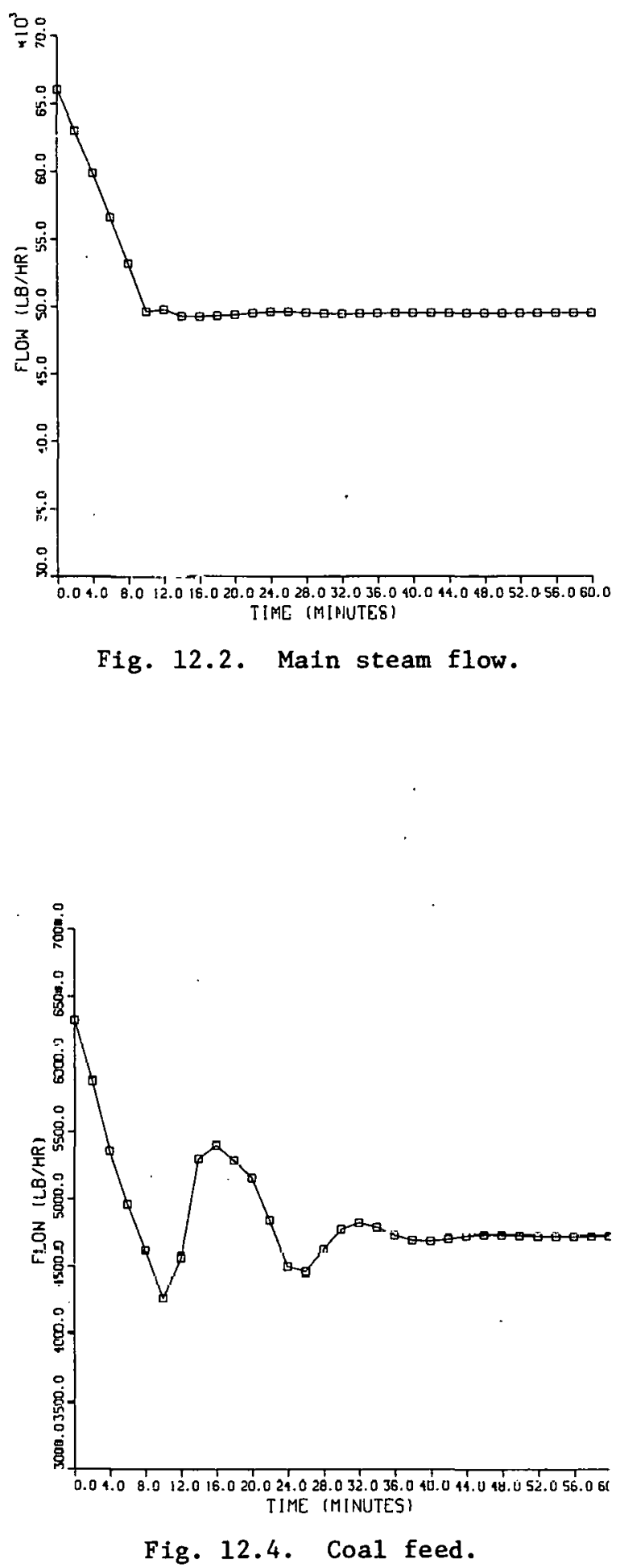

Fig. 12.4. Coal feed. 


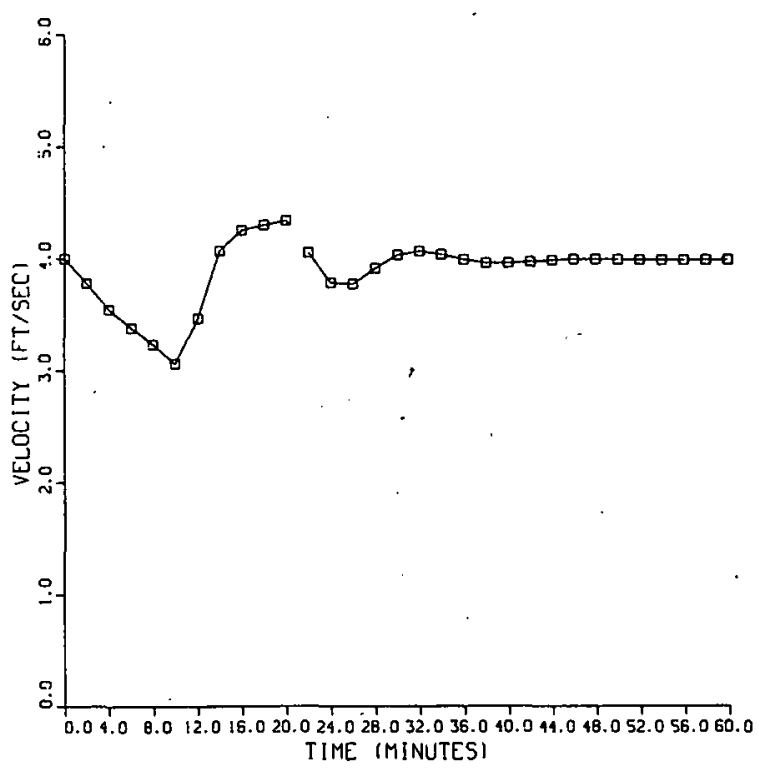
loctty.

Fig. 12.5. Superficial ve-

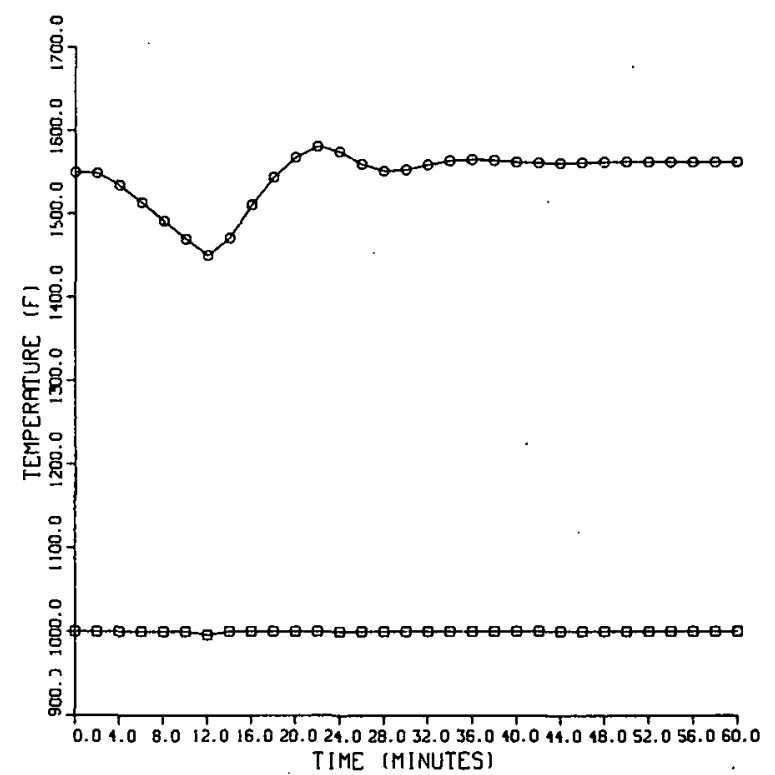

Fig. 12.7: Temperaturesquares, throttle; hexagons, bed.

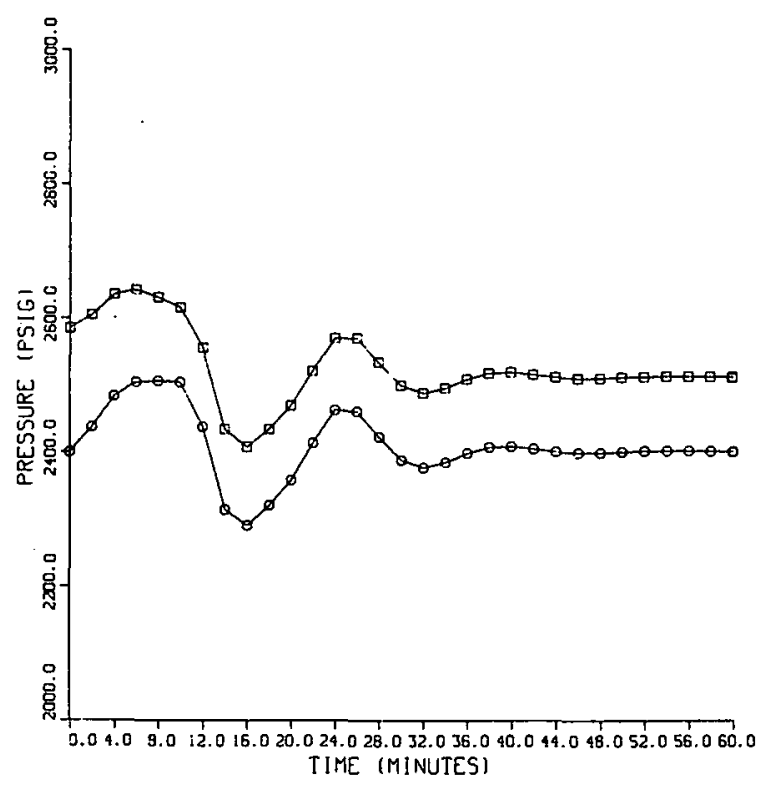

Fig. 12.6. Steam pressuresquares, drum; hexagons, throttle.

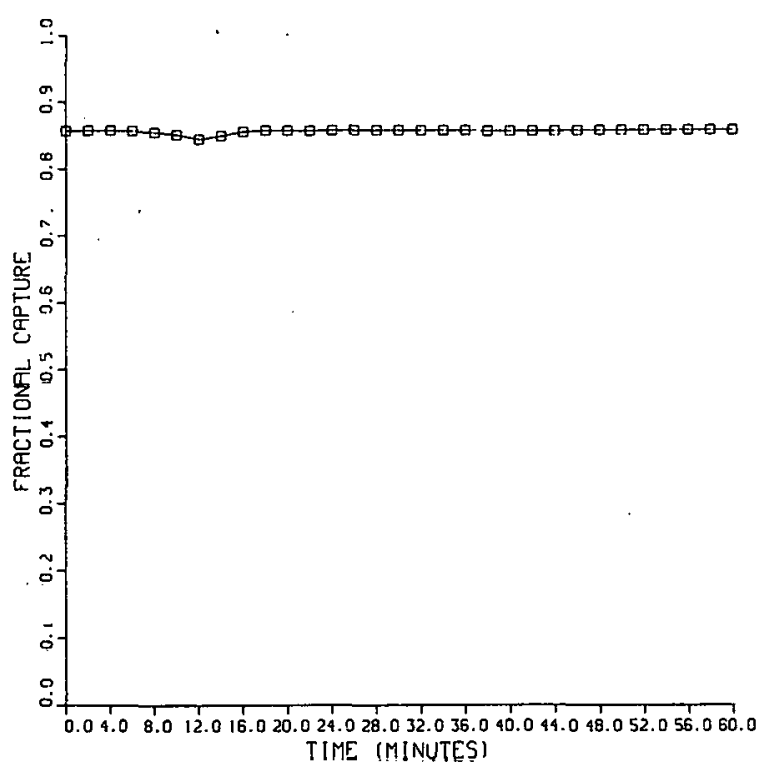

Fig. 12.8. $\mathrm{SO}_{2}$ capture. 


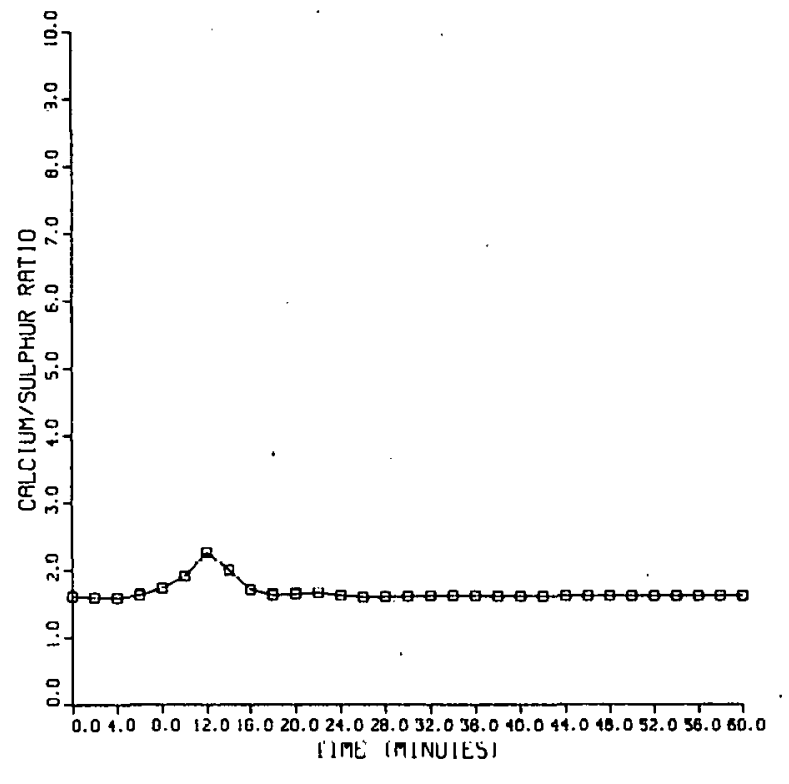

Fig. 12.9. Limestone feed.

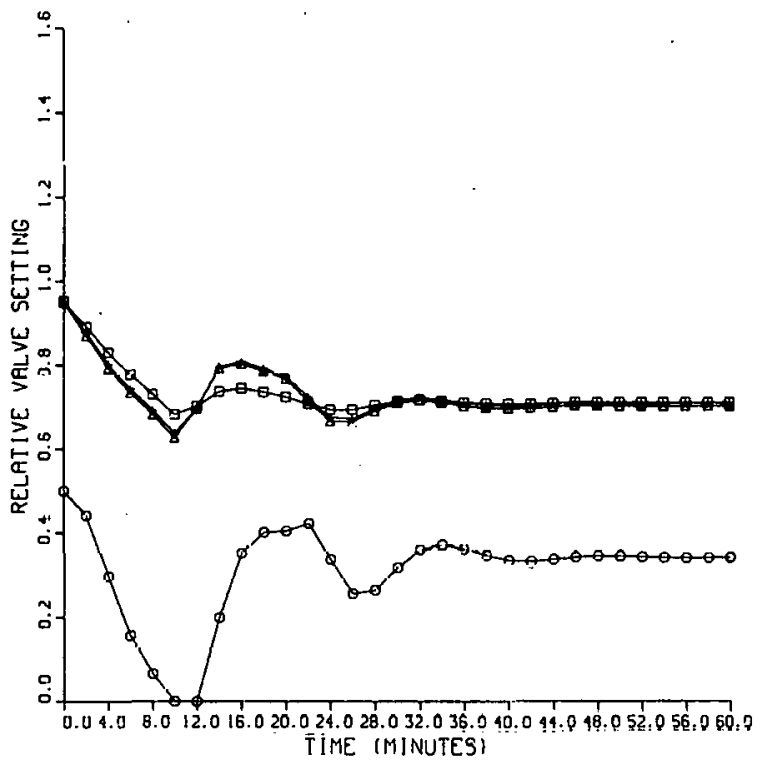

Fig. 12.10. Control valve settings-squares, throttle; hexagons, spraywater; triangles, FD damper; crosses, ID damper.

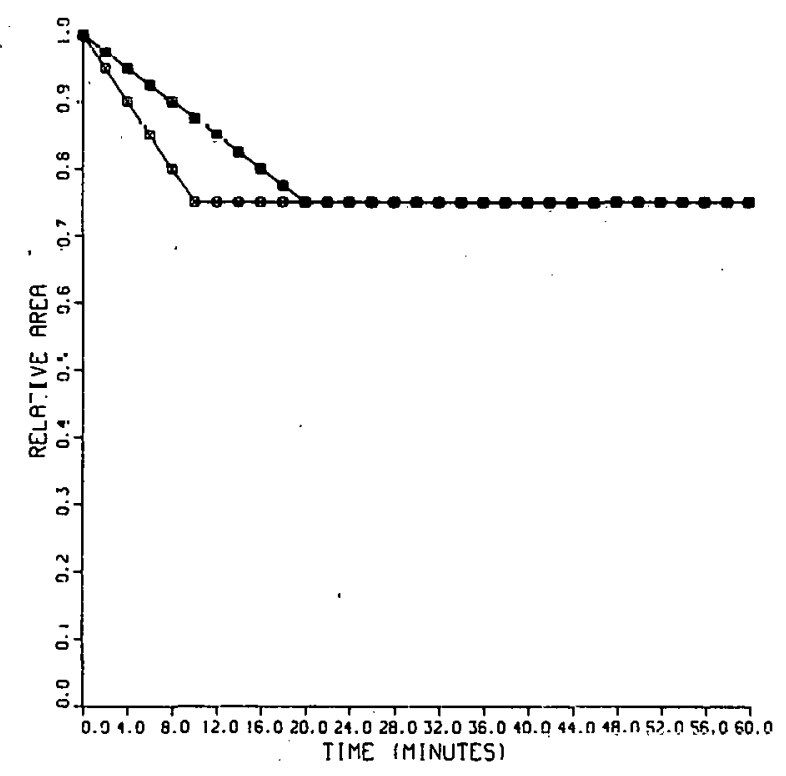

Fig. 12.11. Fraction of bed fluidized and heat transfer surface active. 


\author{
12.10 Coal. Feed Tests - Task 11 \\ C. S. Daw, J. F. Thomas, M. E. Lackey, \\ and V. R. Brantley
}

\title{
12.10 .1 Objective
}

The objective of this task is to experimentally investigate feeding techniques and equipment for AFBC application. Fundamental tests will be conducted in order to establish the key operating variables over which reliable coal and limestone pneumatic feeding can be achieved.

\section{$12.10,2$ Etatuo oummary}

We are now able to routinely feed coal having $8 \%$ surface moisture with little difficulty. By trfal and error, it was discovered that the $15.2 \mathrm{~cm}$ (6 in.) tapered rotary valve can feed wet coal without having pressure equalization across the valve. This means that we can hand feed the coal from an open top hopper and prevent bridging by havng a very small inventory of coal (about $5 \mathrm{~cm}$ or $2 \mathrm{in.}$ ) above the valve at any time.

In previous tests, we had tried to feed with a closed hopper, and the weight of the coal above the valve caused compression and bridging. Pressure equalization was thought necessary because it had previously been found to be essential in getting steady feed from the $10.2 \mathrm{~cm}$ ( 4 in.) rotary valve. It appears that the clearances of the $15.2 \mathrm{~cm}(6 \mathrm{in}$.) rotary valve are much tighter than those of the $10.2 \mathrm{~cm}(4 \mathrm{in.})$ rotary valve, thereby reducing backflow of air and fluidization of the coal.

Using this feeding technique, we have continued to demonstrate that $8 \%$ moisture coal has a significant bulldup tendency, even in the long sweep $90^{\circ}$ elbows. As discussed in the March monthly report, the two $90^{\circ}$ "cross" bends were replaced with $90^{\circ}$ tee sections in an effort to reduce plugging. We found that the tees did not reduce plugging so these were replaced with two short radius $90^{\circ}$ elbows $(R / D=5$ for the top and 6 for the bottom elbow). Since plugging in the "crosses" was no longer overwhelming everything else, we were able to confirm plugging in all of the elbow sections.

From visual observation of the elbows, it appears that the buildup occurs as "knobs" of coal (each about $1 \mathrm{~cm}$ high) along the outer radius walls of the elbow. ... The appearance and location of the "knobs" suggest that the buildup is an impaction phenomenon. That is, the coal appears to strike the wall and stick, much like mud sticking to a smooth surface.

Tests have now been run with three different air velocities: 15.2 , 22.9 , and $30.5 \mathrm{~m} / \mathrm{s}(50,75$, and $100 \mathrm{ft} / \mathrm{s})$. As before, the occurrence of buildup was monitored after each run by noting the increase in pressure drop with only air flowing through the pipe. The results of these tests are shown in Figs. 12.12 through 12.15. Plugging was seen in all cases; but the rate of bulldup appeared as a strong function of air velocicy; 


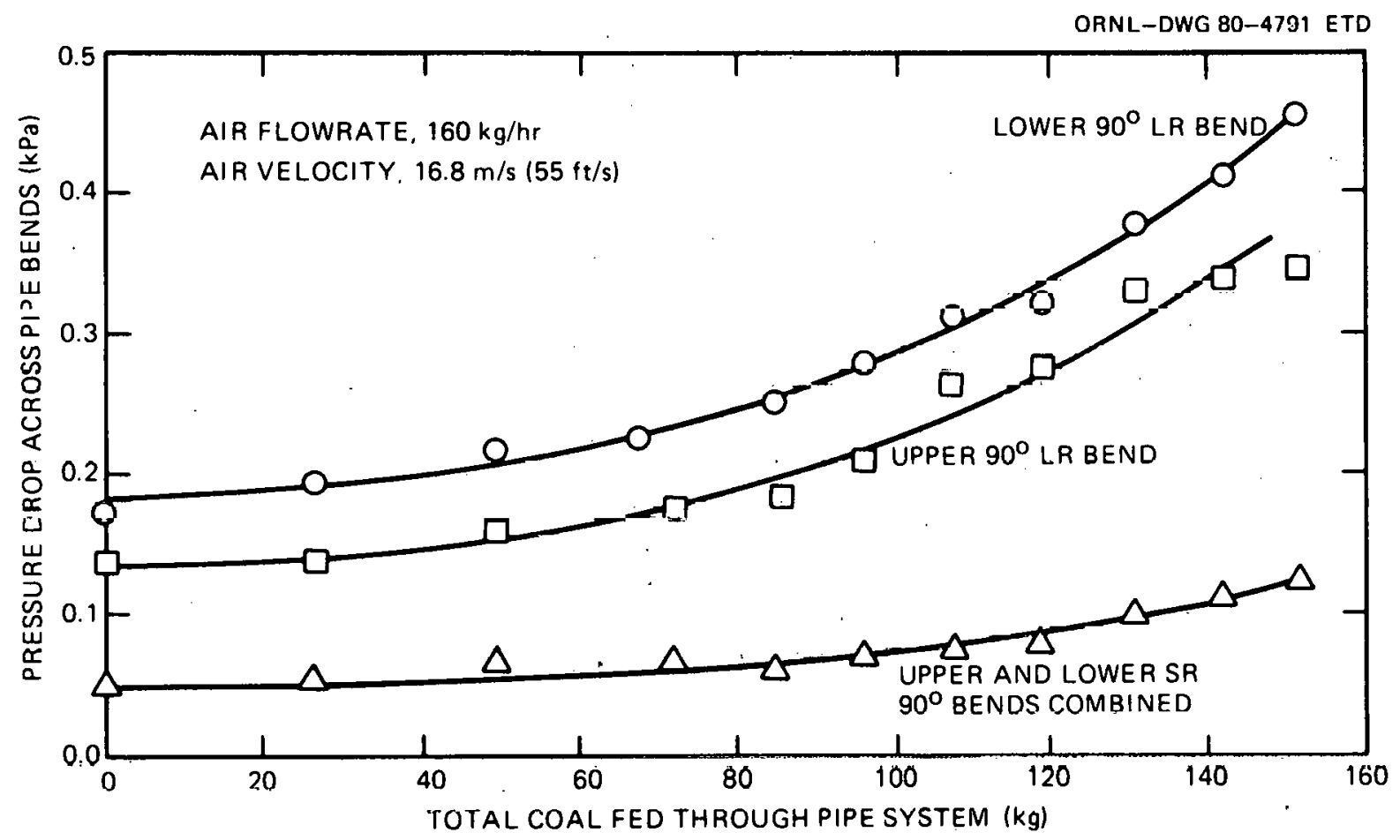

Fig. 12.12. Increase in bend pressure drops while feeding $8 \%$ moisture coal. (Coal feed rate constant at approximately $360 \mathrm{~kg} / \mathrm{h}$.) 


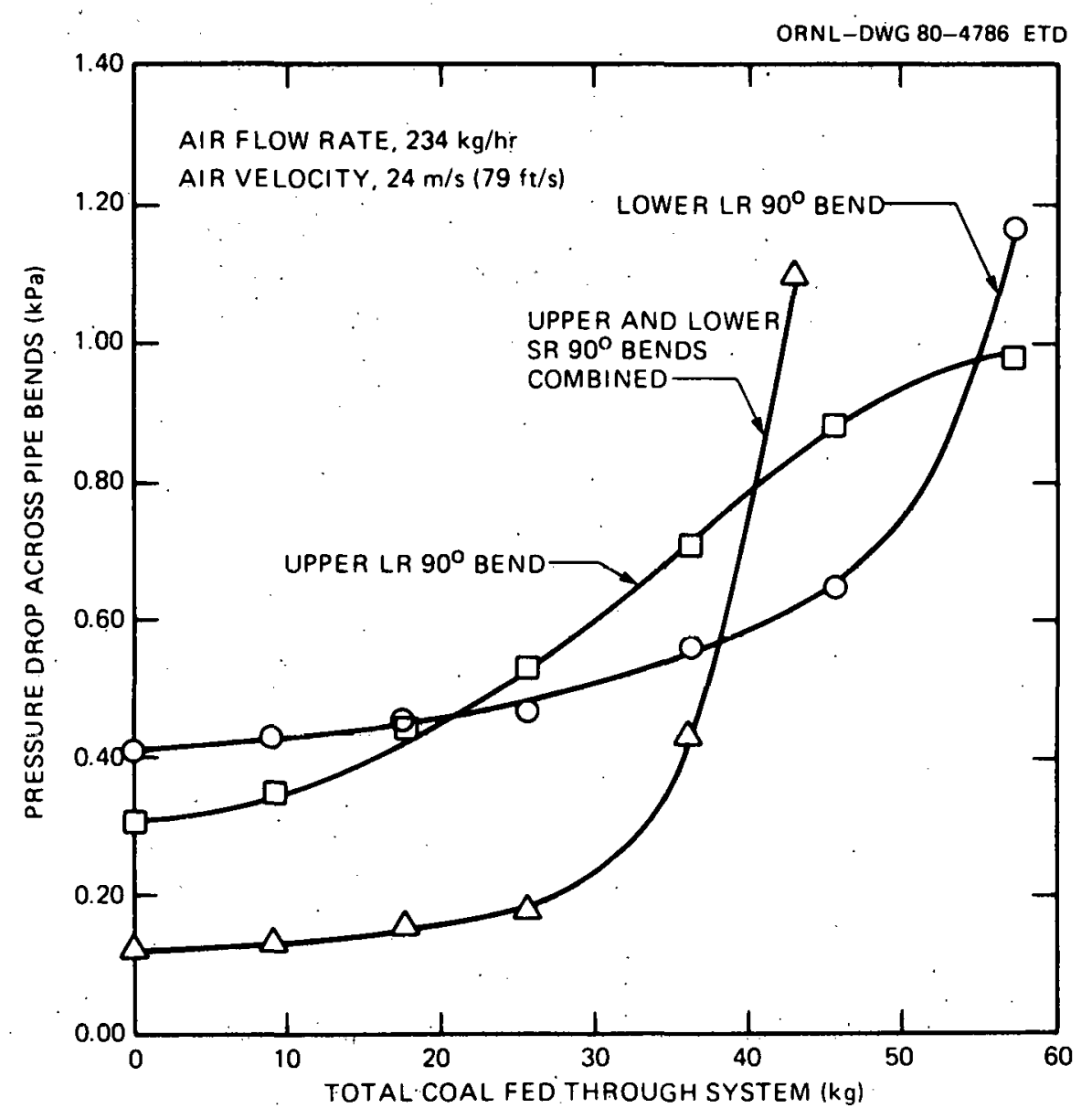

Fig. 12.13. Increase in bend pressure drops while feeding $8 \%$ moisture coal. (Coal feed rate constant at approximately $360 \mathrm{~kg} / \mathrm{h}$.) 


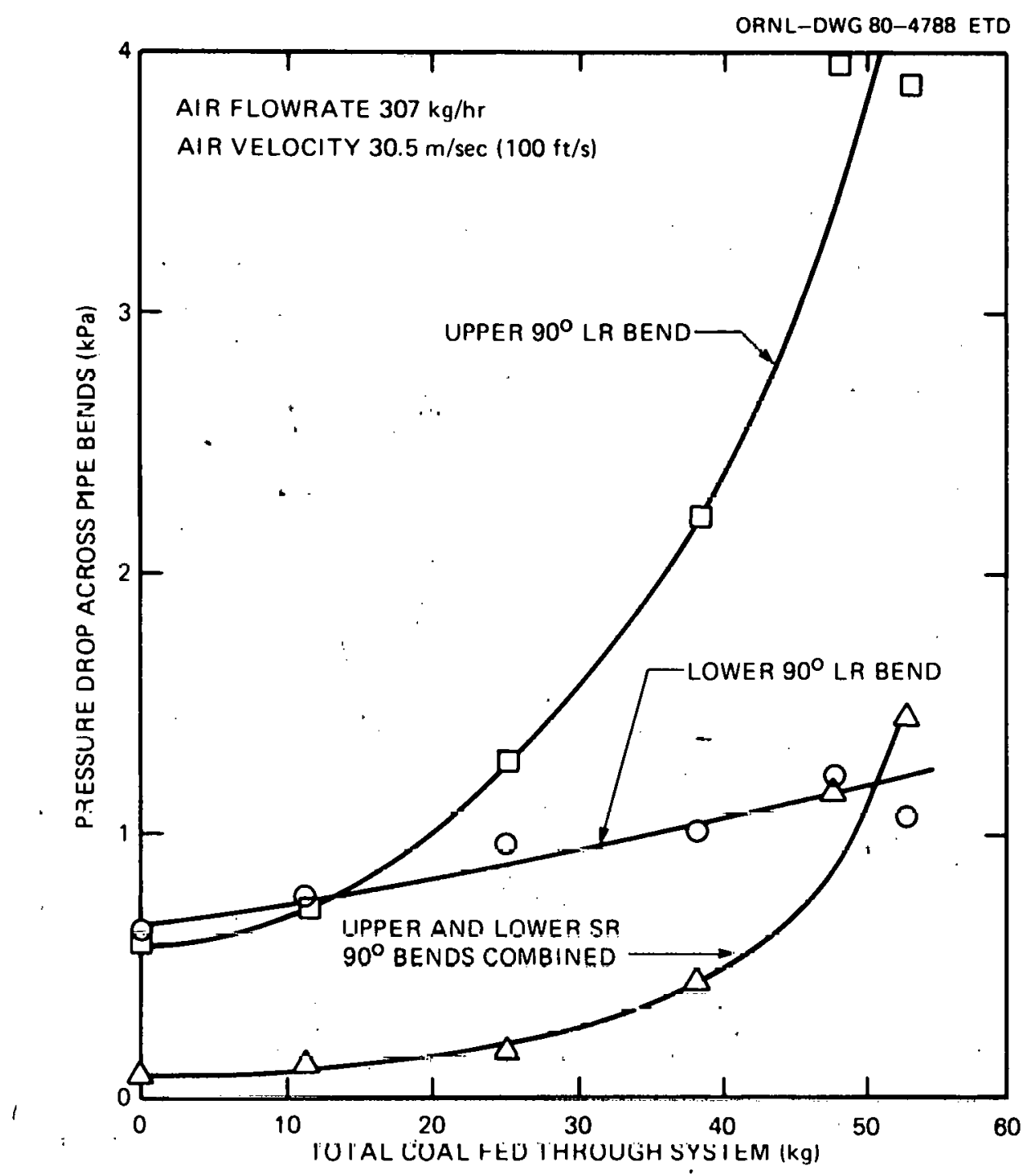

Fig. 12.14. Increase in bend pressure drops while feeding $8 \%$ moisture coal. (Coal feed rate constant at approximately $360 \mathrm{~kg} / \mathrm{h}$.) 


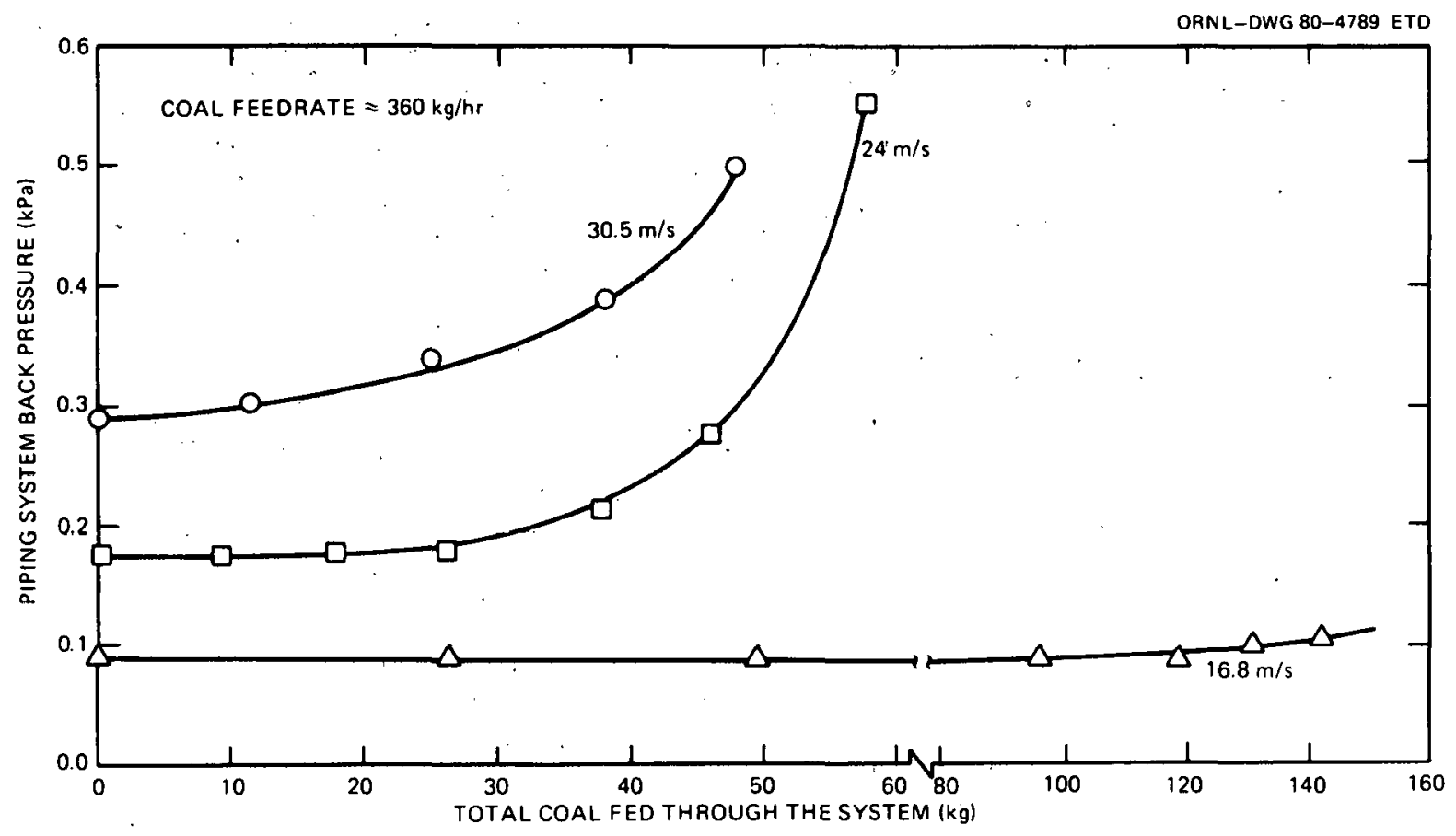

Fig. 12.15. Effect of velocity on plugging rate using $8 \%$ moisture coal. 
i.e., the higher the air velocity, the faster the rate of buildup. It is difficult to conclude which elbows plugged the fastest, because it was frequently found that the individual pressure caps became plugged themselves. Only the general pressure drop trends can be considered reliable.

After each $8 \%$ coal test, we tested the efficiency of limestone scrubbing for removing the buildup. This simply involved feeding measured amounts of limestone through the conveying system and noting the decrease in the air only preessure drop. In general, this appeared to be a good method of cleaning the system. It worked especially well when large limestone (nominally $1.3 \mathrm{~cm},[0.5 \mathrm{in.}]$ ) was used. This also indicates that plugging may be reduced or prevented by feeding limestone with the wet coal.

Since the plugging limit has heen reached for wet coal, testing of higher moisture with coal flow only is not planned. Preliminary runs with dual feed of coal and limestone have been made to test the combined feeder system, and everything operates satisfactorily. We are awaiting final approval of the test program by TVA before proceeding with dual feed runs. If limestone addition ellminates plugging with $8 \%$ coal, testing of wetter coal. will be considered.

\subsection{Materials Evaluation and Testing - Task 12}

R. H. Cooper, Jr., T. B. Lindemer, R. E. Potter, J. H. DcVan, and R. A. Bradley

\subsection{1 .1 Objective}

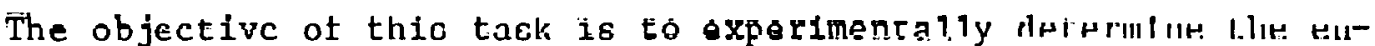
velope of operating conditions which will result in safe and reliable performance of in-bed materials. 'lhis goal is to be met with a three-phased program. The first phase involves thermodynamics calcularions lncludlug al1 likely reactants and products from combinations of selected candidate alloys and in-bed environmental conditions. The second phase 1ncludes exposures of candidate materials in carefully controlled environments simulating the range of possible AFBC environments that could be envisioned in normal and of f-normal operation. 'lhe third phase w111 be made up of eiglit 200-h exposures of materials in an actual fluld1zed bed. Operaling cundi: tions for these runs will progressively vary from normal to off-normal.

\subsection{1 .2 Status summary}

'To ensure that materials infurmation generated by this activity is provided to TVA in a manner that will have a meaningful impact on the operation of the pilot plant facility, an accelerated schedule for all three subtasks has been adopted. As a result of this accelerated schedule, some aspects of all three subtasks are being carried out concurrently. A summary of the progress on each of the three subtasks follows. 
Subtask I. Thermodynamic Calculations - The last quarterly report indicated that the initial set of thermodynamic calculations have been completed. A brief summary of these results was included in that report. A letter report was prepared and transmitted to W. D. Goins of TVA on February 20, 1980.

Subtask II. Muffle Furnace Tests - A work plan for muffle furnace testing has been prepared and approved by W. D. Goins of TVA. The first test run called for in the test plan has been completed. Following this run, a series of runs was made to characterize the relationship between initial $\mathrm{CO}_{2}$ and $\mathrm{CO}$ inputs on the output of the zirconia probe with various material in the specimen zone. Runs were made with no samples present, pre-oxidized samples, and samples with heavy bed deposits. The resulting runs indicate that these samples had only a small effect on the reproducibility' of oxygen levels in the test facility.

Subtask III. In-bed Testing - The definitive contract with FluiDyne is in place. Half of all of the needed tubes for the eight 200-h tests have been shipped to FluiDyne. The remaining tubes have been cut to length and will be shipped to Fluibyne soon. The initial shakedown of the Fluibyne facility is scheduled for June $9,1980$.

\subsection{References for Section 12}

1. C. Y. Wen, M. Ishida, Environmental Science and Technology, Vo1. 7 , No. 8, August 1973.

2. M. Hartman, R. W. Coughlin, AIChE Journal, Vo1. 22, No. 3, May 1976.

3. C. Georgakis, T. Trinh, C. G. Chang, Quarterly Technical Report to ERDA (No. 5), May 1, 1977 to July 31, 1977.

4. C. Georgakis, G. Williams, J. Szeke1y, C. G. Chang, T. Trinh, J. Chrostowski, W. Doerr, "A 'First Order' System Model of Fluidized Bed Combustors," February 1978.

5. R. H. Borgwardt, R. D. Harvey, Environmental Science and Technology, Vo1. 6, No. 4, 1972 . 


\title{
13. COAL COGENERATION/DISTRICT HEATING PLANT ASSESSMENT
}

\author{
M. A. Karnitz and R. L. Graves
}

\subsection{Objective}

The objective of this work is to provide the Office of Coal Utilization Division of DOE with an evaluation of the coal-fired closed-cycle gas turbine as a cogeneration power plant specifically for district heating in the Minneapolis-St. Paul area. This entails a preliminary design study, including a cost estimate. The design study is a cooperative effort between ORNL, United Engineers and Constructors (UE\&C), and Northern States Power (NSP). Design of an extraction steam system for the same application is begin carried out simultaneously by UE\&C and will allow a comparative evaluation of both cogeneration plants. These design studies are part of a considerably larger program involving other divisions of DOE with the objective of evaluating district heating in Minneapolis-St Paul.

\subsection{Status Summary}

The conceptual reference design work of United Engineers is now at the $95 \%$ completion stage. The only remaining task on the reference design is the capital cost estimates for the closed-cycle gas turbine. Extensive progress was made on the documentation. The documentation will be in four volumes with several appendices. The four volumes consist of an executive summary, the $200 \mathrm{MW}(e)-350 \mathrm{MW}(\mathrm{t})$ reference design, $400 \mathrm{MW}(\mathrm{e})-700 \mathrm{MW}(\mathrm{t})$ reference design, and an economic summary

During the month, UE\&C composed a letter describing the closed-cycle concept and the operating mode. The letter will be submitted to a gas turbine manufacturer (Rocketdyne) with whom contact has been established. The letter is to be mailed during the first week in May.

ORNL approved NSP's request for a two month no-cost extension. The contract termination date is now July 31. A draft report is still expected by the end of May. However, this will allow time for UE\&C to incorporate review comments. 


\section{PERFORMANCE ASSURANCE SYSTEM SUPPORT FOR FOSSIL ENERGY PROJECTS}

T. W. Pickel, H. A. Mitchell, V. H. Guthrie, L. Parsly, A. N. Smith

Performance assurance support is being provided for major DOE-Fossil Energy projects. This support covers the areas of reliability, system safety, and quality assurance. Current activities include support for the liquefaction projects being managed by DOE and assistance in developing guidelines for a Safety Analysis and Review System.

\subsection{Objective}

The ORNL Performance Assurance System Support Office is responsible for acquiring, generating, and disseminating information relating to performance assurance (PA). The Support office will provide performance assurance related technical support services to those Fossil Energy programs under the decentralized management control of the Oak Ridge Operations (ORO) Office and to programs under the direct management control of the Washington Headquarters Office. The Support Office will, as required, design and develop appropriate procedures, tools, and methodology necessary to provide the PA support services indicated.

\subsection{Status Summary}

Two specific tasks have been initiated at the request of Fossil Energy Headquarters Office: (1) preparation of generic failure modes and effects analyses and (2) assistance to ORO projects to review contracts and deliverables. Currently, there is no activity associated with the second task.

Related to the first task, a failure modes and effects analysis (FMEA) of a generic coal slurry preheater was completed during a previous reporting period and is currently being reviewed. A general plan for completion of the FMEA has been developed. Each component is identified in a functional block diagram or schematic of the preheater subsystem. The effects of component failure on the preheater subsystem, the adjacent subsystem or the overall system are identified and classified as critical or catastrophic where appropriate. A discussion of the actions or systems necessary to limit or control those failures are identified. Revised work sheets, summary, and conclusions are to be prepared during the next reporting period. 


\section{INTERNATIONAL ENERGY TECHNOLOGY ASSESSMENT}

The Oak Ridge National Laboratory is supporting the Lawrence Livermore Laboratory in a broad program funded by the DOE Office of International Affairs. The program is designed to alert DOE management to foreign energy-related technologies of potential interest to the United States.

ORNL has responsibility for the following three areas of work: coal liquefaction including gasifier development status, coal 1iquefaction materials, and atmospheric fluidized bed combustion. These efforts are closely coordinated with similar activities underway at Argonne National Laboratory in the areas of pressurlzed fluidized bed combustion and coal gasification materials.

\subsection{Liquefaction Technology Including Gasifier Development Status}

$$
\text { W. C. Ulrich }
$$

\subsubsection{Objective}

Broad objectives of the IETA program are to report foreign technology developments of current interest and to identify and assess those developments of significance to U.S. programs. Detailed assessments in selected areas will also be provided. A specific objective of the ORNL effort is to provide a substantive technical review of the status of foreign technology for the liquefaction of coal, including gasifier development status.

\subsubsection{Status summary}

A request for a research and development subcontract to assist ORNL in this effort was prepared: Under this arrangement it is proposed that the subcontractor, Gilbert/Commonwealth (G/C), will make an initial review of the state-of-the-art of coal liquefaction, based on information available in foreign and domestic literature, and in trip reports submitted by technical travelers who visited countries where the subject technology is in use or under development. G/C will also conduct technical interviews with individuals and organizations based in the U.S. that have relevant experience or contacts with developments taking place in foreign coal liquefaction technology.

The information developed by G/C will be used in preparing a summary report and analysis covering direct and indirect coal liquefaction technology, identifying significant items and interpreting their impact on U.S. R\&D and commercialization activities.

The subcontract request was submitted to the UCCND Purchasing Department on April 10; approval is expected by the end of the month. 


\subsection{Coal Liquefaction Materials}

A. R. Olsen and G. M. Caton

The objectives of this phase of the assessment program are to identify materials research and development programs in foreign countries in support of liquefaction processes and to assess the programs and findings in terms of their status, applicability to United States coal liquefaction development and commercialization programs, and the potential value of possible cooperative agreements.

During this first month an action plan was defined, contacts were made with other groups responsible for the liquefaction process technology assessment for exchanging information, a preliminary definition of the materials assessment methodology was developed, and information gathering initiated.

The initial information-gathering activities are concentrating on searching available commercial data bases including the DOE Energy Data Base, Chemical Abstracts, COMPENDEX (Engineering Index), METADEX (the American Society for Metals), API (the American Petroleum Institute), abstracting services such as the IEA Coal Abstracts or Corrosion Abstracts, and available foreign trip reports. Published information on specific materials development programs or materials problem resolutions appear to be severely limited. The search will be expanded to include specific information requests, such as letter contacts, when the appropriate sources are identified.

15.3 International Survey of Atmospheric Fluidized Bed Combustion Technology

R. P. Krishnan, E. C. Fox, and. R. S. Holcomb

\subsubsection{Objective}

The objective of this program is to provide an international assessment of the status of atmospheric fluidized bed combustion (AFBC). The assessment will describe the applications, critical problem areas, and the current developmental projects that address these problem areas in $A F B C$ technology in foreign countries.'

\section{3 .2 Scope}

This assessment is part of a broader program designed by the DOE Office of International Affairs (IA) to alert DOE management to foreign energy-related technologies of potential value to the United States. ORNL and Argonne National Laboratory (ANL) have been assigned the area of fluidized bed combustion. ORNL will survey AFBC, and ANL will survey pressurized fluidized bed combustion (PFBC). 


\subsubsection{Status summary}

An extensive literature search has been initiated for gathering information related to AFBC technology in foreign countries. Proceedings of the recent and earlier conferences on fluidized bed combustion are being reviewed to identify individuals and organizations for direct inquiry to update and extend the information presented in the proceedings.

The Sixth International FBC Conference in Atlanta, April 9-11, provided an excellent opportunity to meet representatives from a number of other countries and obtain information about FBC development. Discussions were held with one or more individuals from these countries: United Kingdom, West Germany, India, Ireland, Japan, Denmark, Finland, and the Netherlands.

United Kingdom - I'he FBC work in the U.K. is Llie best known of any foreign country. Papers given by Douglas Willis, Raynond Hoy, John Highley, and A. J. Grant were heard, and brlef discussiuns were held with Hoy, Highley, Krishna K. Pillai, and Alan G. Roberts. The broad picture was presented well in the Technology Overview paper by Douglas Willis, Coal Research Establishment, Stoke Orchard, U.K.

From 1970 to 1973 , most FBC research and development work in U.K. was funded by U.S. agencies. In 1974, the situation changed following the implementation of a "Plan for Coal" to displace oil and gas in industrial and commercial applications. Since then the National Coal Board (NCB) has been concentrating on developing FBC for the industrial market. Prior to 1973, the target of the FBC program in U.K. was coal-fired power station boilers. NCB has commissioned the design and manufacture of four FBC boilers for operation at commercial sites. The range of designs and operating concepts in these boilers are fairly wide. Nine companles are now offering commercial $A \bar{F} \bar{B} \bar{C}$ units in a variety of sizes. The primary applications in England are the conversion of small o11-[1red sliel1-type and watertube boilers to AFBC service. The Combustion Systems Ltd. design (marketed in the U.S. by Johnston Boiler Co.) are representative of the smaller AFBC boilers being offered. Larger AFBC industrial boiler designs are typified by the units being of fered by Babcock Ltd. modeled after the Renfrew boiler. The1r design is marketed in the U.S. by Babcock lontractors - Riley Stoker, and their first installation is the project to retrofit a $60,000 \mathrm{lb} / \mathrm{hr}$ boiler at the Central Psychiatric Hospital in Columbus, Ohio.

The main thrust of the advanced develupment work is directed toward PFBC at Leatherhead and Grimethorpe. A pressurized fluidized bed combustor experimental facility is under construction at Grimethorpe jointly financed by U.K., USA, and West Germany. There are three smaller FBC units operating at Leatherhead to conduct tests which can be linked (scale-up) to the tests planned in the larger unit under construction at Grimethorpe. A series of tests will be initiated in August, 1980, in the 
Leatherhead facility for DOE [ $30 \mathrm{cms}$ ( $\sim 1 \mathrm{ft}$ ) diameter, 6 atmosphere pressure $P F B C]$ on the dynamic behavior and load-following capability of PFBC. This will be followed by sorbent effectiveness tests for IEA. Development work in the aeras of instrumentation, vibration analysis, and hot gas clean up is also underway at Leatherhead.

Federal Republic of Germany - It appears that FBC development there is proceeding on a fairly broad front including AFBC industrial and power boilers, AFBC indirect-fired gas turbine combined cycle power plants, circulating FBC boilers, PFBC combined cycle power plants, and supercharged FBC industrial and power boilers. Papers given by

Dr. Johann Batsch, V. Peterson, and H. G. Krischke were heard, and discussions were held with Dr. Batsch and Willy Meyer. The Technology Overview paper given by Dr. Batsch provided a good description of the overall effort. The work on AFBC systems ranges from a $6 \mathrm{MW}(t)$ boiler at Konig Ludwig and a $35 \mathrm{MW}(t)$ boiler at Flingern that began operation in 1979, to a $124 \mathrm{MW}(t)$ boiler in the design phase and an AFBC indirect-fired $24 \mathrm{MW}(\mathrm{e})$ gas turbine coupled to a $185 \mathrm{MW}(\mathrm{e})$ pulverized coal-fired boiler on which construction has just begun at Volklingen. There is a great deal of interest in the circulating $\mathrm{AFBC}$ concept, and Lurgi has a small operating test unit. Construction has just begun on a $77 \mathrm{MW}(t)$ boiler of this type at Lunen, and a design study is in progress for a $200 \mathrm{MW}(\mathrm{t})$ boiler at Duisburg.

The PFBC effort includes participation in the IEA project at Grimethorpe and a $22.5 \mathrm{MW}(t)$ PFBC boiler with a $3 \mathrm{MW}(\mathrm{e})$ gas turbine under design for construction soon at Bottrop. In addition, supporting research is being done on pressurized high temperature electrostatic precipitators. Dr. Peter Herberholz of Steinmuller (a private boiler manufacturer) indicated during a visit to ORNL that they are in the process of developing an intermediate pressure ( 3 to $4 \mathrm{~atm}$ ) supercharged FBC boiler for industrial and district heating applications. They believe that the technology for this system is near term and that it can be successfully developed rapidly. They have a longer range interest in circulating FBC boilers, but feel that it will require 7 to 10 years to develop that system.

Ireland - It was learned from a conversation with David O'Hanlon of the Electricity Supply Board of Ireland that they have plans to build an $A F B C$ demonstration boiler in the near future. They are in the process of preparing the specifications for the plant at the present time. He and another representative of Ireland had planned to visit ORNL on April 14 to discuss their project further, but they were unable to make the visit. We will contact them and obtain additional information.

Japan - Fluidized bed development in Japan is in the early stage, but they are directing their experimental work toward designs that will give high performance, particularly in the area of $\mathrm{NO}_{\mathrm{x}}$ emission. Their interest is current1y focused on AFBC development. Papers given by M. Tomito and S. Mori were heard, and discussions were held with S. Ikeda and S. Hori at the conference and with T. Hashimoto and Y. Fujioka at ORNL on April 23. Development work has been done on a two-stage AFBC test unit 
at the Government Industrial Development Laboratory at Hokkaido to achieve lower levels $(50 \mathrm{ppm})$ of $\mathrm{NO}_{\mathrm{x}}$ emission. The National AFBC program is directed primarily toward a $40,000 \mathrm{lb} / \mathrm{hr}$ steam pilot plant to be placed in operation in 1981 and a $400,000 \mathrm{lb} / \mathrm{hr}$ steam prototype plant to be in operation by 1984. Their major environmental concerns are with $\mathrm{NO}_{\mathbf{x}}$ emission and solid waste disposal. The major developers of fluidized boilers in Japan are Hitachi-Babcock, Inshikawajima, Kawasaki, and Mitsubishi. The developmental work is promoted by the Japan Coal Mining Research Center.

Denmark - Discussions with Vagn Kollerup and F. N. Christiansen of the firm of Burmeister and Wain revealed that there is very much interest in Denmark in AFBC boilers fueled by wood waste and coal for district heating applications. A privately financed $5 \mathrm{MW}(t)$ boiler was placed in operation in December, 1979. A $10 \mathrm{MW}(t)$ plant is scheduled to begin operation in the fall of 1980 .

Finland - The efforts on FBC development by the A. Ahlstrom Company of Finland was presented in a paper by F. Engstrom. They began AFBC development in 1968 and installed a $4 \mathrm{MW}(t)$ boiler fueled by peat in a district heating system in Kajaani in 1975. The firm turned their development effort to circulating AFBC systems in 1976. They began operation of a $1.5 \mathrm{MW}(t)$ pilot plant in 1977. Two commercial circulating AFBC plants have since been placed in operation: a $15 \mathrm{MW}(t)$ boiler fueled by bark at the Ahlstrom Works at Pihlava began operation in January, 1979, and a $7 \mathrm{MW}(t)$ boiler for district heating at Suonenjoki was started up in October, 1979. A $65 \mathrm{MW}(t)$ boiler to be installed at the Kauttua Paper Mill in 1981 is currently under design. A test program was initiated in 1979 to evaluate the combustion of high sulfur olls, perroleum cuke, U.s. high sulfur coals, and lignite in their $1.5 \mathrm{MW}(t)$ pllot plant. EPRI and TVA are participating in this program and it will lnclude cests on olio No. 6, Kentucky No. 9 coals, North Dakota (Beulah) lignite and Lowellville and Ciarksville limestones.

Netherlands - It was learned from a discussion with I. H. Bartelds of TNO of Apeldoorn that they have an AFBC test boiler with a bed area of $2 \mathrm{~m}^{2}$ under construction. Its design is very similar to the B\&W $6 \times 6$ unit except for the smaller bed area. The in-bed tube bundle generates saturated steam at 15 atm pressure.

India - Research and development work in AFBC is belng carried out at Bharat Heavy Électricâls L1miced (BHEL) In Tiluclíldualli, India. It was learned from $K$. T. U. Malliah of BHEL that the thrust of the $\triangle F B C$ program in India has been toward development of industrial size AFBC boilers to burn high ash, sub-bituminous coals. The AFBC boiler at BHEL has a rated output of $10,000 \mathrm{~kg} / \mathrm{h}$ steam at $0.98 \mathrm{HPa}$ and $452^{\circ} \mathrm{K}$. BHEL has commercialized industrial size fluidized bed boilers in the capacity range of 36,000 to $45,000 \mathrm{Kg} / \mathrm{hr}$ of steam. Developmental work is ongoing to extend the technology to utility boilers. FBC pilot plants have been commissioned at the Regional Research Laboratory in Jorhat and Central Fuel Research Institute in Dhanbad for combustion related and sulfur retention studies. 
Letters will be written to the individuals contacted in the meeting for specific details on their programs. A meeting will be arranged in the coming weeks with the Argonne National Laboratory (ANL) group to exchange information and coordinate future efforts: 


\section{THIS PAGE}

\section{WAS INTENTIONALLY \\ LEFT BLANK}


ORNL/TM-7375

\section{INTERNAL DISTRIBUTION}

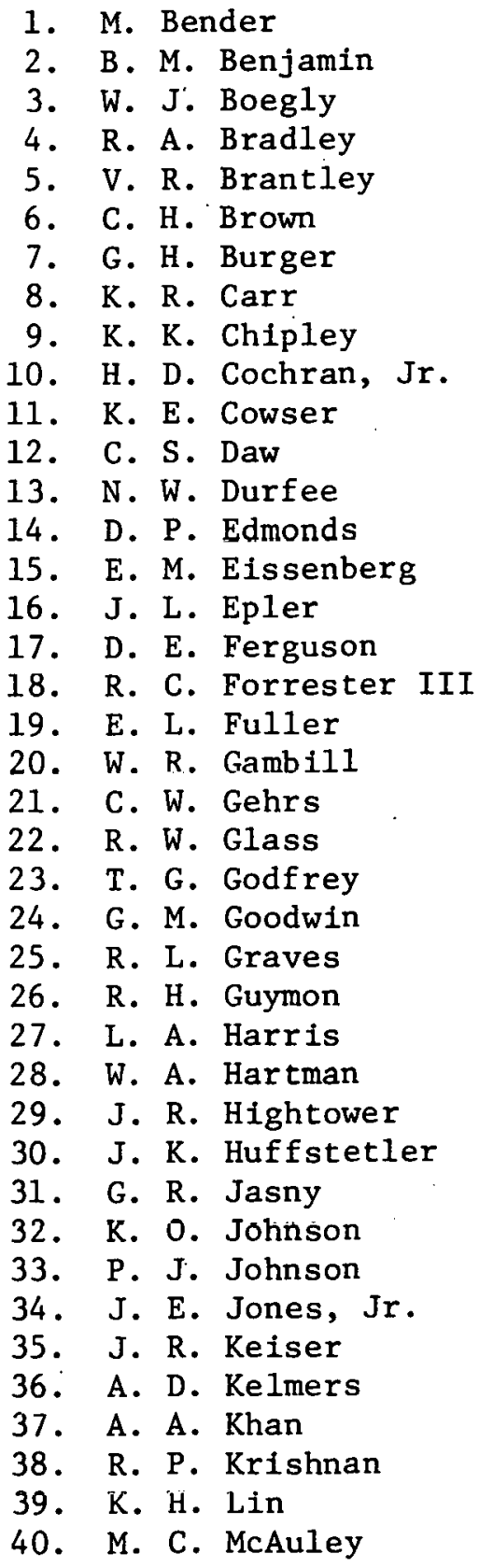

41. R. W. McClung

42. C. J. McHargue

43-47. L. E. McNeese

48. C. A. Mills

49. J. E. Mrochek

50. B. Niemann

51. C. J. Den

52. G. E. Oswald

53. L. F. Parsly

54. T. W. Pickel

55. M. L. Poutsma

56. L. W. Rickert

57. B. R. Rodgers

58. M. W. Rosenthal

59. T. H. Row

60. R. Salmon

61. C. D. Scott

62. M. Siman-Tov

63. C. B. Smith

64. G. P. Smith

65. 0. L. Smith

66. I. Spiewak

67. R. W. Swindeman

68. V. J. Tennery

69. J. F. Thomas

70. W. C. Ulrich

71. J. S. Watson

72. J. R. Weir

73. J. W. Wells

74. D. J. Wilkes

75. M. K. Wilktnson

76. J. H. Wilson

77. L. V. Wilson

78. E. L. Youngblood

79. G. P. Zimmerman

80. Patent office

81-85. Laboratory Records

86. Laboratory Reçords - RC

87-38. Central Research Library

89. Document Reference Section 
EXTERNAL DISTRIBUTION

DOE-Oak Ridge Operations

90. C. W. DiBella

91. L. Radcliffe

DOE-Office of Fossil Energy, Washington, DC 20545

92. D. L. Bauer

102. T. K. Lau

93. W. M. Crim

103. J. E. Malcolm

94. A. Dietz

104. G. V. McGur1

95. J. J. Forst

105. C. L. Miller

96. S. I. Freedman

97. J. E. Gámon

98. R. M. Hamilton

106. G. A. Mills

99. A. K. Ingherman

107. E. S. Pierce

100. L. M. Joseph

108. H. E. Poda:11

101.

C. A. Kinney

109. D. K. Stevens

110. I. Wender

DOE-Environment, Washington, DC 20545

111. R. A. Lewis

112. F. E. Witmer

DOE-Morgantown Energy Research Center, P. O. Box 800, Morgantown, WV 26506

113. J. S. Halow

115. R. E. Schafer

114. L. Headley

116. J. S. Wilson

DOE-Pittsburgh Energy Technology Center, P. O. Box 10940; Fittsburgh, PA 15236

117. S. Akhtar

118. A. F.Baker

119-134. J. P. Barreca

135. D. Rienstnrk

136. A. W. Deurbrouck

137. J. D. Hickerson
138. R. E. Hucko

139. J. J. Lacey

140. L. Lorenzi

141. J. Ruether

142. A. G. Sharkey

143. J. T. Wizzard

Pittsburgh and Midway Coal Mining Co., 5970 S. Syracuse, Englewood, CO 80111

144. J. Sobernheim

145. D. Jones 
Tennessee Valley Authority, 1020 Chestnut St., Tower 2, Chattanooga, TN 37401

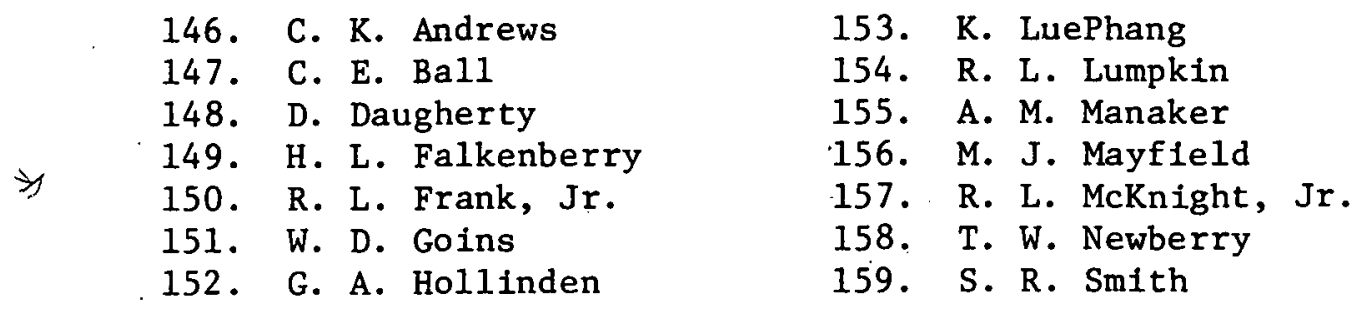

University of Kentucky, Institute for Mining and Minerals Research 213 Bradley Hall, Lexington, KY 40506
160. T. Wiley
162. J. K. Shou
161
O. J. Hahn

U. S. Environmental Protection Agency, Research Triangle Park, NC 27711

163. J. McSorley

164. C. B. Sedman

165. S. B. Alpert, Electric Power Research Institute, 3412 Hillview Ave., Palo Alto, CA 94304

166. F. Baranowsk1, Mechanical Technology Inc., 2731 Prosperity Ave., Fairfax, VA 22031

167. L. Batta, Union Carbide Corp., 61 E. Park Dr., Tonawanda, NY 14150

168. H. Beuther, Gulf Research and Development Co., P. O. Box 2038, Pittsburgh, PA 15230

169. A. A. Bishop, Chemical Engineering Dept., Univ. of Pittsburgh, Pittsburgh, PA 15213

170. N. S. Boodman, U. S. Steel Corp., Applied Research Laboratory, 125 Jamison Lane, Monroeville, PA 15145

171. E. L. Clark, Chemical Engineering Services, 4615 North Park Ave., Chevvy Chase, MD 20015

172. R. C. Corey, Mitre Corp., Metrek Division, 1820 Dolley Madison Blvd., McLean, VA 22101

173. B. Crynes, School of Chemical Eng., Oklahoma State Univ., Stillwater, OK 74074

174. A. K. Dubberly, 650.S. Cherry St., Suite 400, Denver Co 80222

175. W. R. Epper1y, Exxon Research and Engineering Co., P. O. Box 101, Florham Park, NJ 07932

176. 0. F. Ghaly, Bechtel Corp., P. O. Box 3695, San Francisco, CA 94119

177. T. M. Godbold, Sta. B, Box 1735, Vanderbilt Univ., Nashville, TN 37235

178. R. A. Greenkorn, Chemical Engineering Dept., Purdue Univ., West Lafayette, IN 47907 
179. W. Hansen, Babcock \& Wilcox, 20 S. Van Buren Ave., Barberton, OH 44203

180. L. R. Harris, National Institute of Occupational Health and Safety, MS 8A-45, 5600 Fishers Lane, Rockville, MD 20857

181. G. Heunisch, Research Division of Conoco Coal Development Co., Library, PA 15129

182. E. Huffman, Southern Company Services, Fuel Processing Programs, P. O. Box 2625, Birmingham, AL 35202

183. J. E.. Jones, Kentucky Center for Energy Resources, P. 0. Box 11888, Ironworks Pike, Lexington, KY 40502

184. R. A. Laza, DOE-Chicago Operations, 9800 S. Cass Ave., Argonne, IL 60439

185. W. J. Lochmann, Ra1ph M. Parsons Co., 100 W. Walnut St., Pasadena, CA 91124

1.86. T. Modrak, Babcuck \& Wilcox Res., 1562 Beeson St., Alliance, OH 44601

187. J. Morhall, Heat Research Corp., 3440 Richmond Ave., Houston, TX 77046

188. T. E. O'Hare, Dept. of Energy and Environment, Brookhaven National Laboratory, Associated Universities, Inc., Upton, LI NY 11973

189. E. G. Pierick, General Electric Co., M/C V02, Vallecitos Nuclear Center, P. O. Box 460, Pleasanton, CA 94556

190. D. Rimmer, City Svc. Co., 1305, 4-NB, Box 300, Tulsa, OK 74102

191. M. Saddy, Senior Engineer, Centro de Technologia Promon-CTP, Praia do Flamengo, 154-120 Floor, Rio de Janeiro, KJ-Brazil 22210, 021/205-0112

192. T. E. Scott, Ames Laboratory, 126 Metals Development Bldg., Iowa State University, Ames, Iowa 50011

193. M. Semchyshen, Climax Molybdenum Res. T.ah., 1600 Huron Parkway, P. 0. Box 1568, Ann Arbor, MI 48106

194. W. R. Siegart, Texaco, Inc., 2000 Westchester Ave., White Plains, NY 10650

195. W. K. Stair, Univ, of Tenn., College of Eng., 101 Perkins Hall. Knoxville. TN 37916

196. C. Strccd, Procece Ree. and Dev. Div., Mobil Res, and nev, Corp., B1llingsport Rd., Paulsboro, NY 08066

197. J. R. Thurguod, ULah Puwes and LiglıL Co., 1407 West North Temple, P. O. Box 899, Salt Lake City, UT 84110

198. B. M. Weiss, Catalytic, Inc., Centre Eq., Wcot, 1500 Market Sit., Philadelphin, PA 19102

199. C. Y. Wen, Dept. of Chem. Eng., West Virginia Univ., Morgantown, WV 26506

200. C. Wysoki, Stearns-Roger, P. O. Box 5888, Denver, Co 80217

201. Office of Assistant Manager for Research and Development, DOE-ORO

202-228. Technical Information Center 